Pai, Chow, et al., (SATPATHY, HELLMANN), p. 1

\title{
Regional and clonal T cell dynamics at single cell resolution in immune checkpoint blockade
}

Joy A. Pai ${ }^{1 *}$, Andrew Chow ${ }^{2,3,4 *}$, Jennifer L. Sauter ${ }^{5}$, Marissa Mattar ${ }^{6}$, Hira Rizvi ${ }^{7}$, Hyung Jun Woo ${ }^{8}$, Nisargbhai Shah ${ }^{3}$, Fathema Uddin ${ }^{3}$, Alvaro Quintanal-Villalonga ${ }^{3}$, Joseph M. Chan ${ }^{3,4}$, Parvathy Manoj ${ }^{3}$, Viola Allaj ${ }^{3}$, Marina Baine ${ }^{5}$, Jamie Chaft ${ }^{3,4}$, Andrew J. Plodkowski ${ }^{9}$, Helen Won ${ }^{8}$, Daniel Wells ${ }^{10}$, Mark T.A. Donoghue ${ }^{8}$, Elisa de Stanchina ${ }^{6}$, Triparna Sen ${ }^{3,4}$, Jedd D. Wolchok ${ }^{2,3,4,11,12,}$ Brian Houck-Loomis ${ }^{7}$, Taha Merghoub ${ }^{2,3,4,11,12}$, Charles M. Rudin ${ }^{3,4,7}$, Ansuman T. Satpathy ${ }^{1 \dagger}$, Matthew D. Hellmann $3,4,11 \dagger$

${ }^{1}$ Department of Pathology, Stanford University, Stanford, CA, USA

${ }^{2}$ Ludwig Collaborative and Swim Across America Laboratory, Memorial Sloan Kettering Cancer Center, New York, NY, USA.

${ }^{3}$ Department of Medicine, Memorial Sloan Kettering Cancer Center, New York, NY, USA.

${ }^{4}$ Weill Cornell Medical College, New York, NY, USA.

${ }^{5}$ Department of Pathology, Memorial Sloan Kettering Cancer Center, New York, NY, USA.

${ }^{6}$ Antitumor Assessment Core Facility, Memorial Sloan Kettering Cancer Center, New York, NY, USA.

${ }^{7}$ Druckenmiller Center For Lung Cancer Research, Memorial Sloan Kettering Cancer Center, New York, NY, USA.

${ }^{8}$ Marie-Josée and Henry R. Kravis Center for Molecular Oncology, Memorial Sloan Kettering Cancer Center, New York, NY, USA.

${ }^{9}$ Department of Radiology, Memorial Sloan Kettering Cancer Center, New York, NY, USA.

${ }^{10}$ Parker Institute for Cancer Immunotherapy, San Francisco, CA, USA; Immunai Inc., New York, NY, USA.

${ }^{11}$ Parker Institute for Cancer Immunotherapy, Memorial Sloan Kettering Cancer Center, New York, NY, USA.

${ }^{12}$ Human Oncology and Pathogenesis Program, Memorial Sloan Kettering Cancer Center, New York, NY, USA.

"These authors contributed equally to this manuscript.

tThese authors contributed equally to this manuscript.

Correspondence to: satpathy@stanford.edu and hellmanm@mskcc.org 
bioRxiv preprint doi: https://doi.org/10.1101/2021.09.27.461389; this version posted September 27, 2021. The copyright holder for this preprint (which was not certified by peer review) is the author/funder, who has granted bioRxiv a license to display the preprint in perpetuity. It is made available under aCC-BY-NC-ND 4.0 International license.

Pai, Chow, et al., (SATPATHY, HELLMANN), p. 2

\begin{abstract}
Paired T cell receptor and RNA single cell sequencing (scTCR/RNA-seq) has allowed for enhanced resolution of clonal T cell dynamics in cancer. Here, we report a scTCR/RNA-seq dataset of 162,062 single T cells from 31 tissue regions, including tumor, adjacent normal tissues, and lymph nodes (LN), from three patients who underwent resections for progressing lung cancers after immune checkpoint blockade (ICB). We found marked regional heterogeneity in tumor persistence that was associated with heterogeneity in CD4 and CD8 T cell phenotypes; regions with persistent cancer cells were enriched for follicular helper CD4 T cells (TFH), regulatory T cells (Treg), and exhausted CD8 T cells. Clonal analysis demonstrated that highly-expanded T cell clones were predominantly of the CD8 subtype, were ubiquitously present across all sampled regions, found in the peripheral circulation, and expressed gene signatures of 'large' and 'dualexpanded' clones that have been predictive of response to ICB. Longitudinal tracking of CD8 T cell clones in the peripheral blood revealed that the persistence of ubiquitous CD8 T cell clones, as well as phenotypically distinct clones with tumor-reactive features, correlated with systemic tumor control. Finally, tracking CD8 $\mathrm{T}$ cell clones across tissues revealed the presence of TCF-1+ precursor exhausted CD8 T cells in tumor draining LNs that were clonally linked to expanded exhausted CD8 T cells in tumors. Altogether, this comprehensive scTCR/RNA-seq dataset with regional, longitudinal, and clonal resolution provides fundamental insights into the tissue distribution, persistence, and differentiation trajectories of ICBresponsive $T$ cells that underlie clinical responses to ICB.
\end{abstract}




$$
\text { Pai, Chow, et al., (SATPATHY, HELLMANN), p. } 3
$$

\section{INTRODUCTION}

Immune checkpoint blockade (ICB) has been a remarkable clinical advance in the treatment of cancer. Nonetheless, the majority of patients do not benefit from ICB therapy, and many of those who do eventually succumb to the disease. Emerging data has highlighted that ICB operates in cancer by unleashing a systemic CD8 response ${ }^{1,2}$. Unfortunately, isolated tumor biopsies at the time of resistance to ICB are limited in their ability to capture $T$ cell dynamics at a systemic level since resistance can manifest heterogeneously across sites $^{3}$. Moreover, although multiregional analyses have revealed substantial immune heterogeneity within an individual tumor lesion in early-stage lung cancer ${ }^{4,5}$, it is unknown whether intra-lesional heterogeneity occurs in the metastatic setting where ICB is most often deployed.

More generally, compared to murine model systems, deconvolution of T cell responses to cancer in humans has been limited by the infeasibility of multi-region and longitudinal profiling of clonally related $T$ cells. The development of paired scTCR/RNA-seq has enabled the deep profiling of T cells in the context of their TCR clonality, phenotypic heterogeneity, tissue distribution, and peripheral persistence ${ }^{6}$. However, few existing datasets have sufficient breadth to allow characterization of T cell clonal dynamics across anatomic sites and over time in the peripheral blood of individual patients. For example, while TCF $-1^{+}$ precursor exhausted T cells have been elegantly profiled in murine systems ${ }^{7}$ and $\mathrm{T}$ cells with the phenotype of TCF $-1^{+}$precursor exhausted cells were recently described in human $\mathrm{LNs}^{8}$, evidence for the existence of a TCF- $1^{+}$precursor exhausted LN-resident CD8 T cell that is clonally linked to its exhausted counterpart in the tumor tissue is lacking. Relatedly, while T cell persistence is an established concept in the field of adoptive $T$ cell therapies ${ }^{9,10}$, a substantial barrier to our understanding of resistance to ICB therapy is knowing which $\mathrm{T}$ cell clones are the functionally important ones to track.

To help address these gaps, we performed paired scTCR/RNA-seq from 32 tumor, adjacent normal tissue, and regional LNs from four surgical resections from three patients undergoing ICB and profile regional $T$ cell heterogeneity that is associated with pathologic tumor heterogeneity. From this $T$ cell dataset, we were able to assess whether T cell paradigms previously demonstrated in mouse models could also be extended to human disease. Specifically, we identified TCF-1+ precursor exhausted cells in the LN of patients that are clonally related to exhausted $\mathrm{CD} 8^{+} \mathrm{T}$ cells in lung tumors. Furthermore, with deep profiling of cell states in the tissues, we were able to select clonal T cells to track in the peripheral blood over time during the course of ICB in three patients, leading to the observation that rapid disease progression was associated with a loss of persistence of both tumor-reactive and ubiquitous clones, suggesting that a broad array of T cells may contribute to the ongoing efficacy of ICB therapy.

\section{RESULTS \\ Clinical and pathological characteristics of lung cancer resections after ICB}

We profiled three patients (MSK 1263, 1302, and 1344) with metastatic non-small cell lung cancer (NSCLC) who were treated with anti-PD-1 monotherapy at Memorial Sloan Kettering Cancer Center (Table S1). All three patients had mixed responses, with most metastatic sites demonstrating clear response but at least one site showing progression or persistence during treatment (Fig 1A). In these cases, the evidently resistant site of disease was surgically resected, and multiple regions from each metastasis were collected for analyses. Following resection, two patients (MSK 1302 and 1344) remain alive nearly two years afterwards, while one patient (MSK 1263) quickly developed systemic disease recurrence and died.

From the three patients, we obtained four tumor resection specimens that underwent sectioning into eight $1-2 \mathrm{~cm}^{2}$ sections per primary tumor that were subjected to pathological evaluation, regional bulk RNA sequencing, flow cytometry, and scTCR/RNA-seq of sorted CD3 ${ }^{+} \mathrm{T}$ cells (Fig 1B). We also obtained adjacent normal tissue and regional LNs (not involved by tumor on pathological analysis) from MSK 1263 and 1302. Serial peripheral blood samples were collected up to 216, 452, and 1013 days after the start of anti-PD-1 therapy in MSK 1263, 1302, and 1344, respectively, to permit clonal tracking of peripheral T cells before, at, and after resection.

Pathological analysis revealed substantial tumor heterogeneity among the various tissue regions (Fig S1, Table S2). MSK 1263 and 1302 each had four regions involved by varying amounts of cancer cells and four regions not involved by viable cancer cells (Fig S1A-B); MSK 1344 had viable cancer cells in all regions but with varying involvement (Fig S1C). Bulk RNA sequencing of tumor regions also demonstrated inter-regional heterogeneity, particularly in MSK 1263 and 1302 (Fig S2A). Using CIBERSORT deconvolution, we noted that the two patients with greater pathological heterogeneity (MSK 1263 and 1302) also had greater regional heterogeneity for estimated immune cell frequencies (Fig S2B). To compare gene expression profiles between tumor regions with and without viable cancer cells, we performed gene set 

available under aCC-BY-NC-ND 4.0 International license.

$$
\text { Pai, Chow, et al., (SATPATHY, HELLMANN), p. } 4
$$

enrichment analysis (GSEA) and found that pathways associated with cell cycle such as 'G2M checkpoint', 'DNA repair', and 'mitotic spindle' and also cancer aggressiveness such as 'epithelial mesenchymal transition' and 'myc targets' were selectively upregulated in regions with viable cancer (Fig S2C, Table S3). The tumor regions with viable cancer cells also showed enrichment for pathways that indicate an ongoing immune response, such as 'inflammatory response' and 'interferon gamma response' (Fig S2C, Table S3). These results suggest that immune cell state differences may be a critical driver of the pathologic heterogeneity. Since intra- and inter-patient heterogeneity can be obscured by bulk analysis, we hypothesized that applying scTCR/RNA-seq to CD3 ${ }^{+}$T cells (Fig S2D) - the critical effectors in ICB - in these heterogeneous regions could yield important insights into the systemic anti-tumor $\mathrm{T}$ cell response during ICB.

\section{Single cell TCR/RNA sequencing reveals inter- and intra-patient heterogeneity}

From the 32 adjacent normal, tumor, and LN regions, we performed droplet-based ScTCR/RNAseq on sorted $\mathrm{CD}^{+} \mathrm{T}$ cells. 31 of 32 regional samples passed initial quality control assessment based on mitochondrial content and the number of genes and UMls detected per cell (Fig S3A, Table S2). After removing the single region that did not pass QC, $63.5-89.9 \%$ of the individual cells per region (Fig S3B, Table S2) passed QC filtering, retaining 162,062 high-quality T cells for downstream analyses. At least one chain of the TCR was captured in 141,110 cells ( $87 \%$ of the cells that passed QC, $76.0-92.7 \%$ per region, Fig S3C, Table S2), and paired TCRa $\beta$ chains were captured in 103,181 cells in total. Utilizing Seurat v3.1.4 ${ }^{11}$, T lymphocytes were clustered into six CD4 T, seven CD8 T, and one mucosal-associated invariant T (MAIT) cell clusters (Fig 1C). These clusters were annotated by examining differentially expressed cluster markers and comparing to previously published cluster definitions in other scRNA-seq datasets ${ }^{12-14}$ (Fig 1D, Fig S3D, Table S4). Naïve CD4 T cells expressed CCR7, SELL, IL7R, and LEF1. Among the two CD4 T effector clusters found, CD4-EFF1 highly expressed IL7R and CD69, while CD4-EFF2 highly expressed GZMA, PRDM1, and CXCR6. Two TFH clusters were annotated with CD4-TFH1 highly expressing ICOS, TNFRSF4, TNFRSF18, CTLA4, SELL, TIGIT, and PRDM1, and CD4-TFH2 highly expressing ICOS, PDCD1, and CXCL13. CD4 Tregs highly expressed FOXP3, TNFSFR9, TNFRSF18, TIGIT, and ENTPD1. Similar to naïve CD4 T cells, naïve CD8 T cells highly expressed SELL, CCR7, and IL7R. There were two effector CD8 clusters: CD8-EFF highly expressed GNLY, NKG7, PRF1, and KLRG1, whereas CD8-GZMK highly expressed GZMK, CCL4, NKG7, GZMA, GZMH, PRF1, LAG3, and PDCD1. A CD8 tissue resident memory (TRM) cluster highly expressed ITGAE, CD69, PDCD1, ZNF683, CXCR3, GZMA, and GZMB. A CD8 cluster that highly expressed GMZK, LAG3, NKG7, ENTPD1, HAVCR2, CD38, CD274, and TCF7 was annotated as CD8-TCF1. Finally, two exhausted CD8 T cells clusters that were distinguished by their proliferative status were identified. CD8-EXH highly expressed GZMB, LAG3, NKG7, ENTPD1, HAVCR2, CXCL13, TNFRSF9, and IFNG, while CD8-PROLIF-EXH expressed high levels of these genes in addition to GZMA, CD38, and proliferation genes (TUBB, TUBA1, MKI67, AURKB). Importantly, all clusters were represented across the four resections from the three patients (Fig S4A-B) and across region types (Fig S4C).

We next utilized our scTCR-seq data to identify and link T cell clones to their cellular phenotypes. As expected, there was minimal TCR overlap among the three patients ( 0 out of 45,607 unique CDR3a $\beta$ nucleotide sequences, 2 sequences out of 45,538 unique CDR3 $\alpha \beta$ amino acid sequences, Fig S4D), demonstrating that the rearranged TCR repertoire is specific to each patient and likely responding to patient-specific antigens. By pairing TCR information with phenotypes, we observed that CD8 T cell clusters contained clones with substantially larger clone sizes relative to CD4 T cell clusters (Fig 1E). We next evaluated TCR repertoire similarity across the regions using the Morisita-Horn Index to globally evaluate TCR heterogeneity in the three patients. Relative to MSK 1263 and 1302, 1344 has less heterogeneity of represented T cell clones across the different regions (Fig 1F), perhaps concordant with this sample having viable tumor throughout each region and being derived from a metastatic LN that may contribute greater background homogeneity of non-tumor-associated T cells. Furthermore, the TCR composition within the three sequenced adrenal regions from MSK 1263 were more similar to each other than to the primary tumor or adjacent normal regions (Fig 1F). These data suggest that integration of TCR repertoire overlap across regions with cell state and pathological features will yield informative insights into the clonal $T$ cell architecture during ICB.

\section{Treg, TFH, and exhausted CD8 T cells are enriched in tumor regions with viable cancer cells}



available under aCC-BY-NC-ND 4.0 International license.

$$
\text { Pai, Chow, et al., (SATPATHY, HELLMANN), p. } 5
$$

We next evaluated whether specific $T$ cell phenotypes were enriched in regions containing viable tumor cells (Fig S4C). We focused on 20 thoracic regions from MSK 1263 and 1302 resection samples that included all representative region types (i.e. LN, adjacent normal, regions without viable tumor cells, and regions with viable tumor cells). In contrast, the adrenal resection from MSK 1263 and LN resection from MSK 1344 did not contain tumor bed regions without viable cancer, and thus, were not included in this analysis. Among CD4 T cell clusters, we observed that CD4-Naïve, CD4-TFH1, and CD4-TFH2 cells were enriched in LNs, and CD4-EFF2 was enriched in adjacent normal regions (Fig 2A). CD4-TFH1, CD4-TFH2, and CD4-TREG cells were enriched in tumor regions relative to adjacent normal regions, and these cells were further enriched in viable tumor regions relative to the regions of the tumor bed without viable tumor. These three CD4 clusters also displayed higher Gini indices among TCR clones in the viable tumor regions, indicating higher levels of clonal expansion (Fig S5A). Furthermore, by using TCRa $\beta$ sequences to trace T cell clones across regions, we observed that clones enriched among regions with viable tumor were overrepresented by TFH phenotypic clusters (Fig S5B-C). Among CD8 T cell clusters, we observed that LNs were enriched for CD8-Naïve and CD8-TCF1 cells, while adjacent normal regions were enriched in CD8EFF cells (Fig 2B). The two exhausted CD8 clusters were enriched in the tumor regions relative to adjacent normal regions, and this effect was more pronounced in the tumor bed regions with viable cancer cells, which is consistent with prior reports ${ }^{12,15,16}$. These exhausted CD8 clusters also demonstrated greater clonal expansion relative to the adjacent normal and tumor regions without viable cancer cells (Fig S5D). These findings are consistent with prior reports of clonal T cell expansion in tumor regions in human lung cancer ${ }^{17}$.

Next, we characterized cell state differences between CD8 T cells across the regions by scoring each cell in terms of a T cell exhaustion signature ${ }^{18}$ (Table S5), which revealed that viable tumor areas displayed the highest level of exhaustion (Fig 2C). To verify this finding, we performed flow cytometry on CD8 $T$ cells and found that cells from viable tumor regions expressed higher levels of the exhaustion markers CD39 and PD-1 than cells from other regions (Fig 2D-E). We next sought to leverage the TCR 'barcode' to determine whether clonal T cells present in both non-viable and viable tumor regions demonstrated greater exhaustion in proximity to viable cancer cells. In this clone-matched analysis of 851 CD8 clones (612 from MSK 1263; 239 from MSK 1302), CD8 T cells demonstrated a greater exhaustion score in viable tumor regions than in non-viable tumor regions (Fig 2F), suggesting that cells within a clone can take on distinct cell states depending on positioning within the tumor. In the two regions from the adrenal resection from MSK 1263, there was also a positive correlation on flow cytometry between presence of viable cancer cells and level of CD39 and PD-1 expressed (Fig 2G). Finally, we hypothesized that T cell states that are concomitantly present in the same region may cross-signal to influence anti-tumor activity. To assess for such interactions, we assessed spatial correlations of T cell states. Across the three patients, we noted a strong correlation between the frequencies per region of CD4-TFH1, CD4-TFH2, CD4-TREG, CD8-EXH, and CD8-PROLIF-EXH (Fig 2H), which are the cell subsets enriched in regions with viable cancer cells (Fig 2A-B). In summary, T cells within regions with viable tumor adopt a more exhausted-like state, even in comparison to their clonal counterparts within regions without viable tumor.

\section{Clonal expansion of tumor regional $\mathrm{T}$ cells is not associated with cancer cell-induced proliferation}

We next sought to better understand T cell heterogeneity based on the regional patterns of TCR clone presence. Large clone sizes could be driven by the local expansion in tumor regions or be explained by a larger precursor frequency. To distinguish these two possibilities, we asked whether clonal frequency correlates with the number of regions in which the TCR clone was found. Indeed, there was a strong correlation between overall clone frequency in the scTCR/RNA-seq dataset and the number of regions in which the clone was found (Fig S6A), suggesting that large clone sizes are not exclusively driven by local expansion. We next categorized TCRs into mutually exclusive regional patterns for each patient (Fig S6BC, Methods). 'Ubiquitous' TCRs were defined as those found in all LN, adjacent normal, and tumor regions sampled, whereas 'LN enriched' and 'normal enriched' clones were those not found in tumor regions, but found in LN and adjacent normal regions, respectively. 'Tumor enriched' clones were those found only in tumor regions, but not $\mathrm{LN}$ and adjacent normal regions. These 'tumor enriched' clones were further subclassified as 'single region', 'oligo-regional', or 'pan-regional' if they were observed in only one, multiple but not all, or all tumor regions, respectively. Clones with the 'Tumor enriched' profile, preferentially found in regions of viable tumor (Fig $\mathbf{3 A}$ ), might represent selective amplification by cancer cell-mediated clonal expansion. Considering the clonal expansion of TFH, Treg, and exhausted CD8 T cells in viable tumor regions, we hypothesized that tumor antigen-specific TCR-driven proliferation in the tumor microenvironment mediated this enrichment. Indeed, others have proposed that CD8 T cells undergo an 


$$
\text { Pai, Chow, et al., (SATPATHY, HELLMANN), p. } 6
$$

additional burst of proliferation in the vicinity of viable tumor, potentially attributable to re-engagement of the TCR in the tumor microenvironment ${ }^{16}$. By identifying TCR clones present in both the tumor regions with and without viable cancer cells, we examined the proliferation of clone-matched T cells in the two regions. Surprisingly, we did not find transcriptional evidence for enhanced proliferation of clone-matched $T$ cells residing in the Treg, TFH, or exhausted CD8 clusters within viable tumor regions (Fig 3B-D). These data suggest that local tumor-induced proliferation of $\mathrm{T}$ cells is not the primary mechanism of clonal $\mathrm{T}$ cell expansion in the tumor microenvironment.

We next evaluated preferential chemotaxis into regions with viable tumor cells, since enhanced proliferation could not account for the accumulation of TFH, Treg, and exhausted CD8 T cells in the tumor microenvironment. Relative to tumor bed regions without viable cancer cells, the regions with viable tumor cells displayed higher bulk transcriptional expression of $\mathrm{Cxc} / 9, \mathrm{Cxc} / 10$, and $\mathrm{Cxc} / 16$ (Fig 3E, Fig S7A). Thus, we queried for expression of their corresponding chemokine receptors, $\mathrm{Cxcr} 3$ and $\mathrm{Cxcr6}$, among the T cell subsets in our scRNA-seq dataset. We observed that $\mathrm{Cxcr3}$ and $\mathrm{Cxcr6}$ were the only chemokine receptors preferentially expressed in Treg and exhausted CD8 T cells (Fig 3F, Fig S7B). Thus, chemotaxis of CXCR3/CXCR6 ${ }^{+}$clonally expanded TFH, Treg, and exhausted CD8 T cells towards CXCL9, CXCL10, and CXCL16, which are abundant in tumor bed regions with viable cancer cells, may explain their accumulation in these areas. Finally, another explanation for the enrichment of TFH, Treg, and exhausted CD8 T cells in the regions with viable tumor cells is increased survival potential of chronically stimulated T cells. Indeed, we observed that the mitochondrial reads were consistently lower (except among Treg) among clonematched T cells in the viable tumor region (Fig 3G-I), suggesting that T cells in the tumor microenvironment have activated mechanisms to promote survival in the setting of chronic antigen stimulation. The correlation of enhanced exhaustion with reduced cell death in the viable tumor regions (Fig 2C, Fig 3G-I) is consistent with the concept that the exhaustion program protects $T$ cells from chronic antigen overstimulation that can result in loss of CD8 T cell persistence ${ }^{19}$.

\section{Loss of ubiquitous clones is associated with rapid progression during ICB}

Having characterized regional T cell clones, we next sought to investigate the nature of TCR clones present across all regions, including adjacent normal tissue and the LN. As expected, ubiquitous clones had the highest proportion of clones that could be observed in clone sizes over 50 and were composed largely of T cells from the effector CD8 clusters (Fig S6D-G). Ubiquitous clones scored highly for the previously reported signatures of 'large clones' and 'dual expanded' clones, which were both associated with the success of $\mathrm{ICB}^{14,20}$ (Fig 4A-B, Table S5), and were over-represented among the clones enriched in regions with no viable tumor (Fig 3A). The ubiquitous clones did not preferentially display tumor-specific, nor virus-specific, signatures (Fig S6H-K). To examine whether these ubiquitous clones were present in the circulation as well, we performed bulk TCR $\beta$ sequencing from the peripheral blood of our cohort of three patients at multiple time points after ICB, which included the time period before, during, and after resection. The latest blood collection ranged from 216 to 1013 days after the start of ICB (Table S1). Along with their widespread presence across regions, ubiquitous clones were also observed more frequently in the peripheral blood relative to clones with other regional patterns, which supports the systemic presence and replenishment of these clones (Fig 4C-D). Next, we utilized the bulk TCR $\beta$ sequencing data to compare the peripheral persistence of ubiquitous clones throughout the course of ICB therapy in the three patients. Despite the relative stability of T cell clones categorized into the non-ubiquitous groups (Fig S8), there was a substantial reduction in the peripheral persistence of ubiquitous T cell clones in MSK 1263, but not MSK 1302 and 1344 (Fig 4E). Thus, rapid disease progression was associated with a loss of persistence of ubiquitous clones in MSK 1263, suggesting that these ubiquitous T cells may contribute to, or reflect, the immune response that is critical for the ongoing efficacy of ICB therapy.

\section{CD8 T cell clones with tumor-reactive features can be tracked in the blood and correlate with systemic efficacy of ICB \\ From our longitudinal analysis of peripheral blood in our cohort, we next assessed whether the} different $T$ cell clusters in resected tumors were differentially represented in the peripheral blood. For both CD4 and CD8 T cell clusters, we noted substantial heterogeneity in the representation of the various clusters in the peripheral blood, both when the circulating TCR clone was linked to each T cell state found in the tissues (Fig 5A) and when linked to its majority phenotype in the tissue (Fig S9A). Among CD4 T cells, Treg clones in the tissue were the least prevalent, while CD4 effector T clones were the most prevalent in the peripheral blood (Fig 5A, Fig S9A). Among CD8 T cells, the variability was even more striking: TCR 

available under aCC-BY-NC-ND 4.0 International license.

$$
\text { Pai, Chow, et al., (SATPATHY, HELLMANN), p. } 7
$$

clones associated with the CD8-TCF1 cluster were the least prevalent in the peripheral blood, whereas clones associated with the CD8-EFF cluster were the most prevalent, with an almost 1000-fold difference between the two (Fig 5A). We next assessed the peripheral persistence of clones linked to the various tissue-defined T cell clusters. CD4 and MAIT clusters were largely stable throughout each patient's time on ICB therapy (Fig 5B-C, Fig S9B). Notably, T cell clones of the CD8-EFF phenotype, which was overrepresented among clones enriched in non-viable tumor regions (Fig S5C), increased at the time of resection for both MSK 1263 and 1344 (Fig 5B-C). In contrast, there were patient-specific patterns in the peripheral dynamics of CD8 T cell clones linked to other cell states in tissue. For example, MSK 1302 and 1344 had peripheral stability and persistence of TCR clones linked to CD8 tissue clusters, while MSK 1263 (the only patient to progress quickly after resection) showed cluster-specific changes (Fig 5B-C, Fig S9B). Unlike the stability of naïve CD8 T cell clones, clones associated with CD8-GZMK, CD8-TRM, CD8PROLIF-EXH, and CD8-EXH steeply declined in the peripheral blood at the time of oligometastatic resection (second timepoint). Additionally, while CD8-TCF1 T cell clones were stable at the time of the first oligometastatic resection, there was a substantial decline at the time of the second oligometastatic adrenal resection (Fig 5B). Taken together, these results suggest that loss of peripheral persistence of CD8 clones with exhausted $\mathrm{T}$ cell states coincides with disease progression.

Persistence of adoptively transferred $T$ cells is strongly correlated with their durable clinical activity ${ }^{9,21}$. Due to the logistical difficulty of tracking a multitude of tumor-reactive CD8 T cell clones, the importance of persistence of endogenous tumor-reactive $T$ cell clones is not well established. To hone in on the CD8 T cells that are more likely to exert direct cytotoxicity against the cancer, we derived a tumorreactivity signature score based on published features of tumor-reactive CD8 T cells ${ }^{22}$ (Table S5). Consistent with prior reports that exhausted T cells comprise the tumor-reactive population $22-28$, we found that the exhausted CD8 T cell clusters had the highest tumor-reactivity score (Fig 6A, Table S5). Two recent publications reported empirically validated transcriptional features of tumor- vs. virus-specific CD8 T cells in human lung cancer and melanoma ${ }^{27,28}$ (Table S5). Concordantly, CD8 T cells in our dataset with tumor-reactivity scores $>0\left(T^{\text {hi }}\right)$ had a greater signature score for tumor specificity from these datasets (Fig 6B-C), supporting the validity of the tumor-reactivity signature. Consistent with the enrichment of exhausted CD8 T cells in the viable tumor regions, we observed that the CD8 T cells in the viable tumor regions had the highest tumor-reactivity score (Fig 6D). Additionally, among the top 40 most expanded TR ${ }^{\text {hi }}$ CD8 T cell clones (Fig S10A), clones were preferentially found in viable tumor regions, whereas TR ${ }^{\mathrm{lo}}$ CD8 $T$ cell clones were more enriched in the $\mathrm{LN}$, adjacent normal lung, and tumor regions without viable cancer (Fig 6E, Fig S10B). Furthermore, TR ${ }^{\text {hi }}$ CD8 T cell clones were often found in the exhausted T cell clusters, CD8-TRM, and CD8-GZMK, whereas TR ${ }^{\circ}$ CD8 clones were enriched in effector CD8 clusters (Fig 6F, Fig S10C), suggesting that $T$ cell clones with tumor-reactive features are preferentially present in an exhausted state within regions with viable cancer.

To better understand potential differences in the cell state transitions among $T R^{\text {hi }}$ vs. $T R^{\text {lo }} C D 8$ clones, we performed pseudotime trajectory analysis on cells from the most highly expanded clones (Fig S10D-F). We observed that the branches involving $\mathrm{TR}^{\mathrm{lo}}$ clones occupy a distinct portion of the UMAP, which is predominantly composed of CD8-EFF and CD8-GZMK phenotypes (Fig S10F). Since the branches involving $\mathrm{TR}^{\text {hi }}$ clones also passed through the CD8-GZMK state, we asked whether there were any differences between CD8-GZMK cells within TR ${ }^{\text {hi }}$ CD8 clones and those within TR ${ }^{\text {lo }}$ clones. Differential gene expression analysis of cells in the CD8-GZMK cluster revealed an upregulation of CCL5, GZMB, GNLY, KLRB1, and the exhaustion-related genes HAVCR2, CTLA4, CXCL13 among TR ${ }^{\text {hi }}$ clones (Fig 6G). In contrast, CD8-GZMK cells from TR ${ }^{\circ}$ CD8 clones expressed higher levels of GZMK, KLRG1, IL7R, and members of the AP-1 transcription factor family, including FOS, FOSB, and JUNB. These results suggest that even within in the CD8-GZMK cluster, T cell clones exist in distinct cell states depending on reactivity and interactions with the tumor.

Finally, we hypothesized that the peripheral persistence of TR ${ }^{\text {hi }}$ CD8 T cell clones might correlate with systemic benefit from ICB. To evaluate this, we assessed the peripheral dynamics of TR ${ }^{\text {hi }}$ CD8 T cell clones from the resected specimens. We observed a reduction in TR ${ }^{\text {hi }} T$ cell clones in MSK 1263 at the time of the first resection, but not in MSK 1302 and 1344 (Fig 6H, Fig S10G). In fact, we were able to track these clones in MSK 1344 for nearly three years after the start of ICB. Thus, MSK 1263, whose clinical course was distinctly characterized by the shortened duration of benefit from ICB and rapid progression following resection of disease, was uniquely found to have a marked reduction in CD8 T cell clones with tumor-reactive features, suggesting that loss of persistence of these clones may contribute to immune escape. 
bioRxiv preprint doi: https://doi.org/10.1101/2021.09.27.461389; this version posted September $27,2021$. The copyright holder for this preprint (which was not certified by peer review) is the author/funder, who has granted bioRxiv a license to display the preprint in perpetuity. It is made available under aCC-BY-NC-ND 4.0 International license.

$$
\text { Pai, Chow, et al., (SATPATHY, HELLMANN), p. } 8
$$

391

392

393

394

395

396

397

398

399

400

401

402

403

404

405

406

407

408

409

410

411

412

413

414

415

416

417

418

419

420

421

422

423

424

425

426

427

428

429

430

431

432

433

434

435

436

437

438

439

440

441

442

443

444

445

446

\section{Intratumoral exhausted CD8 T cells can be found in a TCF-1 ${ }^{+}$progenitor state in the LN}

Recent studies using TCR transgenic systems have demonstrated that exhausted CD8 T cells in the tumor derive from LN TCF-1 $1^{+}$precursor exhausted CD8 T cells ${ }^{29-31}$ and that TCF-1 $1^{+}$populations can be found in human primary lung cancers ${ }^{16}$ and $\mathrm{LNs}^{8}$. However, whether these TCF-1 $1^{+}$precursor exhausted cells originate from regional LNs in human cancers has not been demonstrated. To probe for a clonal relationship between TCF $-1^{+}$precursors and exhausted CD8 T cells, we first examined the CD8-TCF1 cluster. Compared to naïve CD8 T cells which can also express TCF-1, the CD8-TCF1 cluster preferentially expressed SLAMF6, NKG7, CD38, CTLA4, HAVCR2, GZMA, and GZMK (Fig S11A-B). Among 361 TCRa $\beta$ clones found in the CD8-TCF1 cluster, 36 could be found in other CD8 T cell clusters, including 15 in CD8-PROLIF-EXH and 4 in CD8-EXH (Fig 7A-B). As a parallel method to identify clonally-related TCF$1^{+}$precursors, we surveyed CD8 TCRa $\beta$ clones that could be found in the exhausted CD8 state (CD8-EXH or CD8-PROLIF-EXH) in the tumor tissue of MSK 1263 and 1302 and identified clone-matched cells in the regional $\mathrm{LN}$. We then assessed the percentage of the matched clones that had a TCF7 transcript $>0$ (Fig S11C). We observed that $16.7 \%$ and $21.4 \%$ of intratumoral exhausted CD8 T cell clones with paired representation in the LN of MSK 1263 and 1302, respectively, were TCF- $1^{+}(5.7 \%$ and $7.3 \%$ of total exhausted CD8 T cell clones, Fig S11D). Since TCF-1 expression may also mark naïve CD8 T cells rather than precursor exhausted populations, and since gene dropout might result in undercounting of TCF-1 ${ }^{+}$ precursors, we repeated this analysis querying for a progenitor score (Table S5). With a cutoff of $>0$ for this progenitor score (Fig S11E), we noted that $24.3 \%$ and $35.7 \%$ of exhausted CD 8 clones that could be found in the LN of MSK 1263 and 1302, respectively, could be found in a precursor exhausted state in the LN ( $8.4 \%$ and $12.2 \%$ of total exhausted CD8 T cell clones, Fig $7 \mathrm{C}$ ). We also performed the same analysis using CD8 T cell clones that exhibited high exhaustion score among the tumor regions (Fig S11F, Table S5), which yielded a similar proportion of clones found in a LN progenitor state (Fig 7D, Fig S11G).

To assess how clonal CD8 T cell states vary across regions, we evaluated the frequency with which the progenitor phenotype of exhausted CD8 clones could be found in LNs, regions of no viable tumor, and regions of viable tumor from the thoracic regions of MSK 1263 and 1302. As expected, the progenitor score of CD8 T cells declined as these clonal CD8 T cells migrated from the LN to the tumor (Fig 7E,G). Comparing the profiles of the adrenal and thoracic lesions of MSK 1263, we observed that clones found in the thoracic or adrenal tumor regions similarly had a lower progenitor score compared to their clonematched counterparts in the LN (Fig $7 \mathbf{F}, \mathbf{H})$. To characterize the human LN progenitor state from an unbiased perspective, we performed differential expression analysis of clone-matched CD8 T cells within the $L N$ and tumor regions. As expected, we observed a higher level of TCF7 in the LN (Fig 7I), as well as increased expression of LEF1, SELL, GZMK, and heat shock proteins (HSPA1A, HSPA1B, HSPA6). Conversely, cells within the tumor regions overexpressed GZMB, GNLY, and exhaustion-related markers such as CXCL13 and CTLA4. Finally, to confirm these findings in another dataset, we examined ScTCR/RNA-seq data from three patients with resection of primary tumor and regional LNs after receiving neoadjuvant nivolumab for lung cancer ${ }^{27}$. We observed that $12.8-21.6 \%$ of clone-matched CD8 T cell clones with high exhaustion scores could be observed in a TCF-1 state (Fig 7J, Fig S11H). In these patients, there was also a reduction in progenitor score when comparing clone-matched CD8 T cells between the LN and tumor (Fig 7K). Altogether, these data provide support for the existence of a TCF-1 $1^{+}$precursor exhausted $\mathrm{T}$ cell population in the $\mathrm{LN}$ that is clonally related to exhausted CD8 T cells in the tumor microenvironment.

\section{DISCUSSION}

Despite the characteristic durability of response to ICB, many patients with initial response will later develop acquired resistance ${ }^{32}$. Up to $65 \%$ of patients who initially obtained a radiographical response to anti-PD-1 therapy in lung cancer progressed within 4 months of follow up. As surgical resection is rarely performed as standard of care in metastatic lung cancer patients receiving ICB therapy, we believe that our dataset of four resected oligometastatic lesions provides a unique window into the regional heterogeneity of the ICB response. To our knowledge, this is the largest reported single cell dataset of human T cells with peripheral tracking of clones over time and serves as an important resource for the cancer immunology community. Insights from this dataset may help to inform strategies to overcome resistance to ICB.

In this study, we performed paired scRNA/TCR-seq of 162,062 T cells from 31 tissue regions, including matched tumor, adjacent normal tissues, and LNs from 3 patients. Using this dataset, we identified several insights into the tissue distribution, persistence, and differentiation trajectories of ICB-responsive T cells. First, we found substantial regional heterogeneity in tumor persistence that was associated with 

available under aCC-BY-NC-ND 4.0 International license.

$$
\text { Pai, Chow, et al., (SATPATHY, HELLMANN), p. } 9
$$

cellular heterogeneity of both CD4 and CD8 T cell phenotypes. Specifically, we demonstrate that regions with persistent cancer cells were enriched for CD4 TFH cells, Tregs, and exhausted CD8 T cells. Furthermore, this phenotypic enrichment in viable tumor regions is associated with reduced $T$ cell death, rather than increased proliferation. Second, by investigating regional patterns of TCR clone presence, we identify ubiquitous $\mathrm{T}$ cell clones that were present in all tissue compartments examined and bear similarity to previously described 'large clones'20 and 'dual expanded' CD8 clones ${ }^{14}$ that have been associated with benefit from ICB. Third, the general persistence of CD8 clones over time in the patients in this study is consistent with other recent reports in lung cancer ${ }^{17}$ and melanoma ${ }^{28}$. By incorporating recently reported transcriptional profiles of empirically validated, tumor-specific CD8 T cells, we interrogated our dataset for T cells with tumor-reactive features and profiled their persistence in the peripheral blood over the course of treatment. We observed that a sharp reduction in CD8 T cell clones with TR ${ }^{\text {hi }}$ and ubiquitous features was associated with systemic progression of disease in MSK 1263, suggesting that a broad repertoire of T cell clones may coordinately contribute to the ongoing efficacy of ICB. However, subsequent peripheral blood tracking studies will be needed to further investigate the causal nature of this relationship. Finally, upon interrogation of clone-matched T cells in the tumor and LN regions, we found definitive evidence of TCF- $1^{+}$ precursor exhausted CD8 T cells in the LN that are clonally related to terminally exhausted CD8 T cells found in the tumor. Altogether, this work not only serves as a comprehensive single cell resource with regional, longitudinal, and clonal resolution, but also provides insights into $\mathrm{T}$ cell responses that underlie clinical responses to ICB.

A limitation of this current study includes the inability to simultaneously profile the tumor cells and non-T immune cells from these patients as our focus was on T cell dynamics. Moreover, we were unable to derive cell lines or patient-derived xenografts from these cases and thus, do not have viable material to further interrogate the malignant cell compartment. Another limitation of the primary dataset is the limited number of total patients represented. Moreover, since this study was not prospectively designed, there are patient-specific differences in timing of tissue and blood collection. Future larger prospectively designed studies will help to overcome these limitations.

\section{MATERIALS AND METHODS}

Human biospecimens

Resection materials and blood were obtained with informed consent from patients under protocol \#06-107 approved by MSKCC.

\section{Pathologic review}

Histologic review for extent of tumor response was performed by J.L.S. following the IASLC multidisciplinary recommendations for pathologic assessment of lung cancer resection specimens after neoadjuvant therapy ${ }^{33}$.

\section{Bulk RNA-sequencing}

Approximately 200-500 ng of FFPE RNA extracted from FFPE slides with a DV200 range between 3-99 or 65-100 ng of fresh frozen RNA (DV200 98-99) per sample were used for RNA library construction using the KAPA RNA Hyper library prep kit (Roche, Switzerland). The number of pre-capture PCR cycles was adjusted based on the quality and quantity of RNA extracted from the samples. Customized adapters with 3bp unique molecular indexes (UMI) (Integrated DNA Technologies, USA) and sample-specific dual-index primers (Integrated DNA Technologies, USA) were added to each library. The quantity of libraries was measured with Qubit (Thermo Fisher Scientific, USA) and the quality was assessed by TapeStation Genomic DNA Assay (Agilent Technologies, US). Approximately $500 \mathrm{ng}$ of each RNA library were pooled for hybridization capture with IDT Whole Exome Panel V1 (Integrated DNA Technologies, US) using a customized capture protocol modified from NimbleGen SeqCap Target Enrichment system (Roche, Switzerland). The captured DNA libraries were then sequenced on an Illumina HiSeq4000 in paired ends (2X100bp) to a target 50 million read pairs per sample. The demultiplexed FASTQs were aligned to the human genome reference hg19/GRCh37 using STAR (v2.7.3a) and deduplicated from the combination of UMI sequence and alignment coordinate using UMI-tools (v1.0.1). Rsubread (v2.6.4) was used to extract the feature count matrix from alignments. We used edgeR (v3.34.1) for normalization, multidimensional scaling, differential expression, and gene ontology (GO) enrichment analyses. For GSEA, we used fgsea (v1.18.0) with MSigDB (v7.4) hallmark pathway gene set. Cell type deconvolution was performed using 


$$
\text { Pai, Chow, et al., (SATPATHY, HELLMANN), p. } 10
$$

CIBERSORTx (https://cibersortx.stanford.edu) with reference matrix derived from one lung tumor sample (LUNG_T31) within previously published single-cell data ${ }^{34}$.

\section{Fresh tumor preparation}

Gross resection specimens were promptly sectioned within 1 hour of the resection and tumor pieces from the various regions were placed into human complete medium (RPMI $+10 \%$ human serum albumin $+1 \%$ penicillin with streptomycin $+0.1 \%$ amphotericin) on ice. Human tissue from the various regions were minced with a razor blade and digested in GentleMACS enzyme mix in individual tubes per region for 3060 minutes according to manufacturer's recommendations. After centrifugation of a filtered single cell mix, the cell pellet was resuspended in human complete medium and underwent one round of ACK lysis. A subset of this cell pellet was cryopreserved for future use in Bambanker media.

\section{Flow cytometry and cell sorting}

Cells were incubated with TruFCX (for human cells) to block nonspecific binding, and then stained (15 min, $4{ }^{\circ} \mathrm{C}$ ) with appropriate dilutions of CD45-BV510 (clone 2D1), CD3-BV650 (clone UCHT1), CD8-PerCPCy5.5 (clone SK1), CD4-Alexa700 (clone A161A1), CD39-APC (clone A1), and PD-1-APC-Fire 750 (clone $\mathrm{EH} 12.2 \mathrm{H} 7$ ). All antibodies were purchased from BioLegend. DAPI- $\mathrm{CD} 45^{+} \mathrm{CD}^{+}$cells analyzed by a BD LSRII or were sorted by FACS Aria. Doublets and dead cells were excluded on the basis of forward and side scatter and 4',6-diamidino-2-phenylindole (DAPI, $1 \mu \mathrm{g} / \mathrm{ml}$ ). Flow cytometry data was analyzed with FlowJo V10.8 (TreeStar). Representative gating strategy is depicted in Fig S2D.

\section{Single cell RNA sequencing}

Sorted T cells were stained with Trypan blue and Countess II Automated Cell Counter (ThermoFisher) was used to assess both cell number and viability. Following QC, the single cell suspension was loaded onto Chromium Chip A (10X Genomics PN 230027) and GEM generation, cDNA synthesis, cDNA amplification, and library preparation of 2,700-11,000 cells proceeded using the Chromium Single Cell 5' Reagent Kit (10X Genomics PN 1000006) according to the manufacturer's protocol. cDNA amplification included 13-14 cycles and 11-50ng of the material was used to prepare sequencing libraries with 14-16 cycles of PCR. Indexed libraries were pooled equimolar and sequenced on a NovaSeq 6000 or NextSeq 500 in a PE26/92, PE28/91 or PE100 run using the NovaSeq 6000 SP, S1, or S2 Reagent Kit (100, 200, or 500 cycles) or TG NextSeq 500/550 High Output Kit v2.5 (150 cycles) (Illumina). An average of 179 million reads was generated per sample.

\section{Single cell TCR sequencing}

An aliquot of cDNA generated using the methods described above was used to enrich for $V(D) J$ regions using the Chromium Single Cell V(D)J Enrichment Kit Human T Cell (10X Genomics PN 1000005) according to the manufacturer's protocol with 10 cycles of PCR during enrichment and 9 cycles during library preparation. Indexed libraries were pooled equimolar and sequenced on a NovaSeq 6000 in a PE150 run using the NovaSeq 6000 SP, S1, or S4 Reagent Kit (300 cycles) (Illumina). An average of 129 million paired reads was generated per sample.

\section{Pre-processing of scTCR/RNA-seq libraries}

Reads from 10x scRNA expression libraries were aligned to human genome assembly GRCh38 (hg19) and quantified using cellranger count (10x Genomics, v3.1.0). The filtered feature-barcode matrices containing only cellular barcodes were used for further analysis. Single cell gene expression matrices were imported into R (v3.6.1) and analyzed using Seurat (v3.1.4) ${ }^{11}$. Cells with $>4,500$ genes captured and $<15,000$ UMls were kept. Additionally, cells with greater than 15\% mitochondrial RNA reads were excluded from subsequent analyses.

Single cell TCR reads were aligned to human genome assembly GRCh38 (hg19) and assembled into reconstructed TCR consensus sequences using cellranger vdj (10x Genomics, v3.1.0). Only productive TCR $\alpha$ and TCR $\beta$ sequences were considered for further analysis. Overall, TCR sequences were annotated for 141,110 cells that passed RNA quality filtering, with paired TCRa $\beta$ sequences detected for 103,181 cells. Cells with multiple TCR $\beta$ chains captured $(\beta \beta, \alpha \alpha \beta, \alpha \alpha \beta \beta)$ were excluded from further analysis. Only cells with conventional paired TCR chain combinations $\alpha \beta$ or $\alpha \alpha \beta$ were kept for downstream TCR clonal 


$$
\text { Pai, Chow, et al., (SATPATHY, HELLMANN), p. } 11
$$

analyses. Cells sharing the same CDR3aß nucleotide sequences were defined as belonging to the same TCR clone.

\section{ScRNA-seq data integration and clustering}

scRNA-seq libraries from each region were log10-normalized individually and integrated with Seurat by identifying anchors between datasets using reciprocal PCA with 30 dimensions. TCR genes were excluded from the selection of integration anchors to prevent TCR chain driven biases. Dimensionality reduction of the integrated matrix was performed using Uniform Manifold Approximation and Projection (UMAP) with the first 30 principal components. Phenotypic clusters were defined by constructing a k-nearest neighbors graph and identifying groups of cells using the Louvain algorithm with resolution of 0.6.

\section{TCR clone regional pattern categorization}

TCR clones were categorized into mutually exclusive regional patterns for each patient by assessing the combination of region types (i.e. LN, adjacent normal, or tumor regions) for which cells with shared CDR3a $\beta$ nucleotide sequences could be found in. 'Ubiquitous' TCR clones were defined as those found in all LN, adjacent normal, and tumor regions sampled. 'LN enriched' and 'normal enriched' TCR clones were those found only in LN or adjacent normal regions, respectively. 'Tumor enriched' clones were found only in tumor regions, but not in LN nor adjacent normal regions, and were further sub-classified as 'single region' (found in only one tumor region), 'oligo-regional' (found in $>1$ but not all tumor regions), or 'pan-regional' (found in tumor regions).

\section{TCR clone enrichment in viable/non-viable tumor}

TCR clones were categorized as enriched in viable tumor regions or no viable tumor regions based on CDR3 $\alpha \beta$ nucleotide sequence. For each clone, the number of cells found in viable tumor or no viable tumor regions was calculated and constructed into a $2 \times 2$ contingency table to test for enrichment by Fisher's exact test. Clones with $p$-value $<0.05$ were considered enriched in viable or no viable tumor regions.

\section{Gene signature scoring}

To characterize cells according to previously reported gene signatures of tumor-reactivity, CD8 T cell dysfunction, progenitor exhausted T cells, tumor- and viral-specificity, and expanded clones (Table S5), gene scores were calculated per cell using the AddModuleScore function from Seurat.

\section{Clone-matched analysis}

To compare cell state differences between $T$ cells in regions with no viable tumor vs. viable tumor, we performed clone-matched analysis of Treg (CD4-TREG), TFH (CD4-TFH1 and CD4-TFH2), and exhausted CD8 clones (CD8-PROLIF-EXH and CD8-EXH). For each phenotype, clones with at least one cell with the given phenotype present in both no viable tumor and viable tumor regions were considered. Clonal scores were calculated per region by averaging the scores of cells within each clone with the given phenotype in each region.

To characterize T cell state transitions of CD8 clones between LN and tumor regions, CD8 clones in an exhausted state were defined in two ways: (1) clones with tumor cells belonging to the CD8-EXH or CD8PROLIF-EXH phenotype cluster, or (2) clones displaying an average exhaustion score $>0$ among tumor cells. Clonal progenitor scores were calculated per region by averaging the scores of cells within each clone in each region.

\section{Trajectory inference}

To perform trajectory analysis of $\mathrm{TR}^{\mathrm{hi}} \mathrm{vs.} \mathrm{TR}^{\mathrm{lo}} \mathrm{CD} 8 \mathrm{~T}$ cell clones, dimensionality reduction of cells within the top 40 most highly expanded $T^{\text {hi }}$ and $T^{10} T$ cell clones was performed using UMAP as described above. Pseudotime analysis was then performed with Monocle $3(\mathrm{v} 0.2 .1)^{35}$ by learning a principal graph for the data and ordering cells along the graph using the cells in the CD8-Naive phenotype cluster to select a root node.

\section{External ScTCR/RNA-seq dataset analysis}


bioRxiv preprint doi: https://doi.org/10.1101/2021.09.27.461389; this version posted September 27, 2021. The copyright holder for this preprint (which was not certified by peer review) is the author/funder, who has granted bioRxiv a license to display the preprint in perpetuity. It is made available under aCC-BY-NC-ND 4.0 International license.

Pai, Chow, et al., (SATPATHY, HELLMANN), p. 12

611 Single cell data from Caushi et $\mathrm{al}^{27}$ were obtained from GEO (GSE176021) and analyzed as described 612 above. Only samples from patients with matched LN and tumor samples (MD01-004, MD01-005, MD043613 011) were analyzed.

614

615

616

Bulk TCR sequencing

gDNA was extracted from the peripheral blood utilizing the AllPrep DNA/RNA Kit (Qiagen) and was sent to

617

618

619

620 Adaptive Biotechnologies for bulk TCR $\beta$ sequencing. Data was processed using the ImmunoSEQ Analyzer (Adaptive Biotechnologies, v3.0).

Statistical analysis

Statistical analysis of bulk and single-cell sequencing data was performed in R (v3.6.1). Statistical analysis of flow cytometry data was performed in GraphPad Prism (v9.0). All box and whisker plots are defined as: center line, median; box, interquartile range; upper whisker limit, maximum without outliers; lower whisker limit; minimum without outliers; points, outliers. 
bioRxiv preprint doi: https://doi.org/10.1101/2021.09.27.461389; this version posted September 27, 2021. The copyright holder for this preprint (which was not certified by peer review) is the author/funder, who has granted bioRxiv a license to display the preprint in perpetuity. It is made available under aCC-BY-NC-ND 4.0 International license.

Pai, Chow, et al., (SATPATHY, HELLMANN), p. 13

Figure 1

A
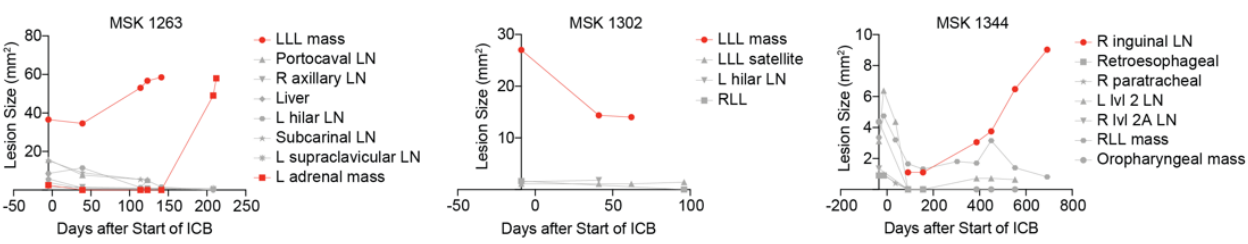

B
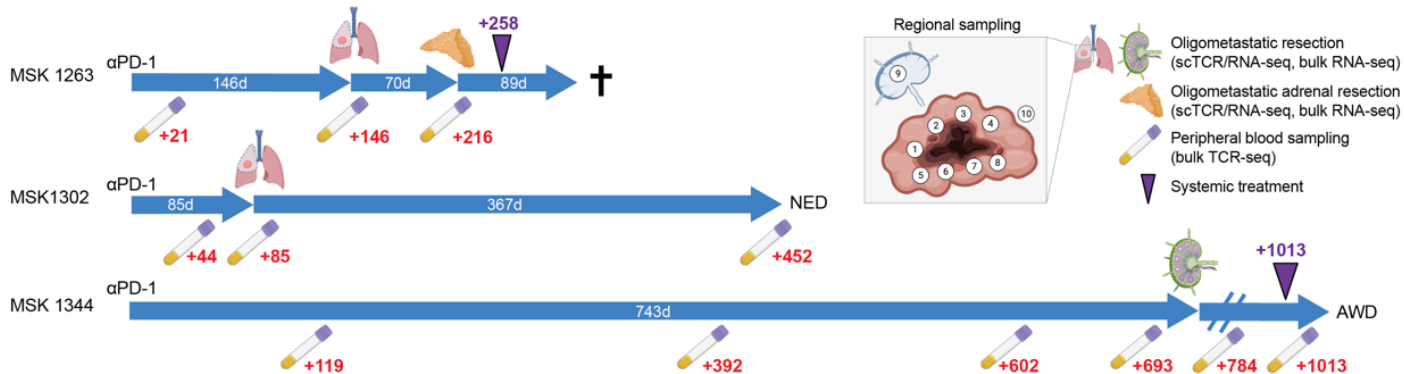

c

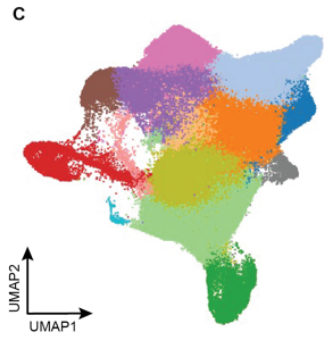

E

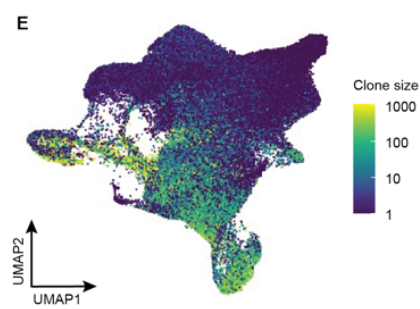

D

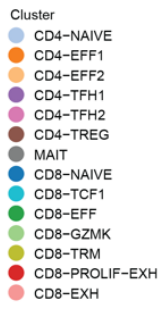

(1)

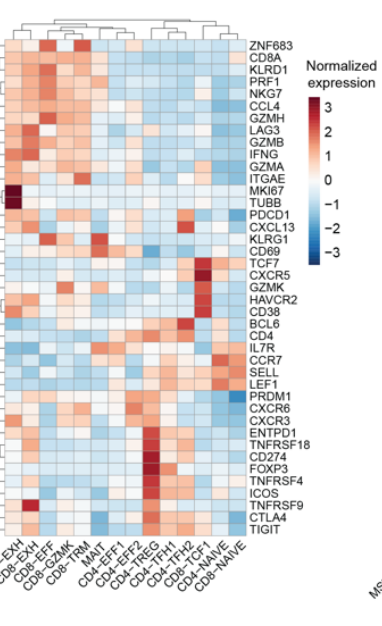

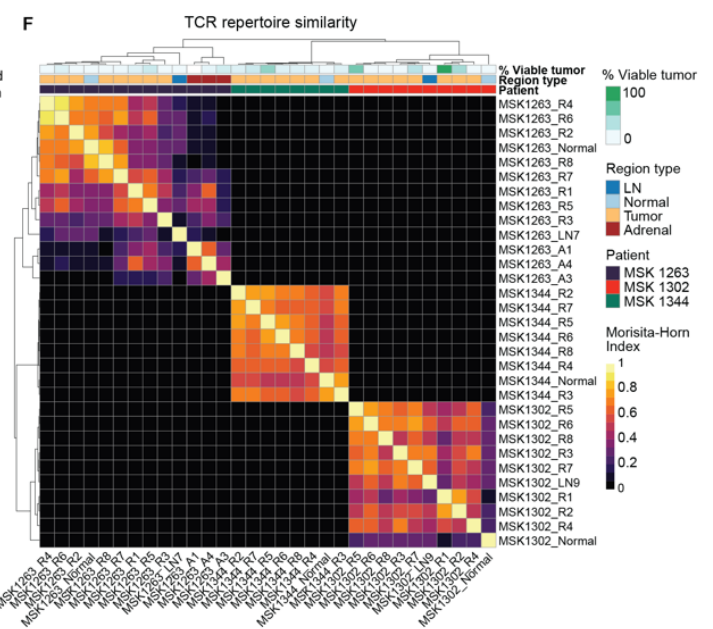

Figure 1. Regional T cell heterogeneity in resections after ICB.

A) Quantification of surface area of individuals lesions on radiographical studies over time in three patients. Red lines indicate lesions that were resected and analyzed in this study.

B) Schematic of time interval from start of anti-PD-1 therapy to time of resections across the three patients. Timeline of associated peripheral blood collections are indicated in red text below. Purple triangle indicates a change in systemic therapy from anti-PD-1 monotherapy. Cross indicates patient death. NED = no evidence of disease. AWD = alive with disease.

C) UMAP of cell clusters obtained from scTCR/RNA-seq of sorted $\mathrm{CD}^{+} \mathrm{T}$ cells, which are further defined

634 in (D).

635 D) Heat map of differentially expressed genes found in each T cell cluster.

636

637

E) UMAP overlaid with TCRaß clone size as assessed from scTCR-seq data.

F) Morisita-Horn Index of TCRa $\beta$ repertoire similarity among different regions (minimum clone size $=10$ ). 
bioRxiv preprint doi: https://doi.org/10.1101/2021.09.27.461389; this version posted September 27, 2021. The copyright holder for this preprint (which was not certified by peer review) is the author/funder, who has granted bioRxiv a license to display the preprint in perpetuity. It is made available under aCC-BY-NC-ND 4.0 International license.

Pai, Chow, et al., (SATPATHY, HELLMANN), p. 14

Figure 2

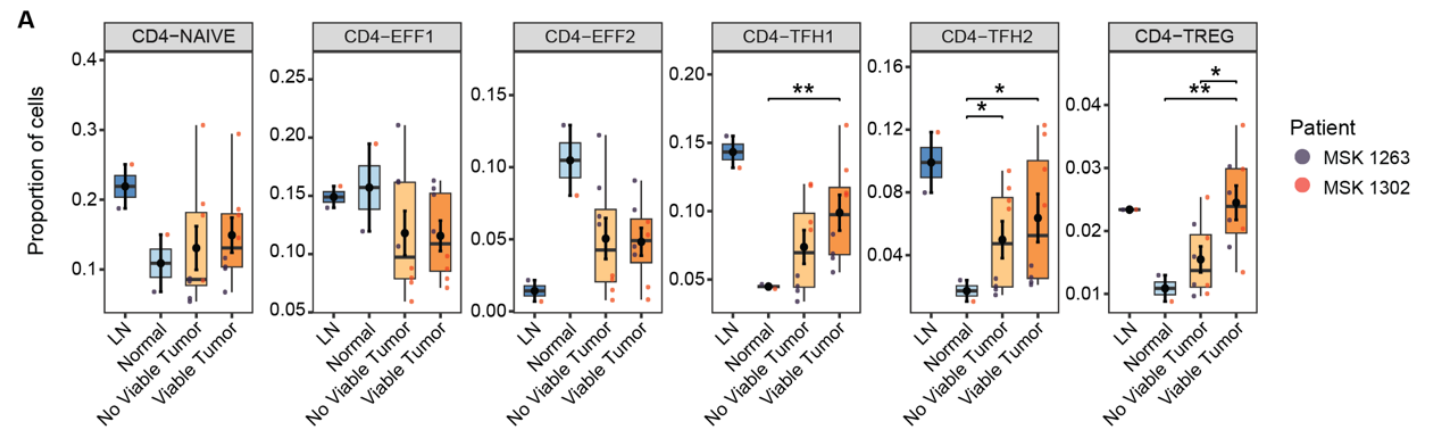

B
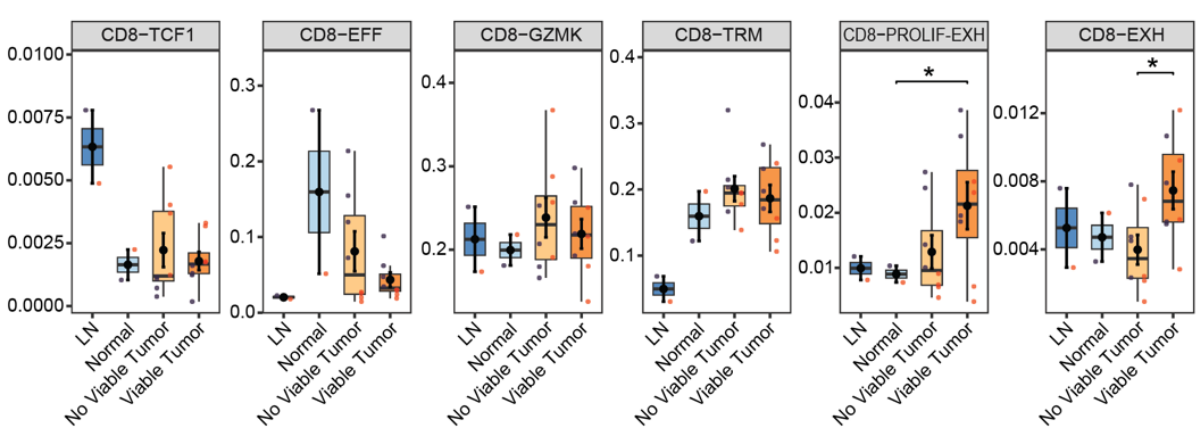

C

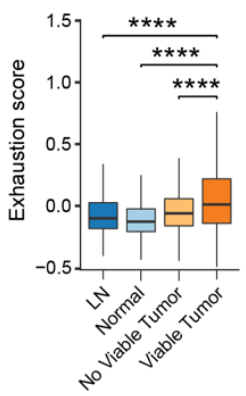

D Thoracic Regions
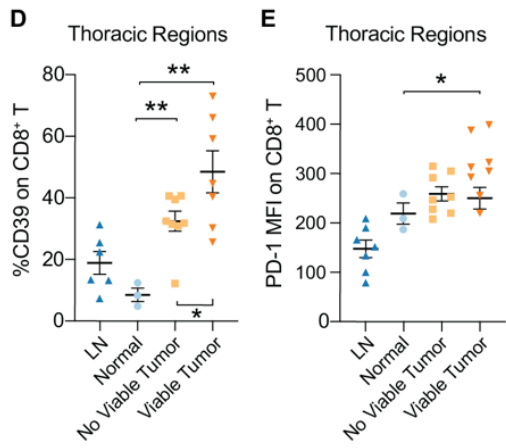

F

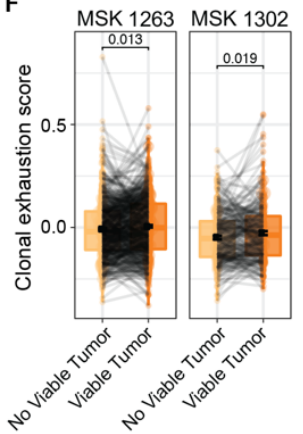

G

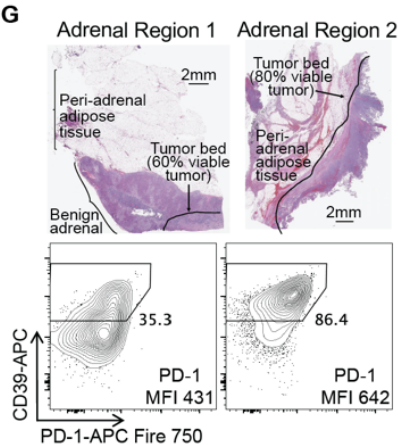

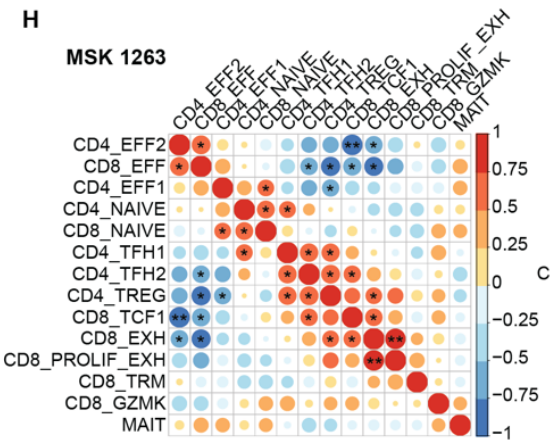
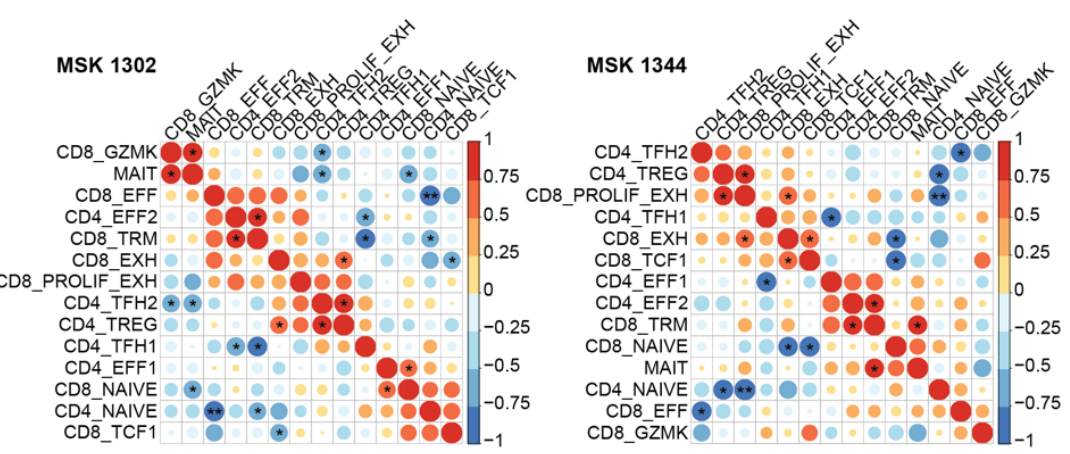

Figure 2. Tumor regions with viable tumor are enriched in CD4 TFH, Treg, and exhausted CD8 T cells.

A) Box and whisker plots of proportion of cells per indicated region with $T$ cells belonging to the indicated CD4 T cells clusters. Statistical testing by two-sided t-test $\left({ }^{*}<0.05,{ }^{* *}<0.01\right)$. Error bars represent standard error of the mean.

B) Box and whisker plots of proportion of cells per indicated region with $\mathrm{T}$ cells belonging to the indicated CD8 T cells clusters. Statistical testing by two-sided t-test $\left({ }^{*}<0.05,{ }^{* *}<0.01\right)$. Error bars represent standard error of the mean. 
bioRxiv preprint doi: https://doi.org/10.1101/2021.09.27.461389; this version posted September 27, 2021. The copyright holder for this preprint (which was not certified by peer review) is the author/funder, who has granted bioRxiv a license to display the preprint in perpetuity. It is made available under aCC-BY-NC-ND 4.0 International license.

Pai, Chow, et al., (SATPATHY, HELLMANN), p. 15

647 C) Box and whisker plot of exhaustion score per cell in the indicated region types. Statistical testing by two648 sided t-test $\left({ }^{* * * *}<0.0001\right)$.

649 D,E) Flow cytometric quantification of \%CD39 or PD-1 MFI on CD8 T cells across the indicated region 650 types. Statistical testing by two-sided t-test $\left({ }^{* *}<0.01\right)$. Error bars represent standard error of the mean.

651 F) Paired box and whisker plots of average exhaustion score per clone that is matched between regions 652 without viable tumor and regions with viable tumor. Statistical testing by paired two-sided t-test. Error bars represent standard error of the mean.

655 simultaneous availability of adjacent normal, no viable tumor, viable tumor, and LN regions.

G) Photograph of H\&E staining from two adrenal regions involved with tumor in MSK 1263 and the associated CD39 and PD-1 flow cytometry plots gated on CD8 T cells.

$658 \mathrm{H})$ Spearman correlation of indicated T cell clusters across the three patients. P-values of correlation are indicated $\left({ }^{*}<0.05,{ }^{* *}<0.01\right)$. 
bioRxiv preprint doi: https://doi.org/10.1101/2021.09.27.461389; this version posted September 27, 2021. The copyright holder for this preprint (which was not certified by peer review) is the author/funder, who has granted bioRxiv a license to display the preprint in perpetuity. It is made available under aCC-BY-NC-ND 4.0 International license.

Pai, Chow, et al., (SATPATHY, HELLMANN), p. 16

Figure 3
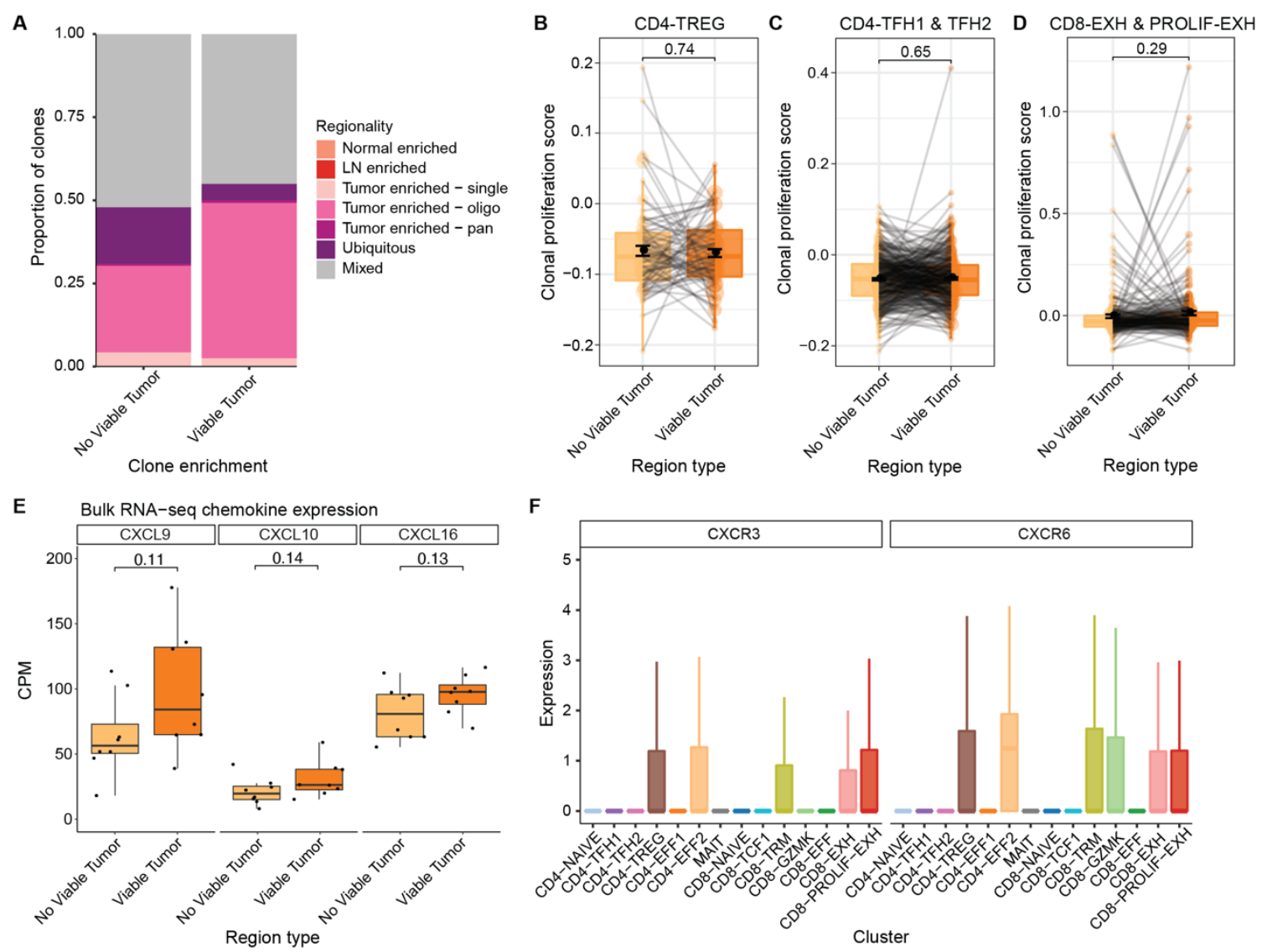

$\mathrm{F}$
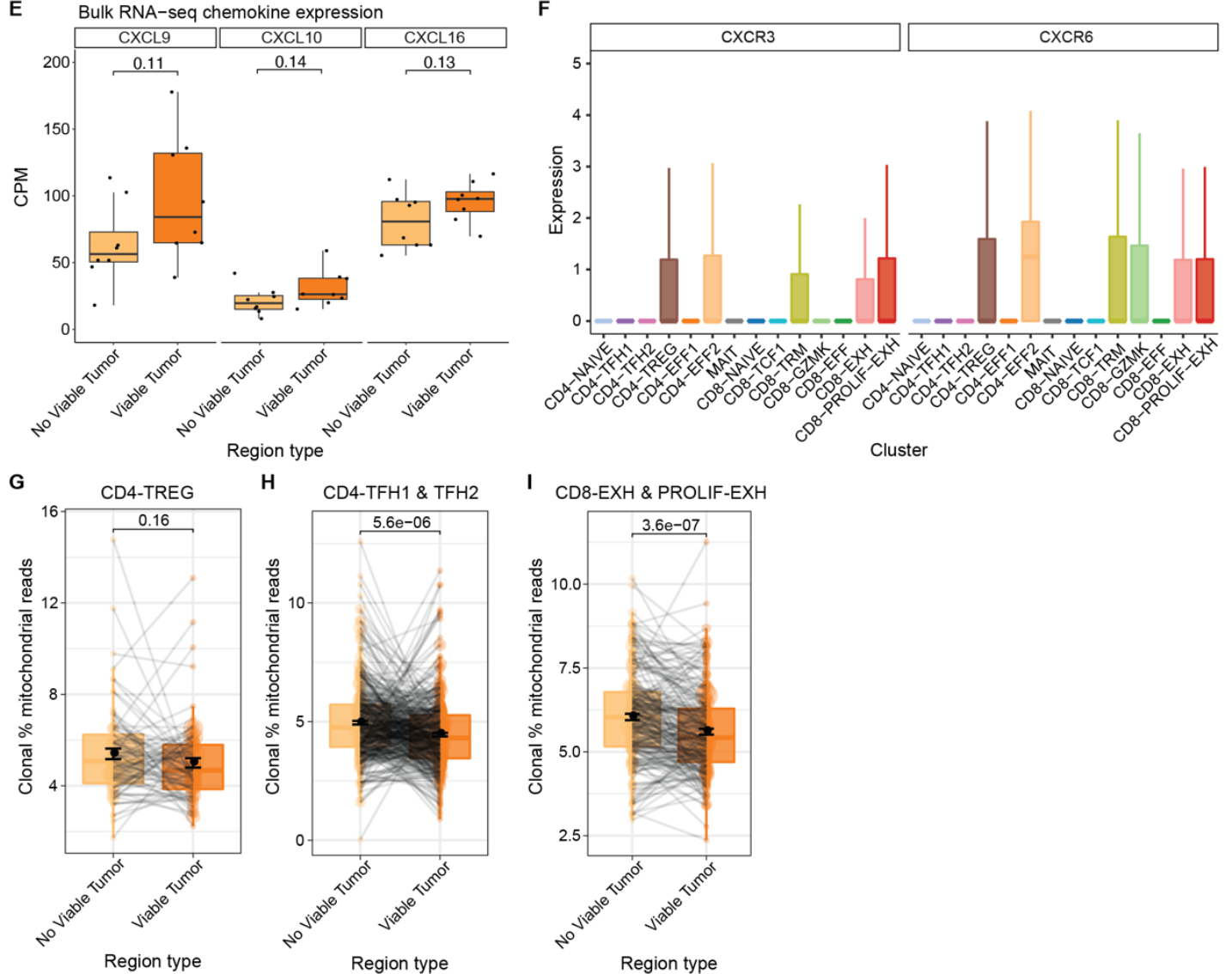

H CD4-TFH1 \& TFH2

1 CD8-EXH \& PROLIF-EXH

Figure 3. T cell proliferation, migration, and cell viability comparing tumor regions without and with viable cancer.
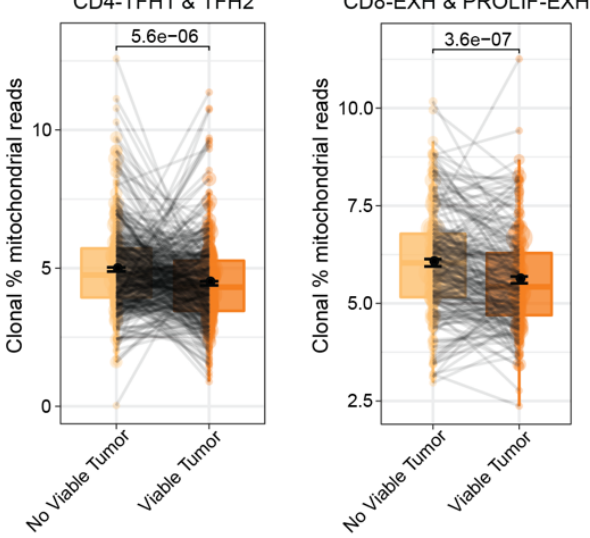

A) Bar plots of the proportion of clones enriched in tumor regions without or with viable cancer cells colored by their TCR regional pattern.

B-D) Paired box and whisker plot of average proliferation score per clone in the indicated phenotype subgroup that is matched between regions without viable tumor and regions with viable tumor. Statistical testing by two-sided t-test. Error bars represent standard error of the mean.

668

E) Expression of chemokines CXCL9, CXCL10, and CXCL16 among no viable and viable tumor regions as

669

measured by bulk RNA-seq. Statistical testing by two-sided t-test. CPM = counts per million.

670 F) Expression of chemokine receptors CXCR3 and CXCR6 among scRNA-seq phenotypic clusters. 
bioRxiv preprint doi: https://doi.org/10.1101/2021.09.27.461389; this version posted September 27, 2021. The copyright holder for this preprint (which was not certified by peer review) is the author/funder, who has granted bioRxiv a license to display the preprint in perpetuity. It is made available under aCC-BY-NC-ND 4.0 International license.

Pai, Chow, et al., (SATPATHY, HELLMANN), p. 17

671 G-I) Paired box and whisker plot of average percent mitochondrial reads per clone in the indicated 672 phenotype subgroup that is matched between regions without viable tumor and regions with viable tumor. 673 Statistical testing by two-sided t-test. Error bars represent standard error of the mean. 
bioRxiv preprint doi: https://doi.org/10.1101/2021.09.27.461389; this version posted September 27, 2021. The copyright holder for this preprint (which was not certified by peer review) is the author/funder, who has granted bioRxiv a license to display the preprint in perpetuity. It is made available under aCC-BY-NC-ND 4.0 International license.

Pai, Chow, et al., (SATPATHY, HELLMANN), p. 18

\section{Figure 4}

A

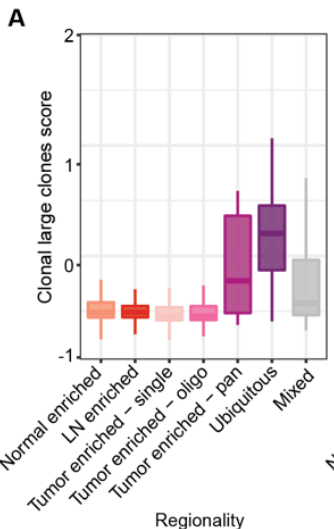

B

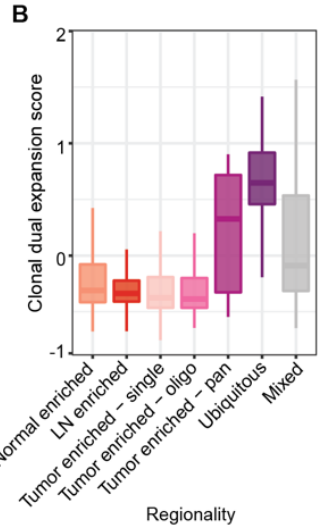

c

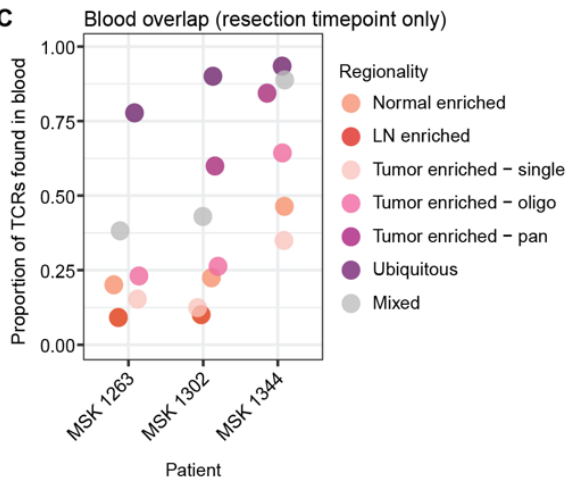

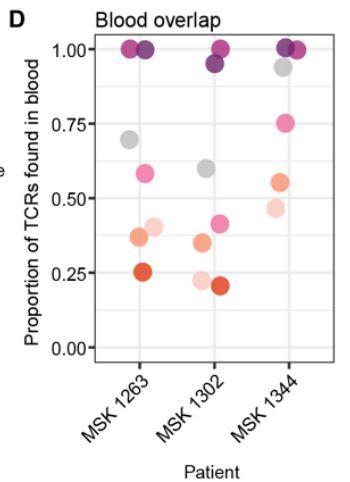

E

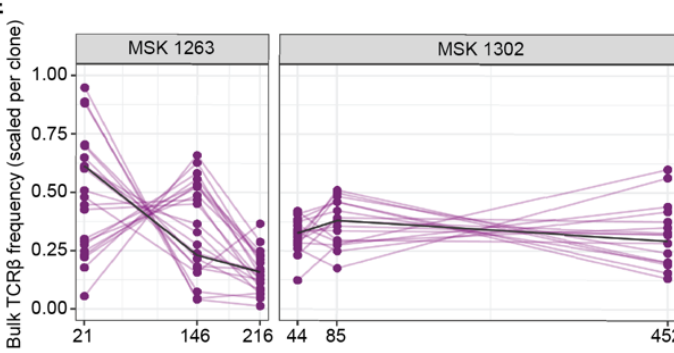

Figure 4. Peripheral T cell dynamics of clonotypes with ubiquitous phenotype.

A-B) Box and whisker plots of gene signature scores for 'large clones'20 $(A)$, or 'dual expansion'14 $(B)$ among clones with the indicated TCR regional pattern.

C,D) Percentage of clones with the indicated regional patterns for which a matched TCR $\beta$ sequence could be found in the peripheral blood at the time of resection (C) or at any time point surveyed (D).

E) Circulating frequency over time of ubiquitous TCR clones. 
bioRxiv preprint doi: https://doi.org/10.1101/2021.09.27.461389; this version posted September 27, 2021. The copyright holder for this preprint (which was not certified by peer review) is the author/funder, who has granted bioRxiv a license to display the preprint in perpetuity. It is made available under aCC-BY-NC-ND 4.0 International license.

Pai, Chow, et al., (SATPATHY, HELLMANN), p. 19

\section{Figure 5}

A

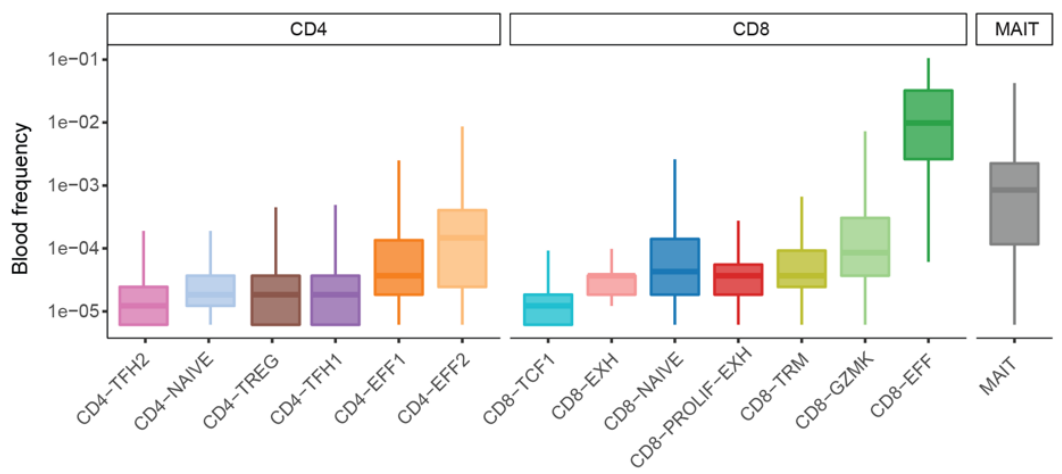

B
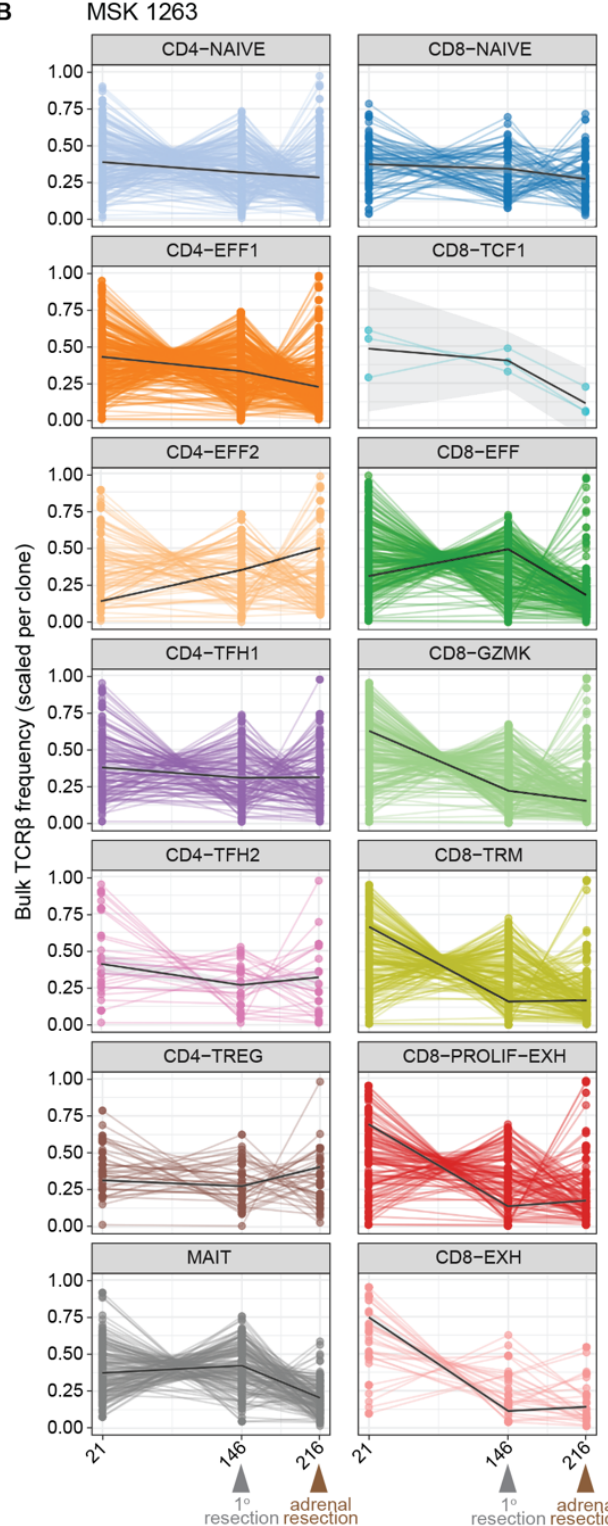

CD8-TCF1
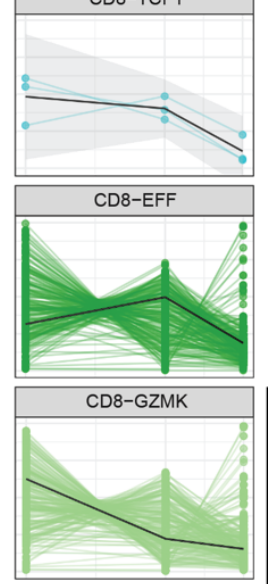

CD8-TRM
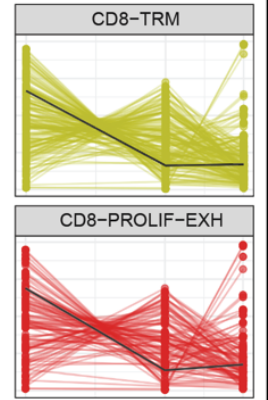

CD8-EXH

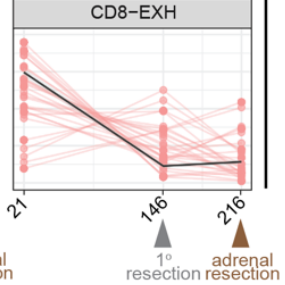

Timepoint (Days after anti-PD1)
MSK 1302
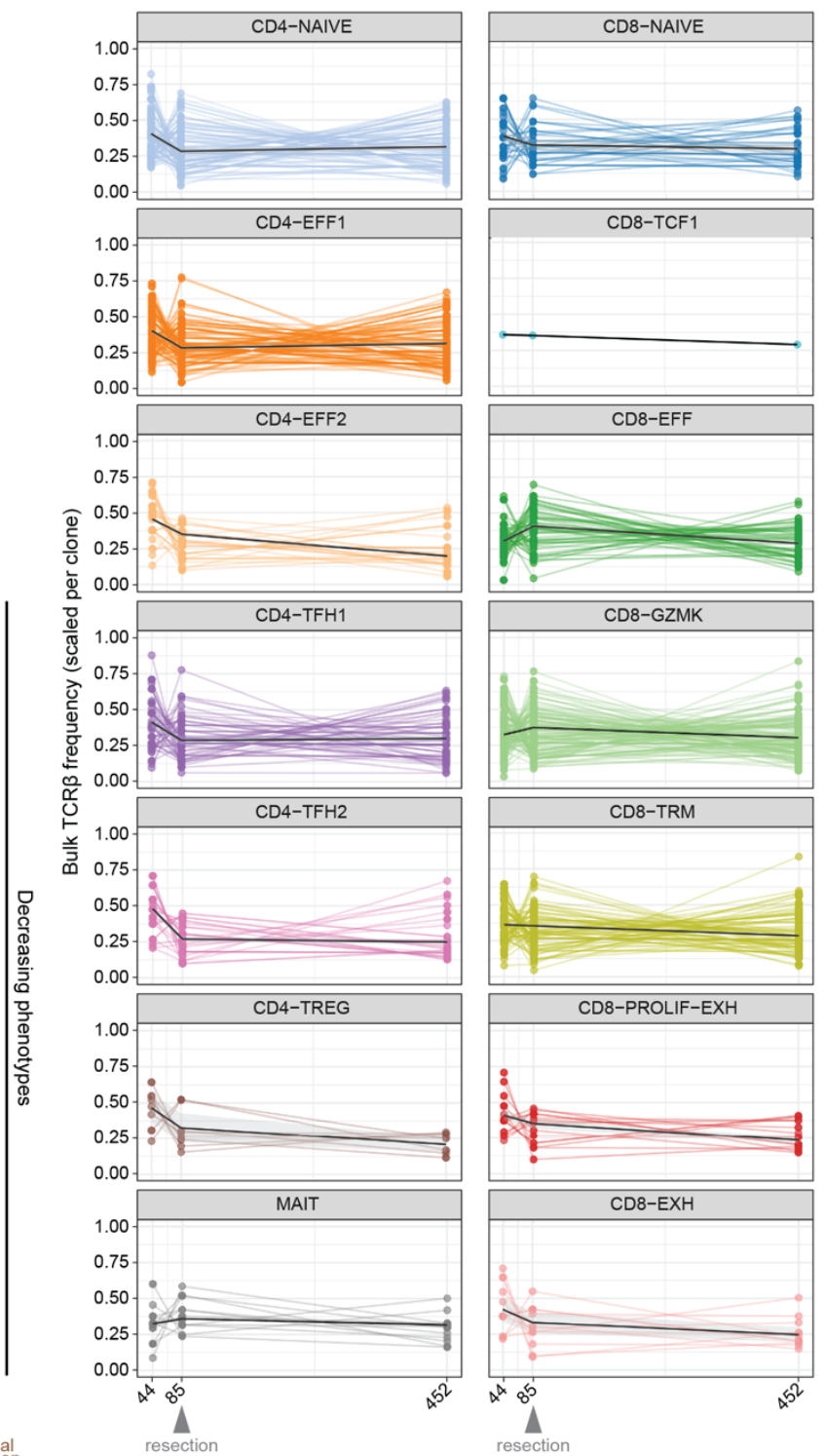

CD8-TRM

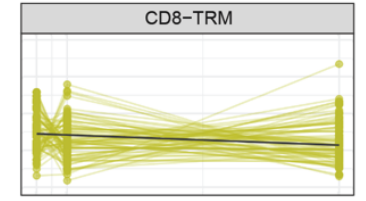

CD8-PROLIF-EXH
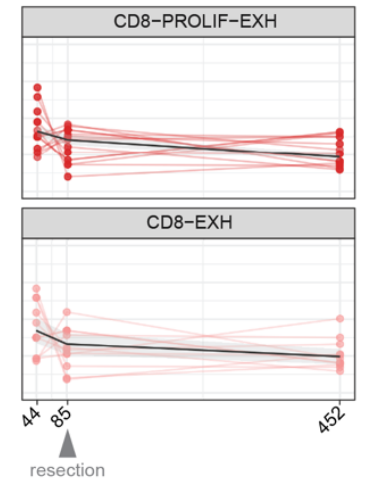

Timepoint (Days after anti-PD1) 
bioRxiv preprint doi: https://doi.org/10.1101/2021.09.27.461389; this version posted September 27, 2021. The copyright holder for this preprint (which was not certified by peer review) is the author/funder, who has granted bioRxiv a license to display the preprint in perpetuity. It is made available under aCC-BY-NC-ND 4.0 International license.

Pai, Chow, et al., (SATPATHY, HELLMANN), p. 20

684

685

686

687

688

689

690

691

692
Figure 5. Peripheral T cell dynamics of clonotypes associated with tissue T cell clusters.

A) Circulating frequency of clonotypes with the indicated CD4, CD8, or MAIT clusters designated by tissue scTCR/RNA-seq in MSK 1263, 1302, and 1344. Each clonotype was counted one time for each cell in the cluster designation to which the cell belonged.

B,C) Circulating frequency over time of clonotypes from patient MSK 1263 (B) or MSK 1302 (C) associated with the indicated CD4, CD8, or MAIT clusters designated by tissue scTCR/RNA-seq. Each clonotype was counted one time for each cell in the cluster designation to which the cell belonged. Grey arrow represents timepoint of primary oligometastatic resection; brown arrow represents timepoint of second oligometastatic adrenal resection. 
bioRxiv preprint doi: https://doi.org/10.1101/2021.09.27.461389; this version posted September 27, 2021. The copyright holder for this preprint (which was not certified by peer review) is the author/funder, who has granted bioRxiv a license to display the preprint in perpetuity. It is made available under aCC-BY-NC-ND 4.0 International license.

Pai, Chow, et al., (SATPATHY, HELLMANN), p. 21

\section{Figure 6}
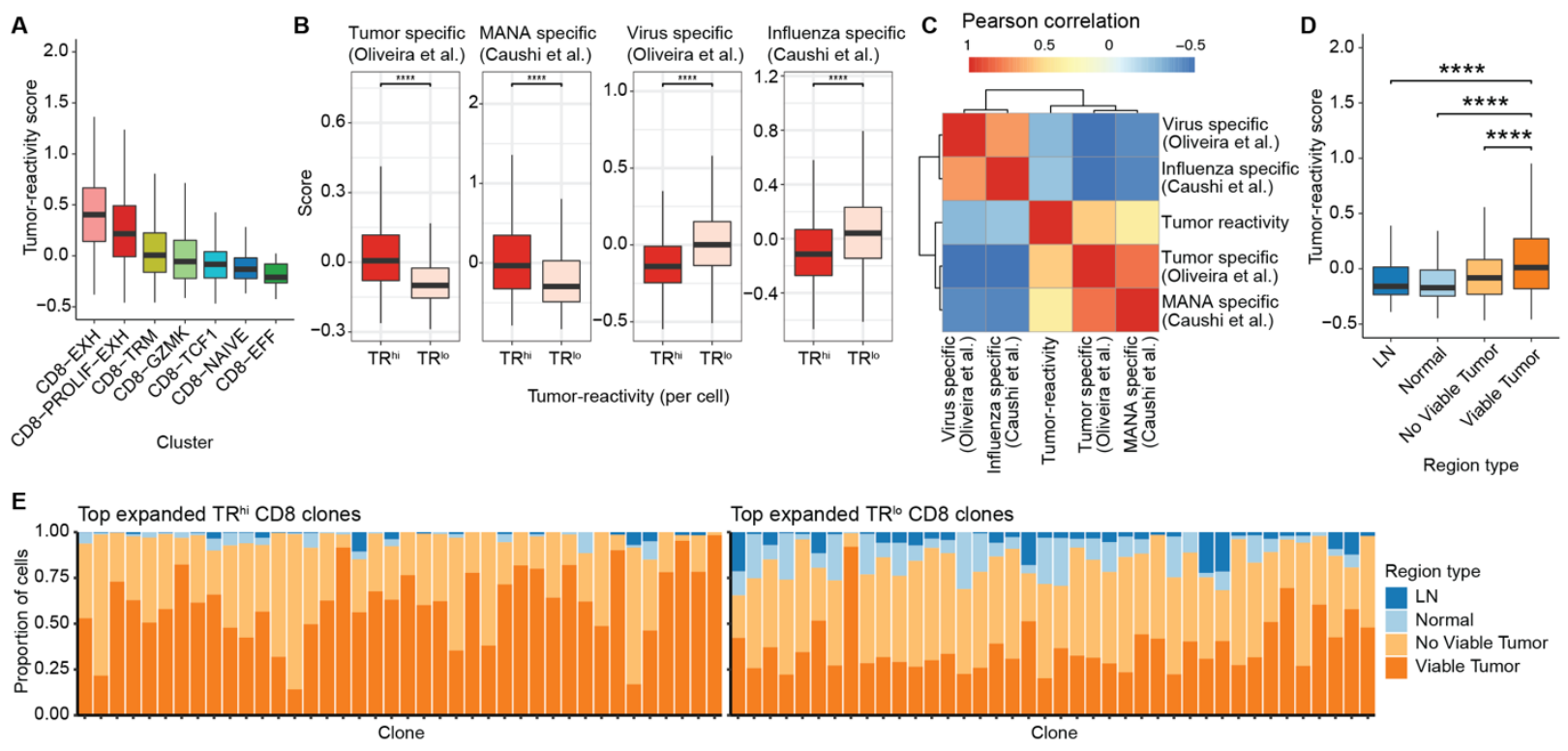

Top expanded $\mathrm{TR}^{10} \mathrm{CD} 8$ clones

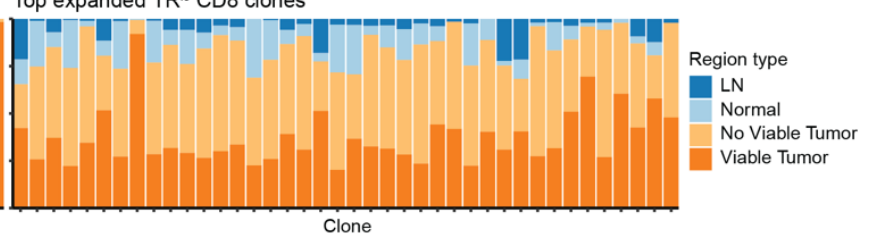

F 1.00 Top expanded TR

Top expanded $\mathrm{TR}^{\circ} \mathrm{CD} 8$ clones
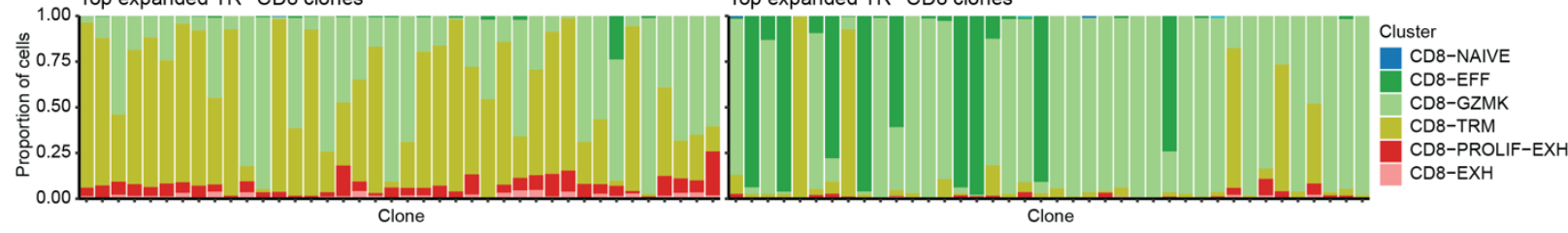

G
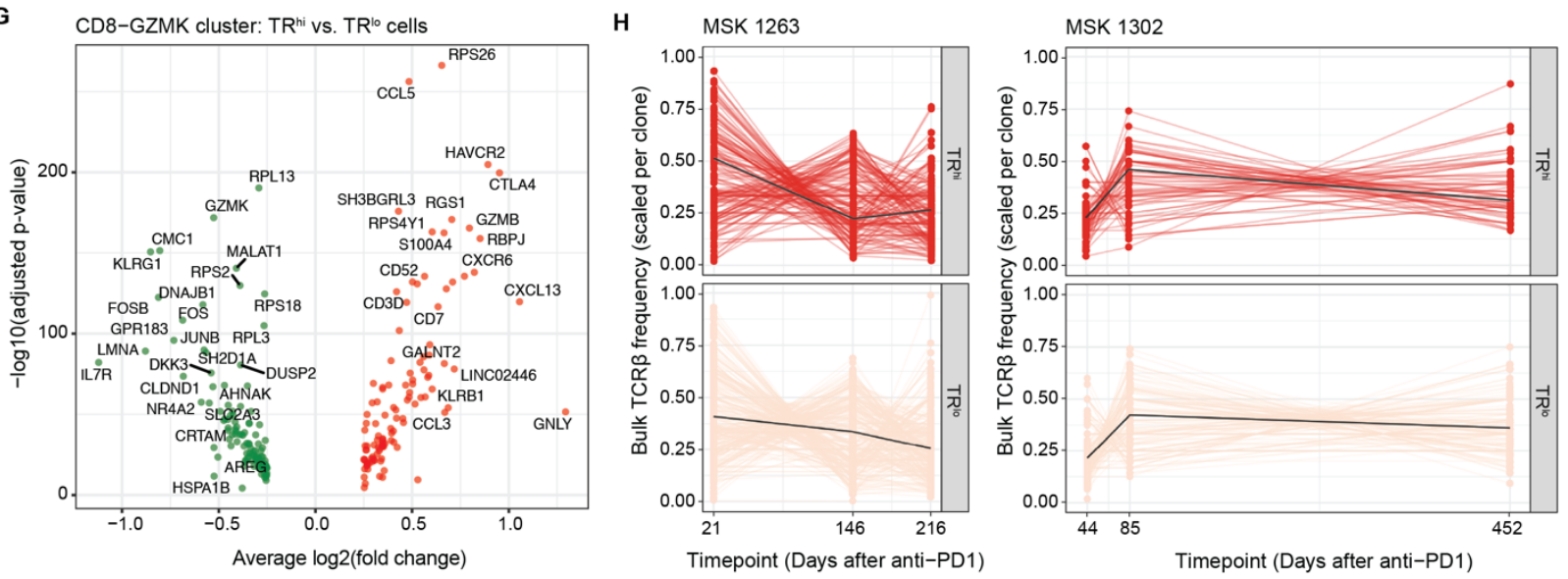

TR category - top TR ${ }^{\text {10 }}$ top TR ${ }^{\text {hi }}$

Figure 6. Peripheral T cell dynamics of clonotypes with high tumor-reactivity features.

A) Box and whisker plot of tumor-reactivity scores ${ }^{22}$ among the indicated CD8 T cell clusters in MSK 1263 , 1302 , and 1344.

B) Box and whisker plots of 'tumor-specific'28, 'MANA-specific'27, 'virus-specific'28, and 'influenzaspecific $^{27}$ scores among CD8 T cells with high $(>0)$ and low $(\leq 0)$ tumor-reactivity scores. Statistical testing by two-sided t-test $\left({ }^{* * * *}<0.0001\right)$.

C) Heat map of Pearson correlation matrix between tumor-reactivity score with 'tumor-specific', 'MANAspecific', 'virus-specific', and 'influenza-specific' scores computed on all cells. two-sided t-test $\left.{ }^{* * * *}<0.0001\right)$. 
bioRxiv preprint doi: https://doi.org/10.1101/2021.09.27.461389; this version posted September 27, 2021. The copyright holder for this preprint (which was not certified by peer review) is the author/funder, who has granted bioRxiv a license to display the preprint in perpetuity. It is made available under aCC-BY-NC-ND 4.0 International license.

Pai, Chow, et al., (SATPATHY, HELLMANN), p. 22

704 E) Bar plots of the proportion of cells in the indicated region type among the top 40 most expanded TR ${ }^{\text {hi }}$ 705 (left) or TR ${ }^{\text {lo }}$ (right) CD8 clones.

706 F) Bar plots of the proportion of cells in the indicated clusters among the top 40 most expanded TR ${ }^{\text {hi }}$ (left) or TR' (right) CD8 clones.

708 G) Volcano plot of differentially expressed genes between CD8-GZMK cluster cells among TR ${ }^{\text {hi }}$ and TR ${ }^{l o}$ clones. H) Circulating frequency over time of TR ${ }^{\text {hi }}$ (top) and TR ${ }^{\text {lo }}$ (bottom) CD8 TCR clones from patients MSK 1263 (left) and MSK 1302 (right). 
bioRxiv preprint doi: https://doi.org/10.1101/2021.09.27.461389; this version posted September 27, 2021. The copyright holder for this preprint (which was not certified by peer review) is the author/funder, who has granted bioRxiv a license to display the preprint in perpetuity. It is made available under aCC-BY-NC-ND 4.0 International license.

Pai, Chow, et al., (SATPATHY, HELLMANN), p. 23

Figure 7

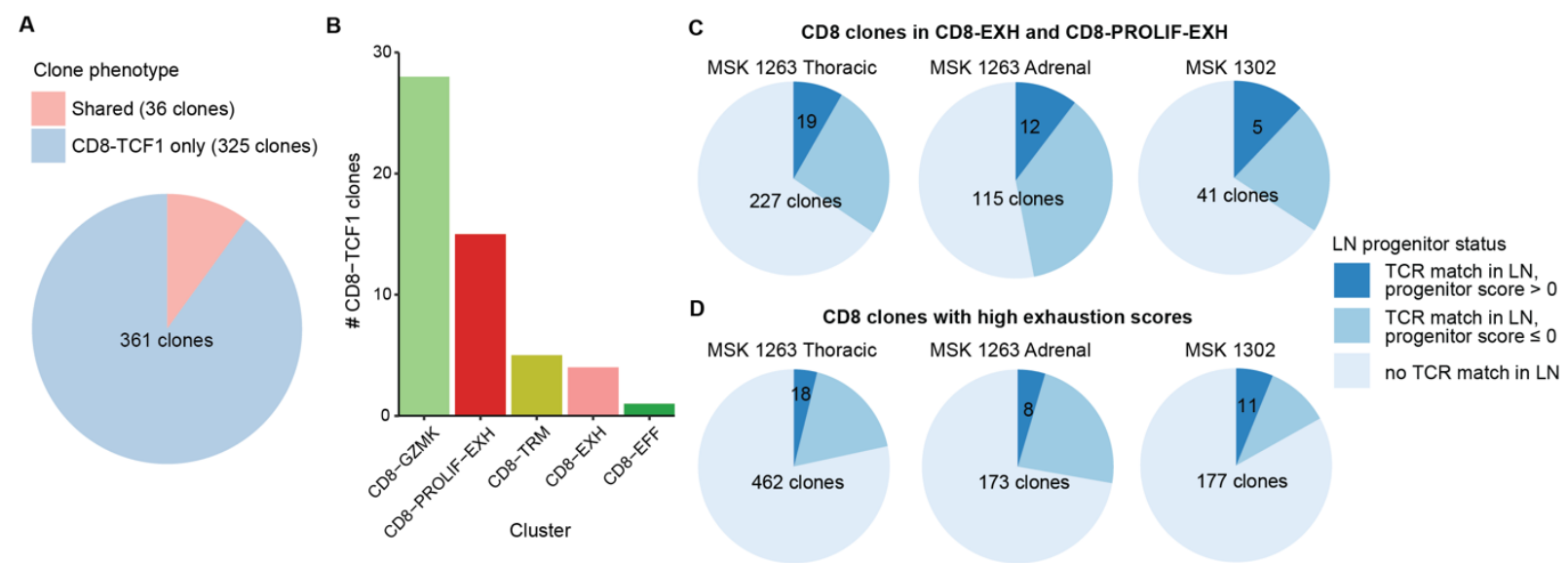

$\mathrm{E}$

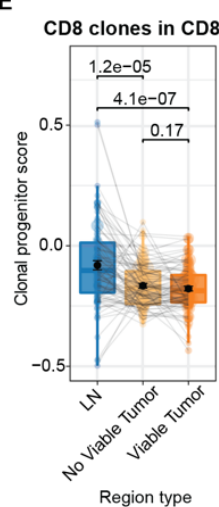

XH and CD8-PROLIF-EXH

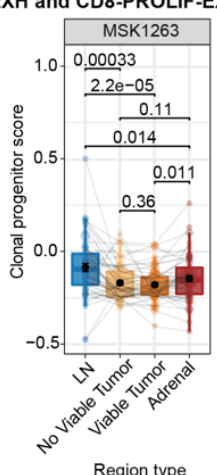

G

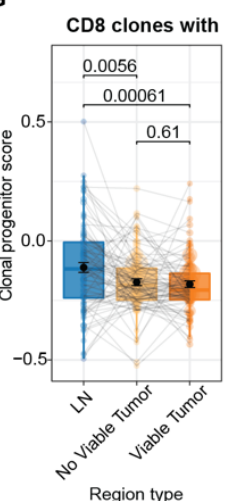

$\mathrm{H}$

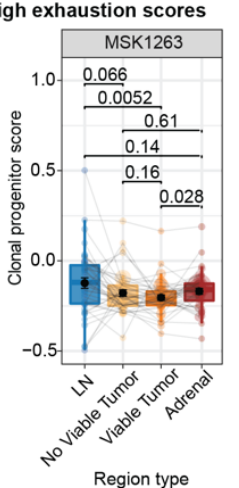

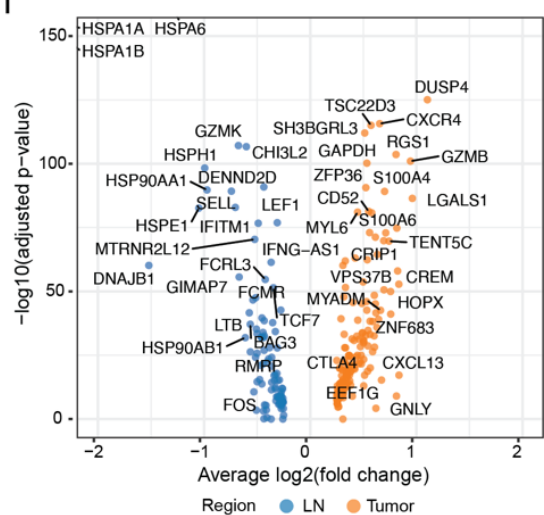

$J$

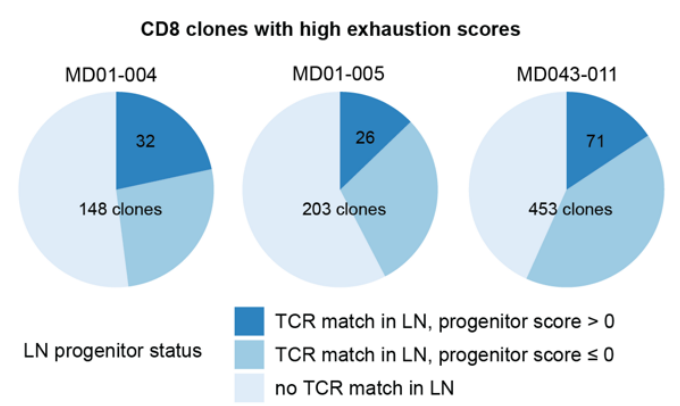

K

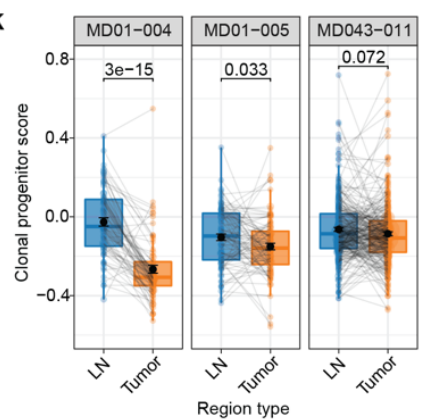

Figure 7. Intratumoral CD8 T cells can be found in a TCF $-1^{+}$precursor exhausted state in the regional LN.

A) Pie chart of clonotypes shared (pink) between CD8-TCF1 cluster and CD8 T cells in tumor regions, and clones found only in the CD8-TCF1 cluster (blue).

B) Bar plot of absolute number of CD8-TCF1 clones found within other CD8 clusters in the tumor.

C,D) Pie chart of CD8 T cell clones in the CD8-EXH and CD8-PROLIF-EXH clusters (C) or with high exhaustion scores (D) in the tumor that could be matched to a clonotype in the LN (medium blue and dark blue, "TCR match in LN"). Dark blue slice indicates that the matched clone could be found with a progenitor score $>0$ in the $L N$.

E,G) Paired box and whisker plots of average progenitor score per CD8 T cell clone in the CD8-EXH and CD8-PROLIF-EXH clusters (E) or with high exhaustion scores in thoracic regions of MSK 1263 and 1302 $(G)$ that is matched among the LN, regions without viable tumor, and regions with viable tumor. Statistical testing by paired two-sided t-test. Error bars represent standard error of the mean. 
bioRxiv preprint doi: https://doi.org/10.1101/2021.09.27.461389; this version posted September 27, 2021. The copyright holder for this preprint (which was not certified by peer review) is the author/funder, who has granted bioRxiv a license to display the preprint in perpetuity. It is made available under aCC-BY-NC-ND 4.0 International license.

Pai, Chow, et al., (SATPATHY, HELLMANN), p. 24

$\mathrm{F}, \mathrm{H})$ Paired box and whisker plots of average progenitor score per CD8 T cell clone in the CD8-EXH and CD8-PROLIF-EXH clusters $(F)$ or with high exhaustion scores in thoracic regions of MSK $1263(\mathrm{H})$ that is matched among the LN, regions without viable tumor, regions with viable tumor, and resected adrenal regions. Statistical testing by paired two-sided t-test. Error bars represent standard error of the mean.

I) Volcano plot of differentially expressed genes between cells from clone-matched CD8 T cell clones in the LN and tumor.

J) Pie chart of CD8 T cell clones with high exhaustion scores in an external data set that could be matched to a clonotype in the LN (medium blue and dark blue, "TCR match in LN"). Dark blue slice indicates that the matched clone could be found with a progenitor score $>0$ in the LN.

K) Paired box and whisker plot of average progenitor score per clone in three separate patients from an external dataset that is matched among the $\mathrm{LN}$ and tumor regions. Statistical testing by paired two-sided $\mathrm{t}$-test. Error bars represent standard error of the mean. 
bioRxiv preprint doi: https://doi.org/10.1101/2021.09.27.461389; this version posted September 27, 2021. The copyright holder for this preprint (which was not certified by peer review) is the author/funder, who has granted bioRxiv a license to display the preprint in perpetuity. It is made available under aCC-BY-NC-ND 4.0 International license.

Pai, Chow, et al., (SATPATHY, HELLMANN), p. 25

Figure S1 (related to Figure 1)

A

B

C

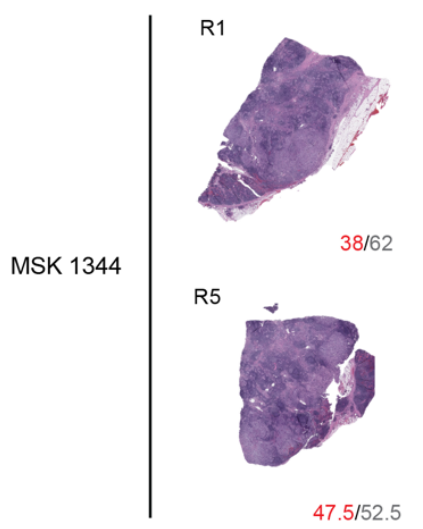

MSK 1263

MSK 1302

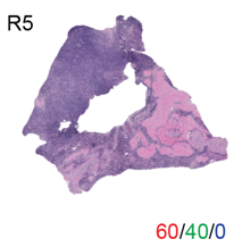

$\mathrm{R} 2$

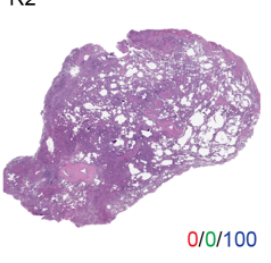

R6
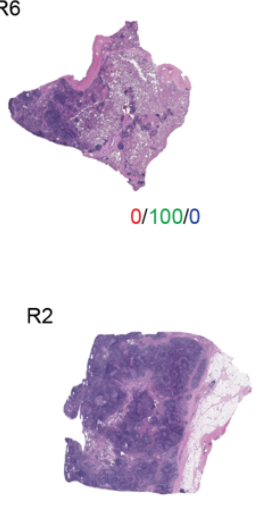

$9.5 / 91.5$

R6

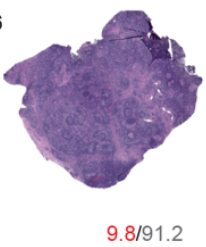

\section{$20 / 20 / 60$}

R3

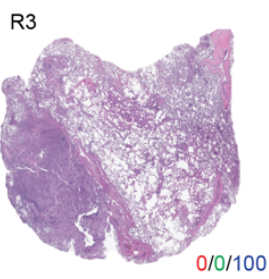

R7

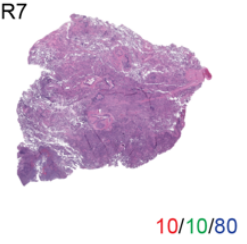

$10 / 10 / 80$

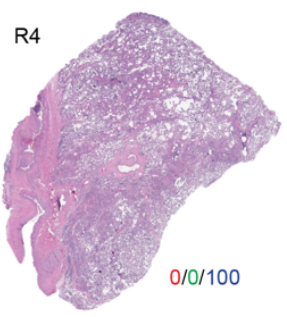

R8

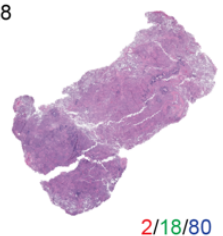

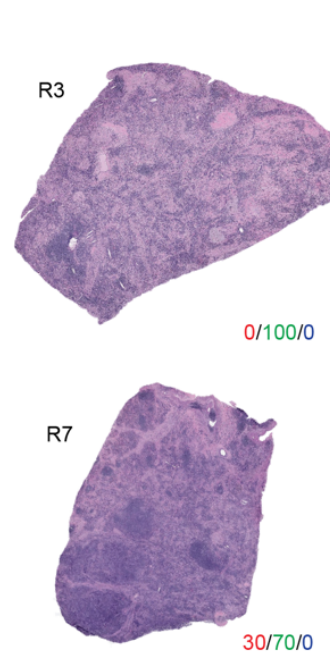
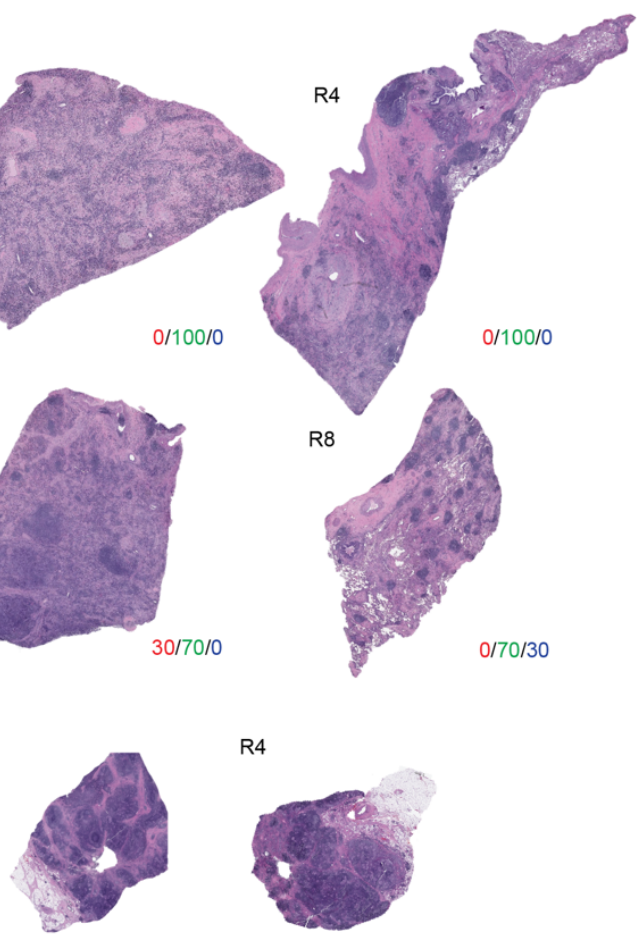

R4

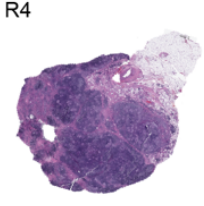

$10 / 90$

$8 / 92$

R7

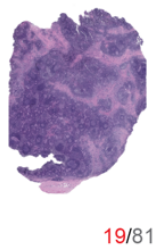

R8

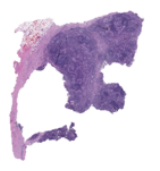

$9.5 / 90.5$

Viable Tumor/Uninvolved LN 
bioRxiv preprint doi: https://doi.org/10.1101/2021.09.27.461389; this version posted September 27, 2021. The copyright holder for this preprint (which was not certified by peer review) is the author/funder, who has granted bioRxiv a license to display the preprint in perpetuity. It is made available under aCC-BY-NC-ND 4.0 International license.

Pai, Chow, et al., (SATPATHY, HELLMANN), p. 26

Figure S2 (related to Figure 1)

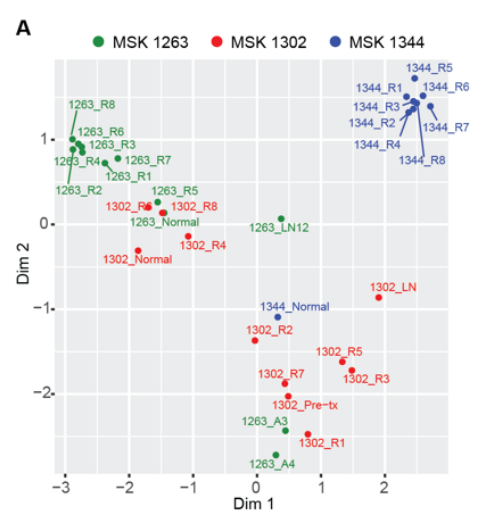

C

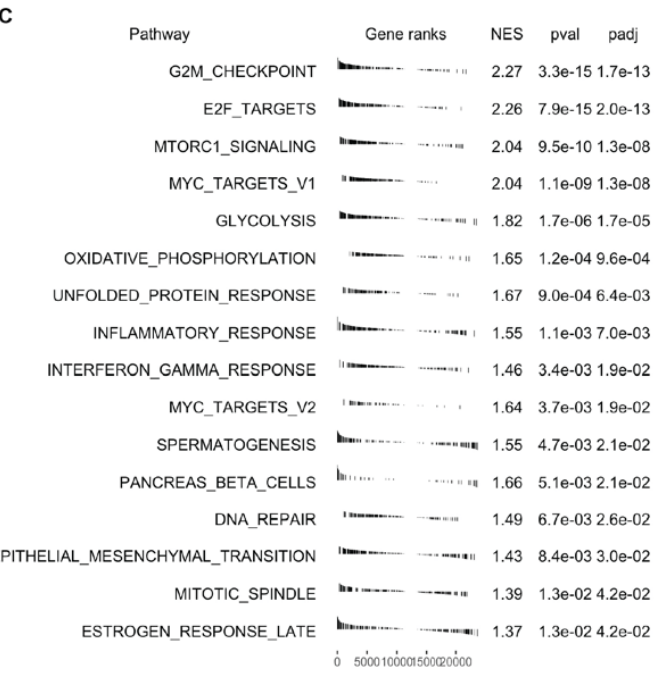

B
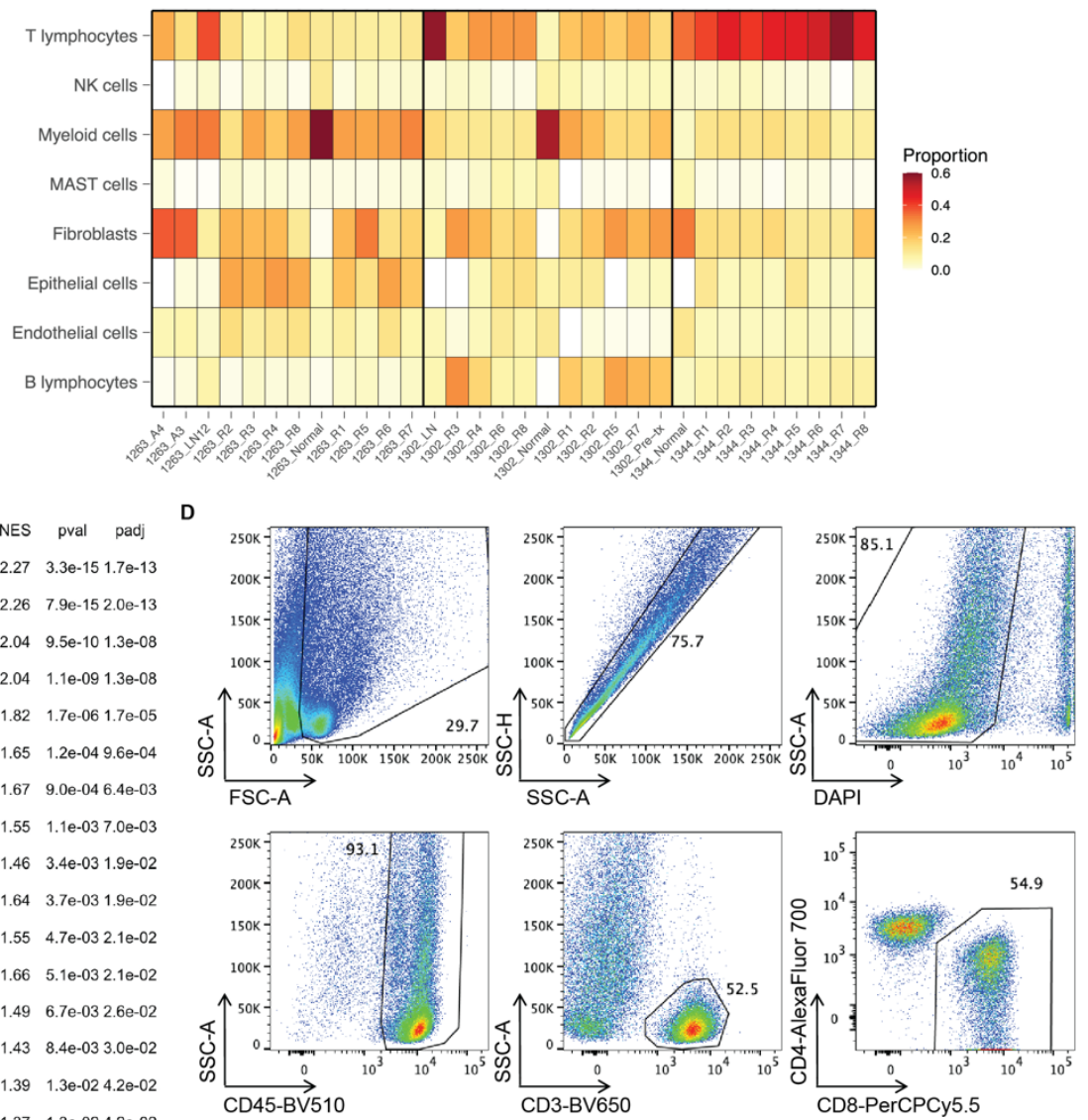

Figure S2. Regional transcriptional heterogeneity in resections after ICB.

A) Principal component analysis of bulk RNA sequencing of regions from three patients undergoing oligometastatic resections.

B) Heat map of CIBERSORT quantification of various immune populations (y-axis) across the different regions from three patients (x-axis).

C) GSEA of pathways differentially expressed among viable vs. no viable tumor regions as measured by bulk RNA-seq. 
bioRxiv preprint doi: https://doi.org/10.1101/2021.09.27.461389; this version posted September 27, 2021. The copyright holder for this preprint (which was not certified by peer review) is the author/funder, who has granted bioRxiv a license to display the preprint in perpetuity. It is made available under aCC-BY-NC-ND 4.0 International license.

Pai, Chow, et al., (SATPATHY, HELLMANN), p. 27

Figure S3 (related to Figure 1)

A
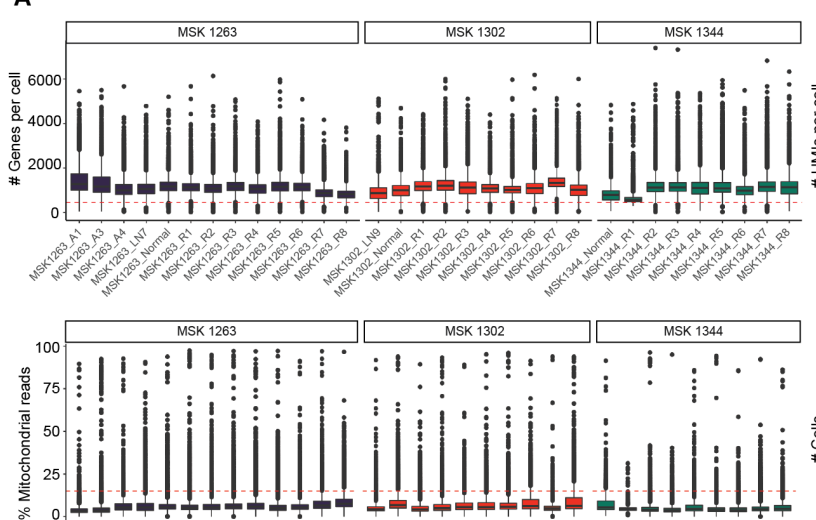

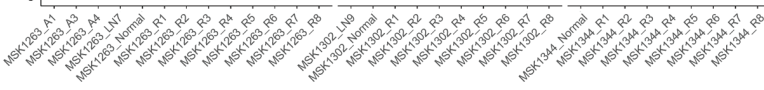

B

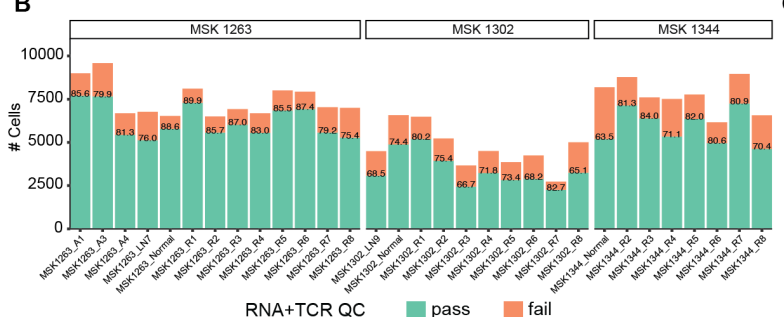

D

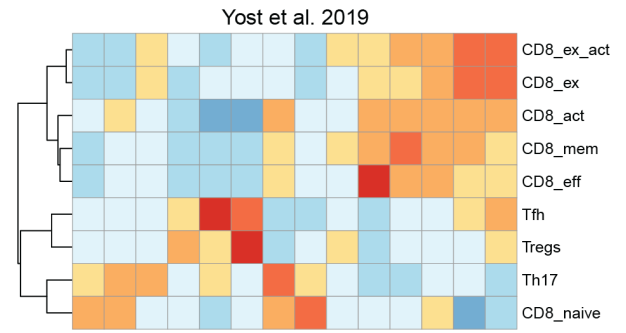

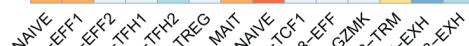
00

Guo et al. 2018

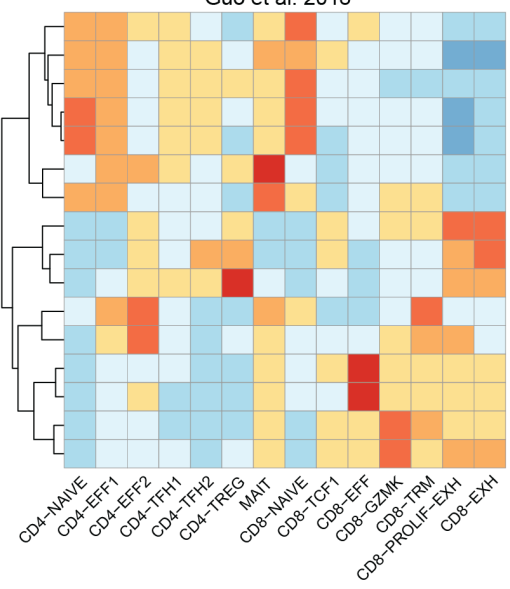

CD4_C8_FOXP3

CD4_C2_ANXA1 CD8_C1_LEF1

CD4_C1_CCR7

CD8_C7_SLC4A10

CD4_C4_CD69

CD8_C6_LAYN

CD4_C7_CXCL13 CD4_C9_CTLA4 CD8_C5_ZNF683 CD4_C6_GZMA CD8_C3_CX3CR CD4_C3_GNLY CD8_C4_GZMK CD4_C5_EOMES

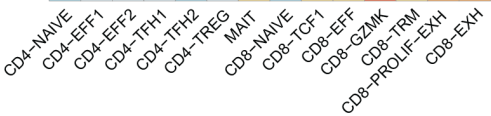

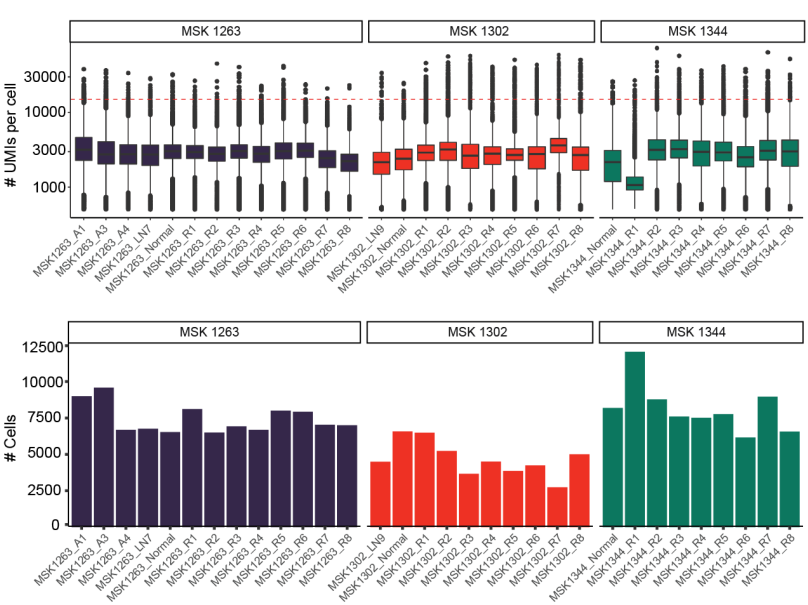

C
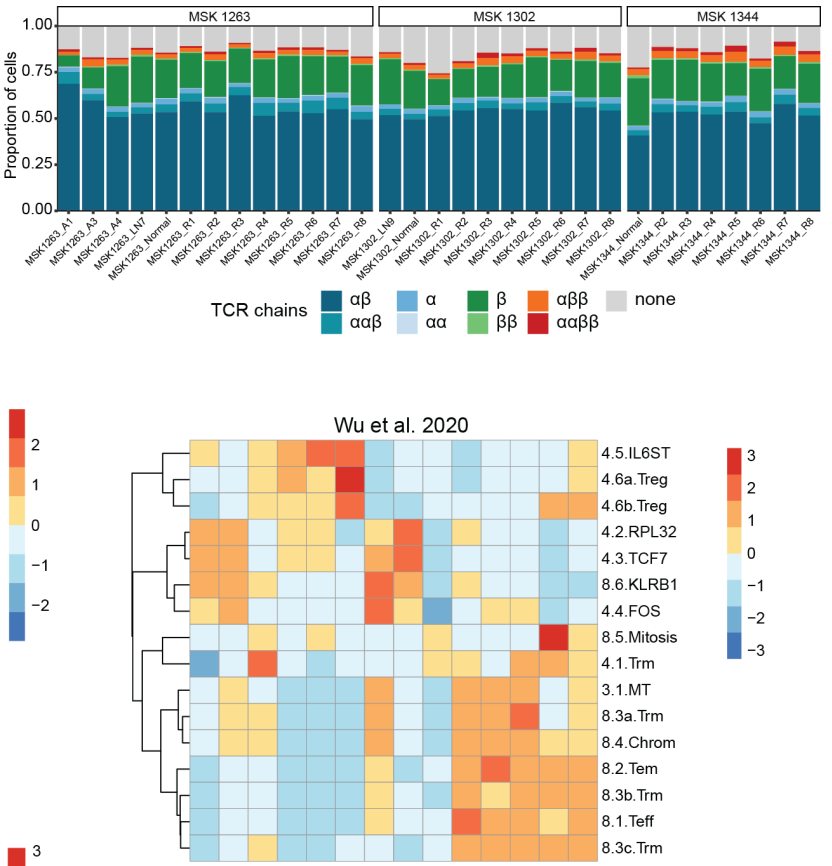

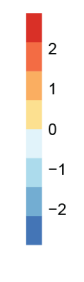

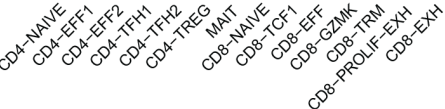

3
2
1
0
-1
-2
-3<smiles>CCCC</smiles> 
bioRxiv preprint doi: https://doi.org/10.1101/2021.09.27.461389; this version posted September 27, 2021. The copyright holder for this preprint (which was not certified by peer review) is the author/funder, who has granted bioRxiv a license to display the preprint in perpetuity. It is made available under aCC-BY-NC-ND 4.0 International license.

Pai, Chow, et al., (SATPATHY, HELLMANN), p. 28

Figure S3. Quality control and comparison of cluster-defining genes to published scRNA-seq clusters.

755

756

A) Box and whisker plots of number of genes detected per cell, number of unique molecular identifiers (UMIs) per cell, percent mitochondrial reads per cell, and number of cells captured per region undergoing scTCR/RNA-seq. Cutoffs used for quality filtering are shown as dotted red lines. B) Bar plot of absolute number of cells passing (green) and failing (orange) QC per region undergoing scTCR/RNA-seq.

C) Bar plot of absolute number of cells for which TCR $\alpha$ only (light blue), TCR $\beta$ only (green), or both TCR $\alpha$ and TCR $\beta$ chains (teal) were reconstructed per region undergoing scTCR/RNA-seq. T cells for which multiple TCR $\beta$ chains were captured (light green, orange, red) were excluded from further analysis. D) Heat map comparing clusters designated in our dataset (x-axis) and clusters designated in the indicated external scRNA-seq datasets ( $y$-axis). Color scale represents external cluster gene scores computed per cell in our dataset and normalized per row. 
bioRxiv preprint doi: https://doi.org/10.1101/2021.09.27.461389; this version posted September 27, 2021. The copyright holder for this preprint (which was not certified by peer review) is the author/funder, who has granted bioRxiv a license to display the preprint in perpetuity. It is made available under aCC-BY-NC-ND 4.0 International license.

Pai, Chow, et al., (SATPATHY, HELLMANN), p. 29

Figure S4 (related to Figure 1)

A

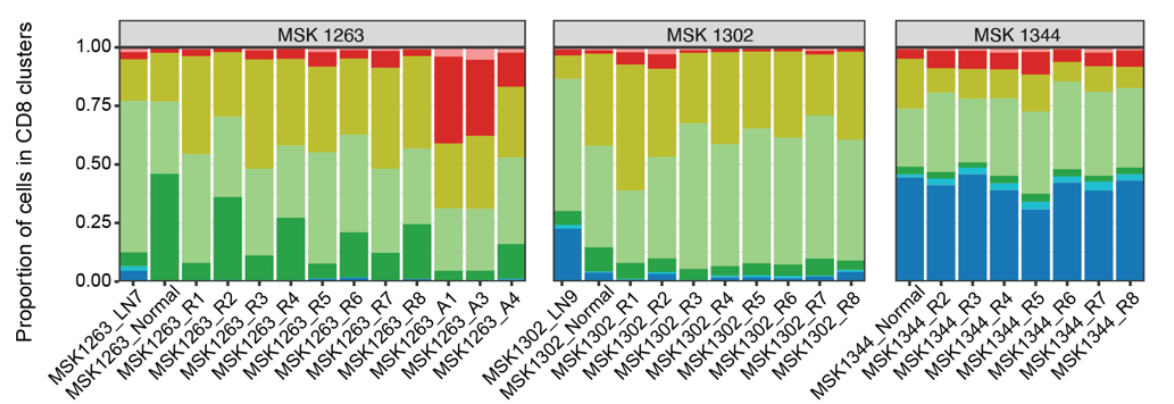

Cluster
CD8-NAIVE

CD8-TCF1

CD8-EFF

CD8-GZMK

CD8-TRM

CD8-PROLIF-EXH

CD8-EXH

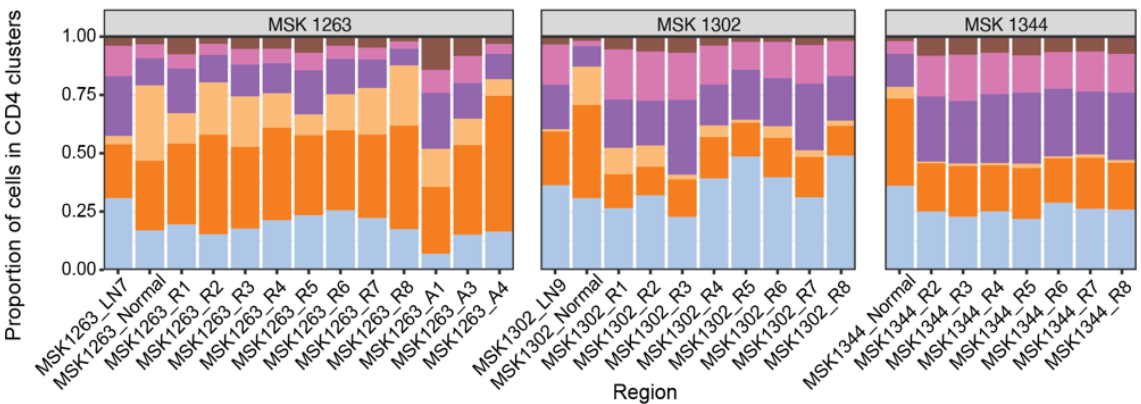

Cluster

CD4-NAIVE
CD4-EFF1
CD4-EFF2
CD4-TFH1
CD4-TFH2
CD4-TREG

B

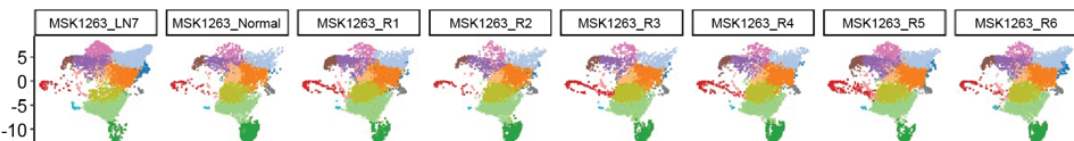

Cluster
CD4-NAIVE
CD4-EFF1

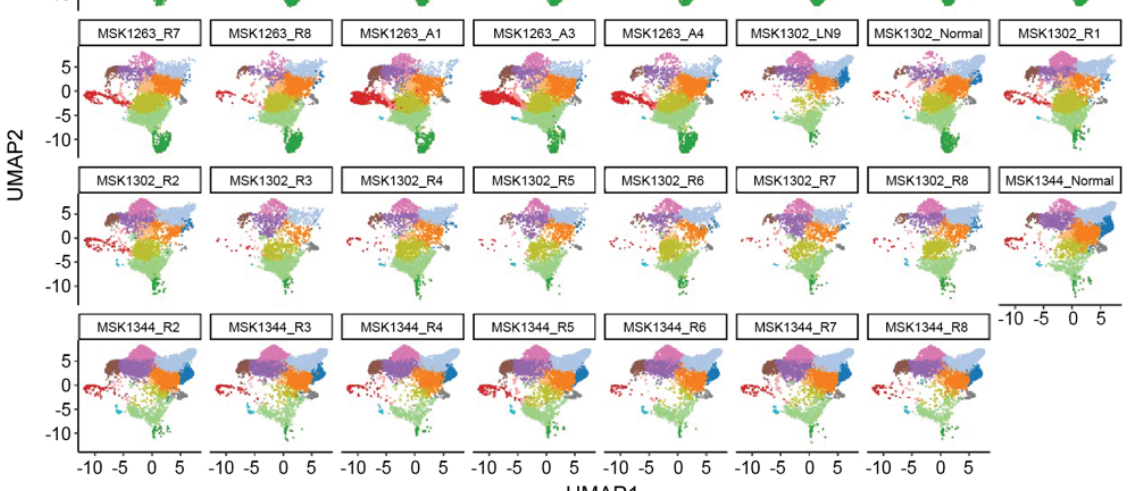

CD4-EFF1
CD4-EFF2

CD4-TFH1

CD4-TFH2

CD4-TREG

CD4-TRE
MAIT

MAIT
CD8-NAIVE

CD8-TCF1

CD8-EFF

CD8-GZMK

CD8-TRM

CD8-PROLIF-EXH

CD8-EXH

C

UMAP1
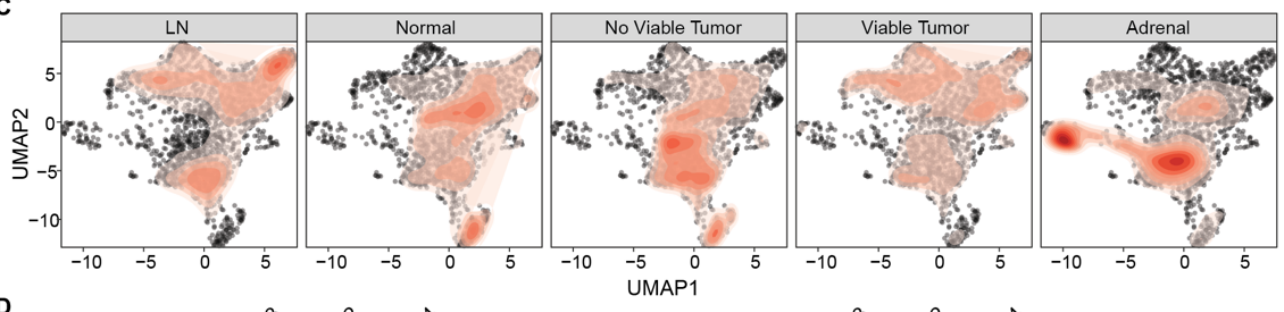

Cell density
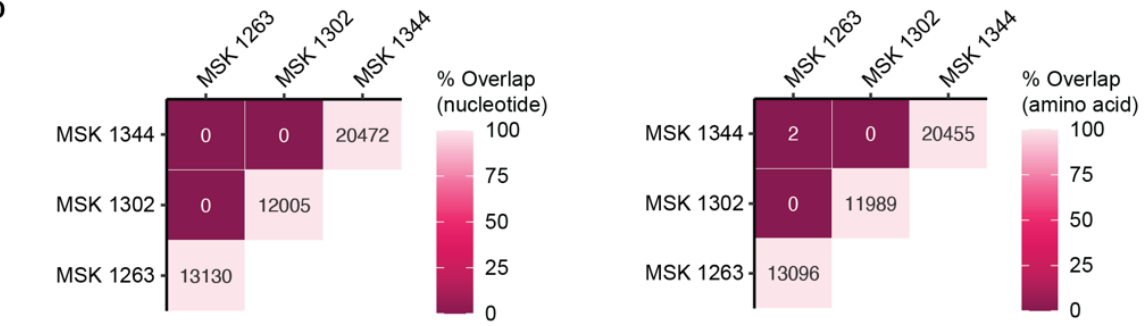
bioRxiv preprint doi: https://doi.org/10.1101/2021.09.27.461389; this version posted September 27, 2021. The copyright holder for this preprint (which was not certified by peer review) is the author/funder, who has granted bioRxiv a license to display the preprint in perpetuity. It is made available under aCC-BY-NC-ND 4.0 International license.

Pai, Chow, et al., (SATPATHY, HELLMANN), p. 30

Figure S4. Cluster and TCR clone representation across patients.

770

A) Bar plots of the proportion of cells in the indicated clusters among CD4 T cells (top) or CD8 T cells

771 (bottom) per region undergoing scRNA-seq.

B) UMAP of cluster representation across the 31 regions undergoing scTCR/RNA-seq that passed QC.

773

C) UMAP of sorted $\mathrm{CD} 3^{+} \mathrm{T}$ cells among each region type colored by cell density.

774

D) Heat map of TCR clonal overlap between patients based on CDR3 $\alpha \beta$ nucleotide (left) or amino acid (right) sequence. 
bioRxiv preprint doi: https://doi.org/10.1101/2021.09.27.461389; this version posted September 27, 2021. The copyright holder for this preprint (which was not certified by peer review) is the author/funder, who has granted bioRxiv a license to display the preprint in perpetuity. It is made available under aCC-BY-NC-ND 4.0 International license.

Pai, Chow, et al., (SATPATHY, HELLMANN), p. 31

Figure S5 (related to Figure 2)

A
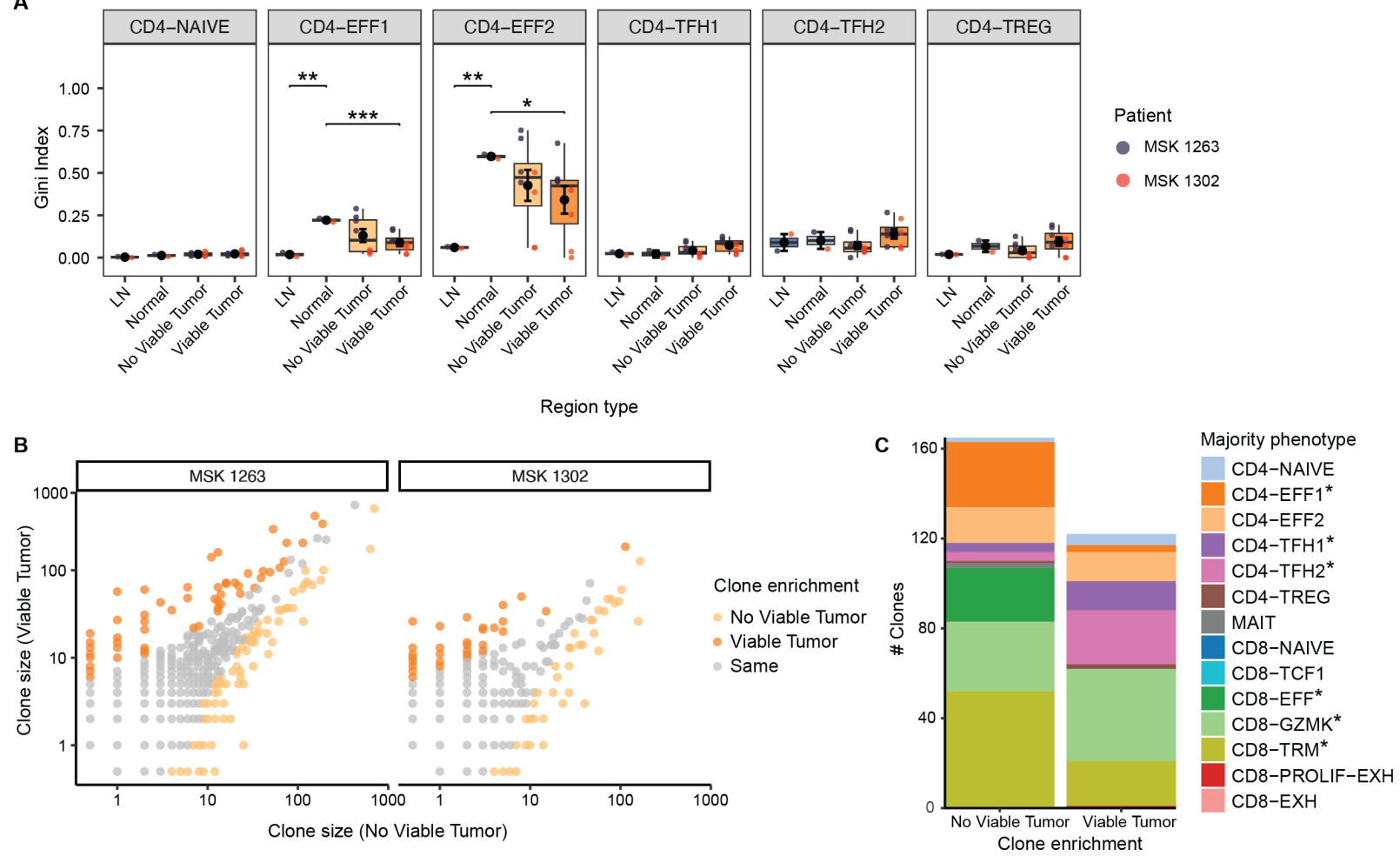

D
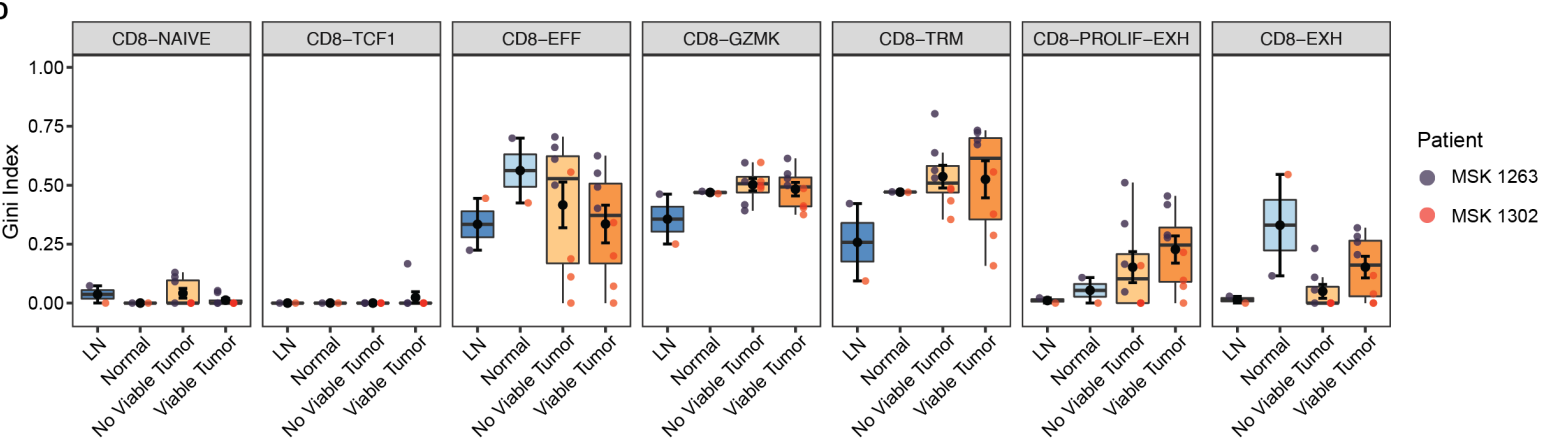

Figure S5. TCR clonal distribution across region types.

A) Box and whisker plots of Gini index of the indicated CD4 T cell clusters across region types. Statistical testing by two-sided t-test. Error bars represent standard error of the mean.

B) Scatterplot of the number of cells in regions with no viable tumor vs. regions with viable tumor. Each point represents one clone classified as enriched in viable tumor (dark orange) or no viable tumor (light orange) regions (Fisher's exact test, $\mathrm{p}<0.05$ ).

C) Bar plot of clones enriched in no viable tumor regions or viable tumor regions, colored by majority phenotype within each clone. ( ${ }^{*}$ denotes significance as determined by Fisher's exact test, $p<0.05$ ). represent standard error of the mean. 
bioRxiv preprint doi: https://doi.org/10.1101/2021.09.27.461389; this version posted September 27, 2021. The copyright holder for this preprint (which was not certified by peer review) is the author/funder, who has granted bioRxiv a license to display the preprint in perpetuity. It is made available under aCC-BY-NC-ND 4.0 International license.

Pai, Chow, et al., (SATPATHY, HELLMANN), p. 32

Figure S6 (related to Figures 3 and 4)

A
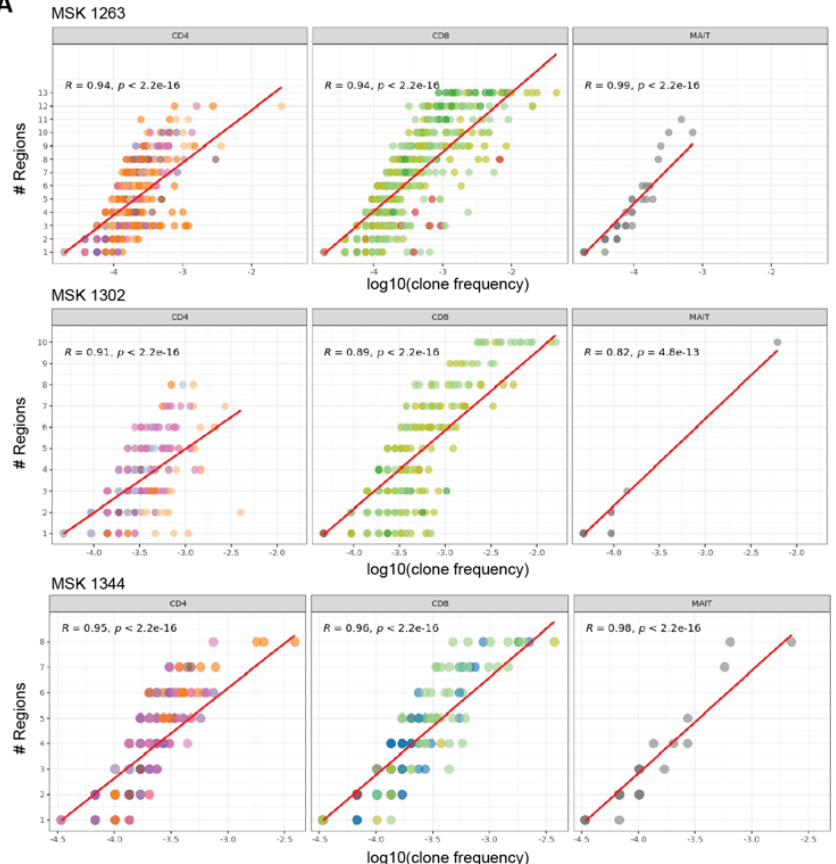

Majority phenotype CDA-NANE $\odot$ CD4-EFF2 $\odot$ CO4-TFH2 $\odot$ MAIT $\odot$ CD8-TCF1 $\odot$ CD8-GZMK $\bullet$ CDB-PROLF-EXH
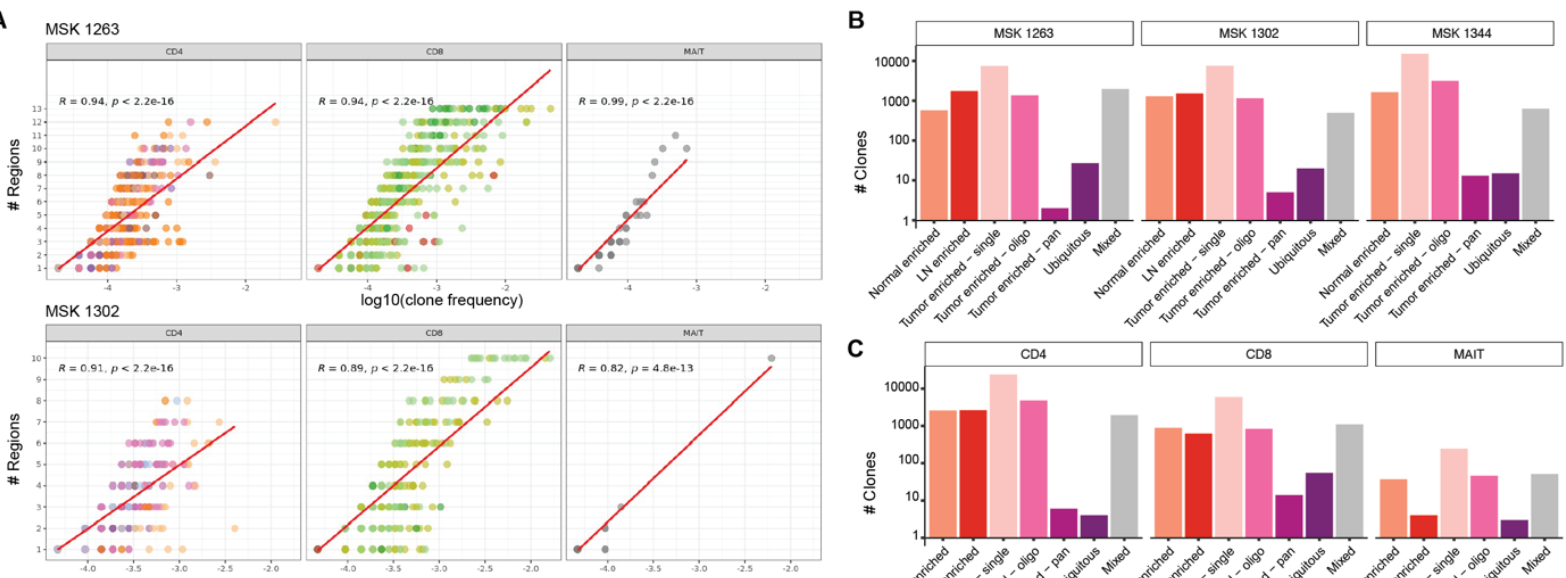

C

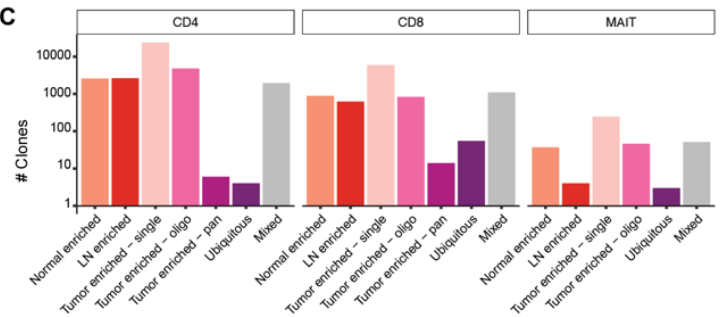

D
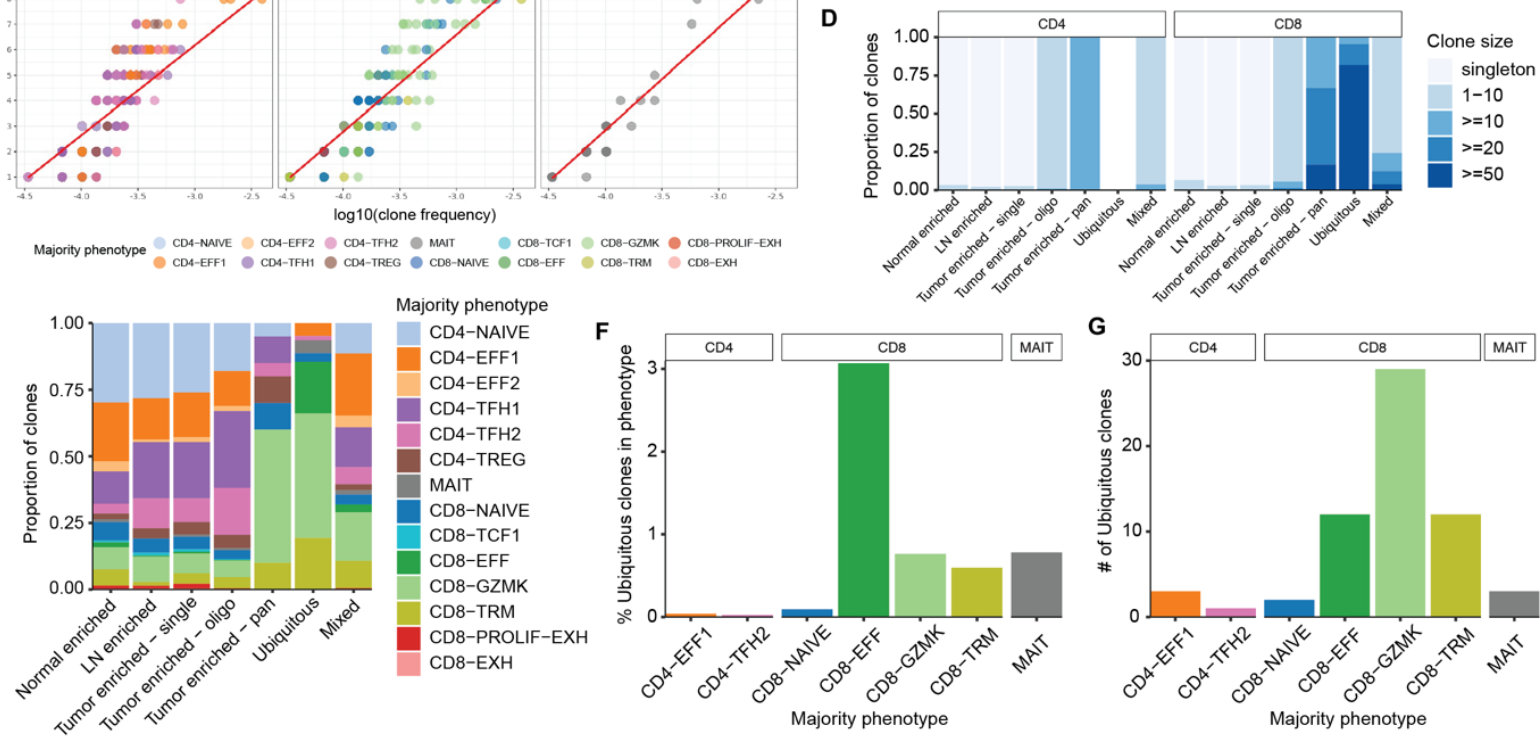

H

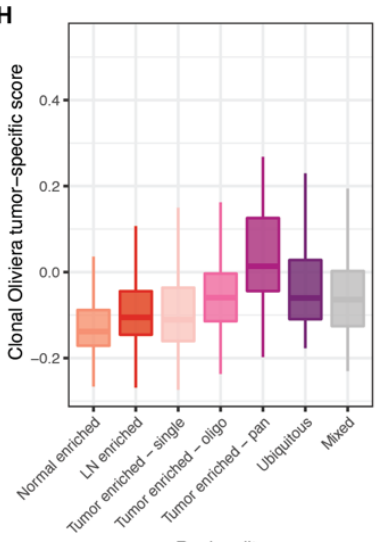

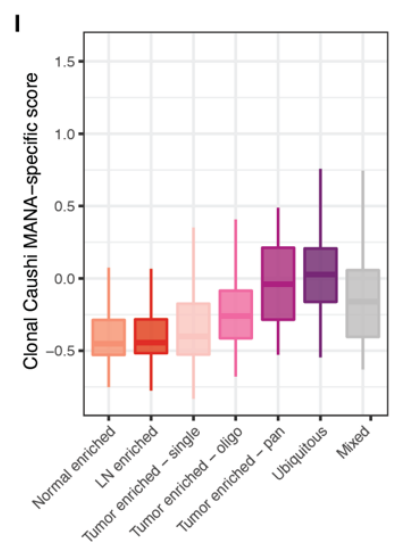

Regionality

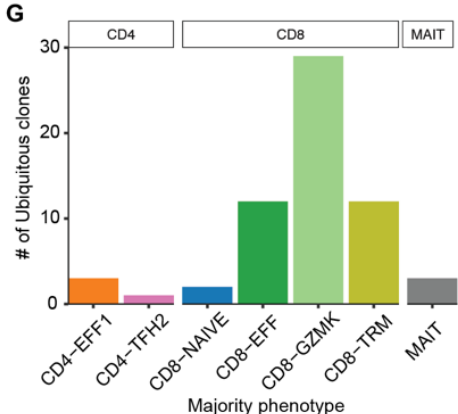

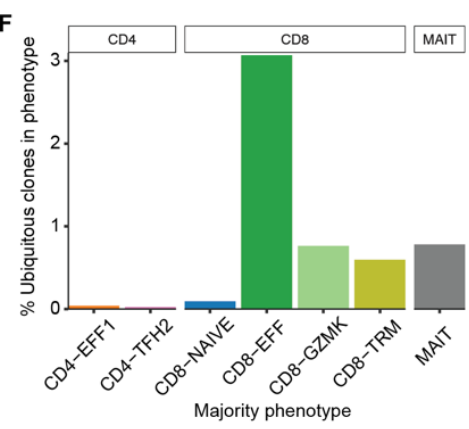

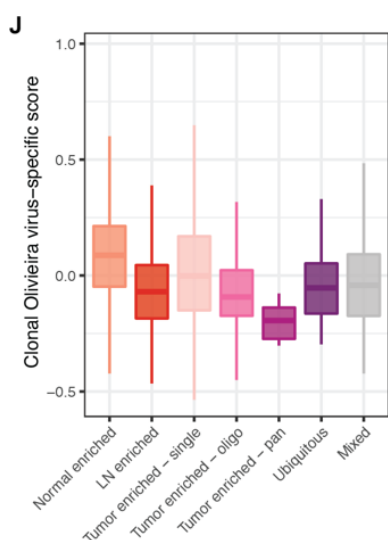

Regionality

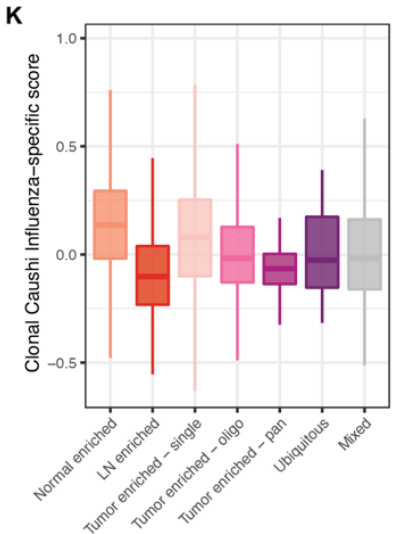

Regionality

Figure S6. Regional patterns of TCR clones.

A) Spearman correlation per patient of indicated CD4, CD8, and MAIT clusters comparing the number of regions in which a $\mathrm{T}$ cell clone was detected and its clonal frequency in the sample's respective scTCR/RNA-seq dataset. 
Pai, Chow, et al., (SATPATHY, HELLMANN), p. 33

B) Bar plot of the number of clones within each non-overlapping TCR regional pattern per patient.

C) Bar plot of the number of clones within each non-overlapping TCR regional pattern per CD4, CD8, or MAIT subset among all patients.

D) Bar plots of the proportion of clones with the indicated clone sizes per TCR regional pattern of CD4 and CD8 T cell clones among all patients.

E) Bar plots of the proportion of clones with the indicated clusters per TCR regional pattern among all patients.

F) Bar plots of the percentage of T cell clones with the indicated majority phenotype cluster designation that

799 exhibit the ubiquitous TCR regional pattern.

800

$\mathrm{G}$ ) Bar plots of the absolute number of ubiquitous $T$ cell clones with the indicated majority cluster designation.

802

$\mathrm{H}-\mathrm{K})$ Box and whisker plots of 'tumor-specific'28 (H), 'MANA-specific'27 (I), 'virus-specific'28 (J), and 'influenza-specific'27 $(K)$ scores among $T$ cell clones with the indicated TCR regional pattern. 
bioRxiv preprint doi: https://doi.org/10.1101/2021.09.27.461389; this version posted September 27, 2021. The copyright holder for this preprint (which was not certified by peer review) is the author/funder, who has granted bioRxiv a license to display the preprint in perpetuity. It is made available under aCC-BY-NC-ND 4.0 International license.

Pai, Chow, et al., (SATPATHY, HELLMANN), p. 34

Figure S7 (related to Figure 3)
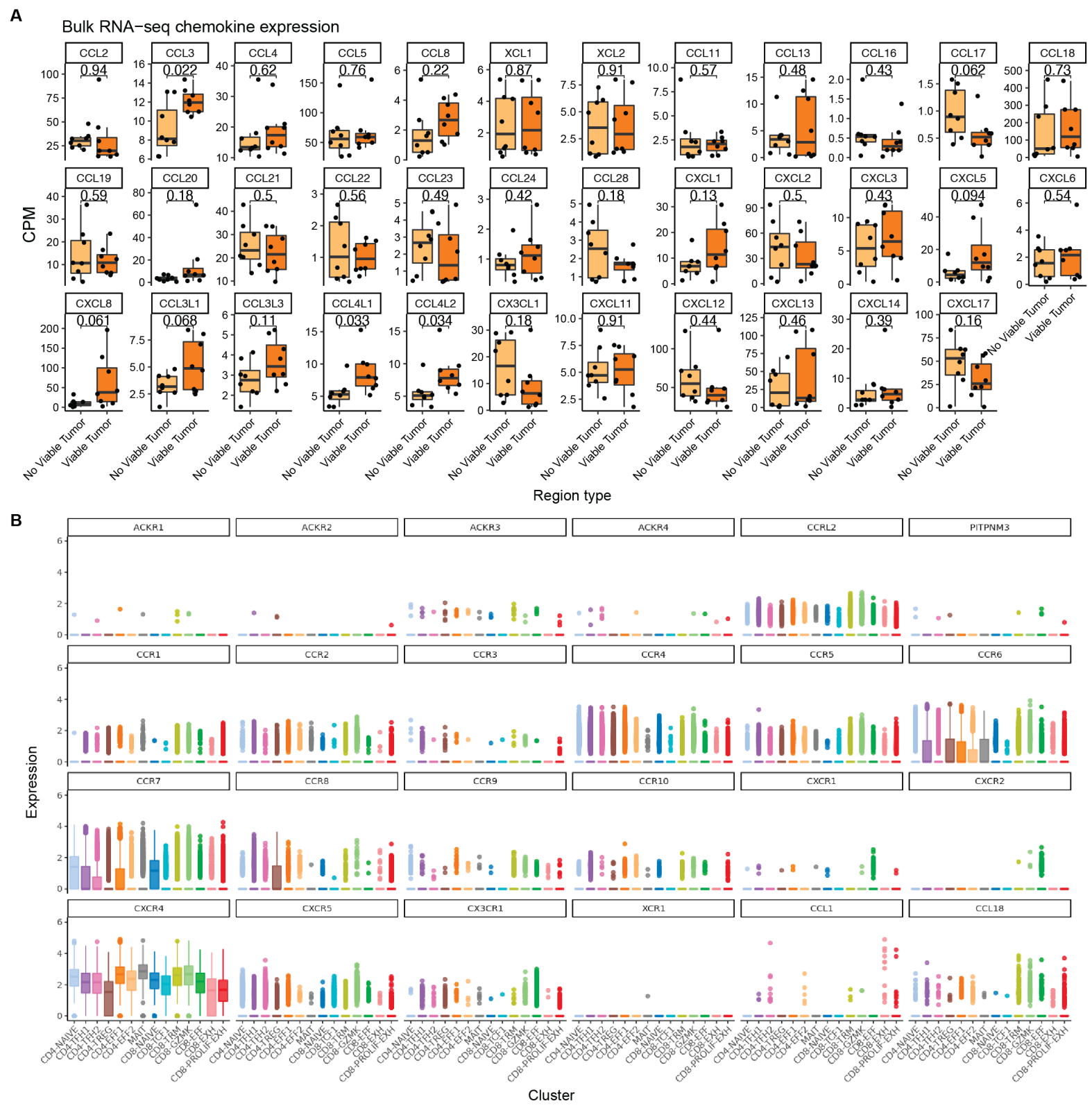

Figure S7. Chemokine ligand and receptor expression.

A) Expression of chemokines among no viable and viable tumor regions as measured by bulk RNA-seq.

807 Statistical testing by t-test. CPM = counts per million. Statistical testing by two-sided t-test.

808 B) Expression of chemokine receptors among scRNA-seq phenotypic clusters. 
bioRxiv preprint doi: https://doi.org/10.1101/2021.09.27.461389; this version posted September 27, 2021. The copyright holder for this preprint (which was not certified by peer review) is the author/funder, who has granted bioRxiv a license to display the preprint in perpetuity. It is made available under aCC-BY-NC-ND 4.0 International license.

Pai, Chow, et al., (SATPATHY, HELLMANN), p. 35

\section{Figure S8 (related to Figure 4)}

A

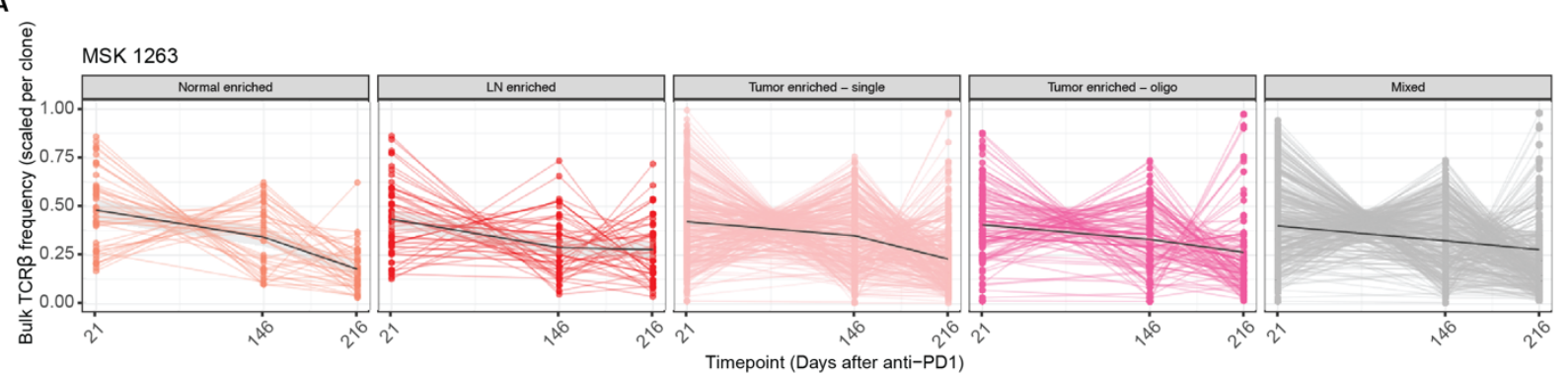

B

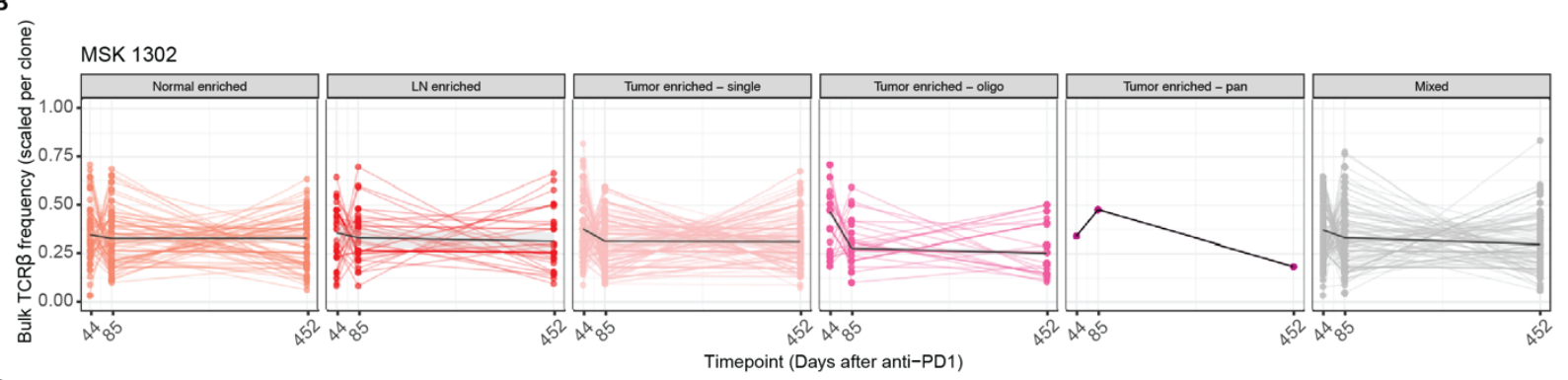

C

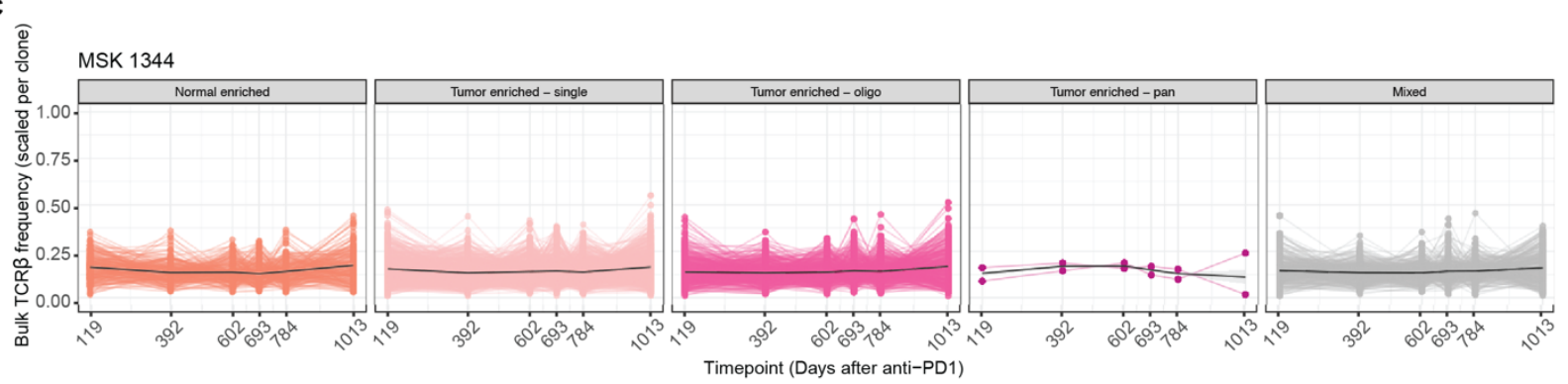

Figure S8. Peripheral T cell dynamics of non-ubiquitous $\mathrm{T}$ cell clones.

811 A-C) Circulating frequency over time of TCR clones from MSK 1263 (A), 1302 (B), or 1344 (C) with non812 ubiquitous TCR regional patterns. 
bioRxiv preprint doi: https://doi.org/10.1101/2021.09.27.461389; this version posted September 27, 2021. The copyright holder for this preprint (which was not certified by peer review) is the author/funder, who has granted bioRxiv a license to display the preprint in perpetuity. It is made available under aCC-BY-NC-ND 4.0 International license.

Pai, Chow, et al., (SATPATHY, HELLMANN), p. 36

Figure S9 (related to Figure 5)

A

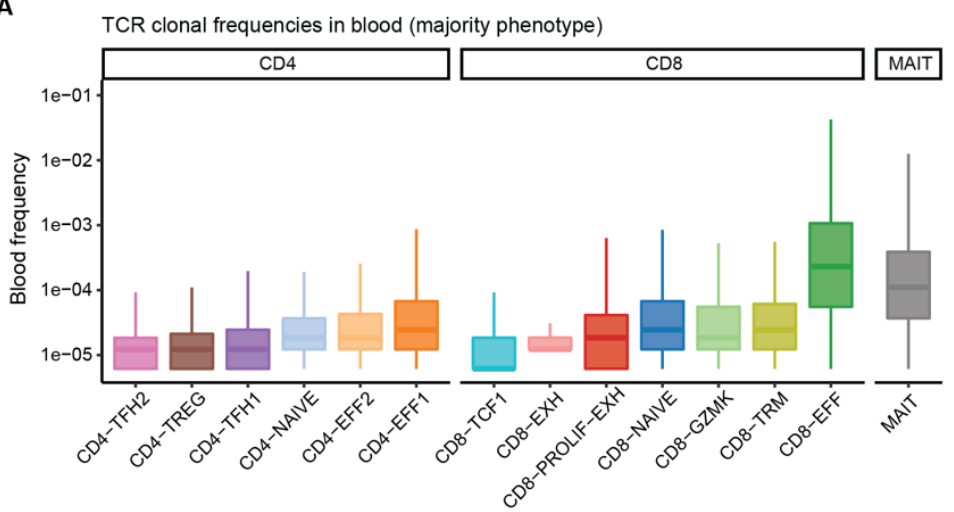

B

MSK 1344

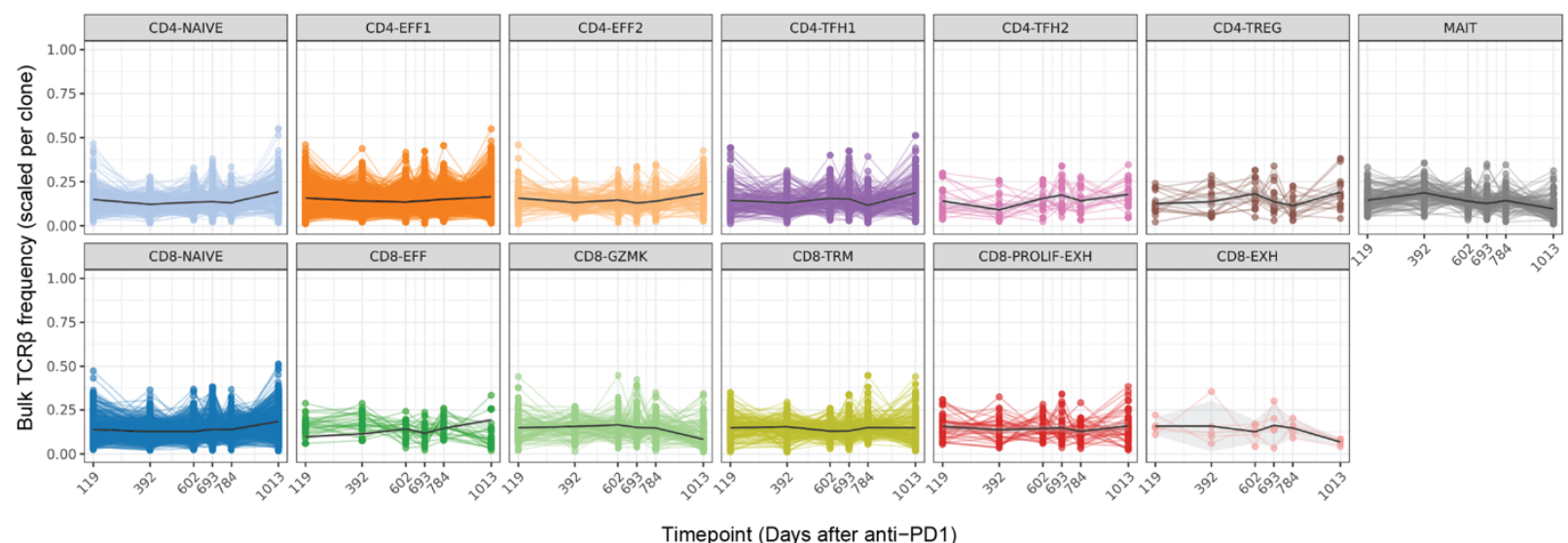

813

814

815

816

817

818

819

820
Figure S9. Peripheral T cell dynamics of clonotypes associated with tissue T cell clusters.

A) Circulating frequency of clonotypes with the indicated CD4, CD8, or MAIT clusters designated by tissue scTCR/RNA-seq. Each clonotype was counted only one time in the cluster in which the majority of cells in the clone resided.

B) Circulating frequency over time of clonotypes from patient MSK 1344 associated with the indicated CD4, CD8, or MAIT clusters designated by tissue scTCR/RNA-seq. Each clonotype was counted one time for each cell in the cluster designation to which the cell belonged. 
bioRxiv preprint doi: https://doi.org/10.1101/2021.09.27.461389; this version posted September 27, 2021. The copyright holder for this preprint (which was not certified by peer review) is the author/funder, who has granted bioRxiv a license to display the preprint in perpetuity. It is made available under aCC-BY-NC-ND 4.0 International license.

Pai, Chow, et al., (SATPATHY, HELLMANN), p. 37

\section{Figure S10 (related to Figure 6)}
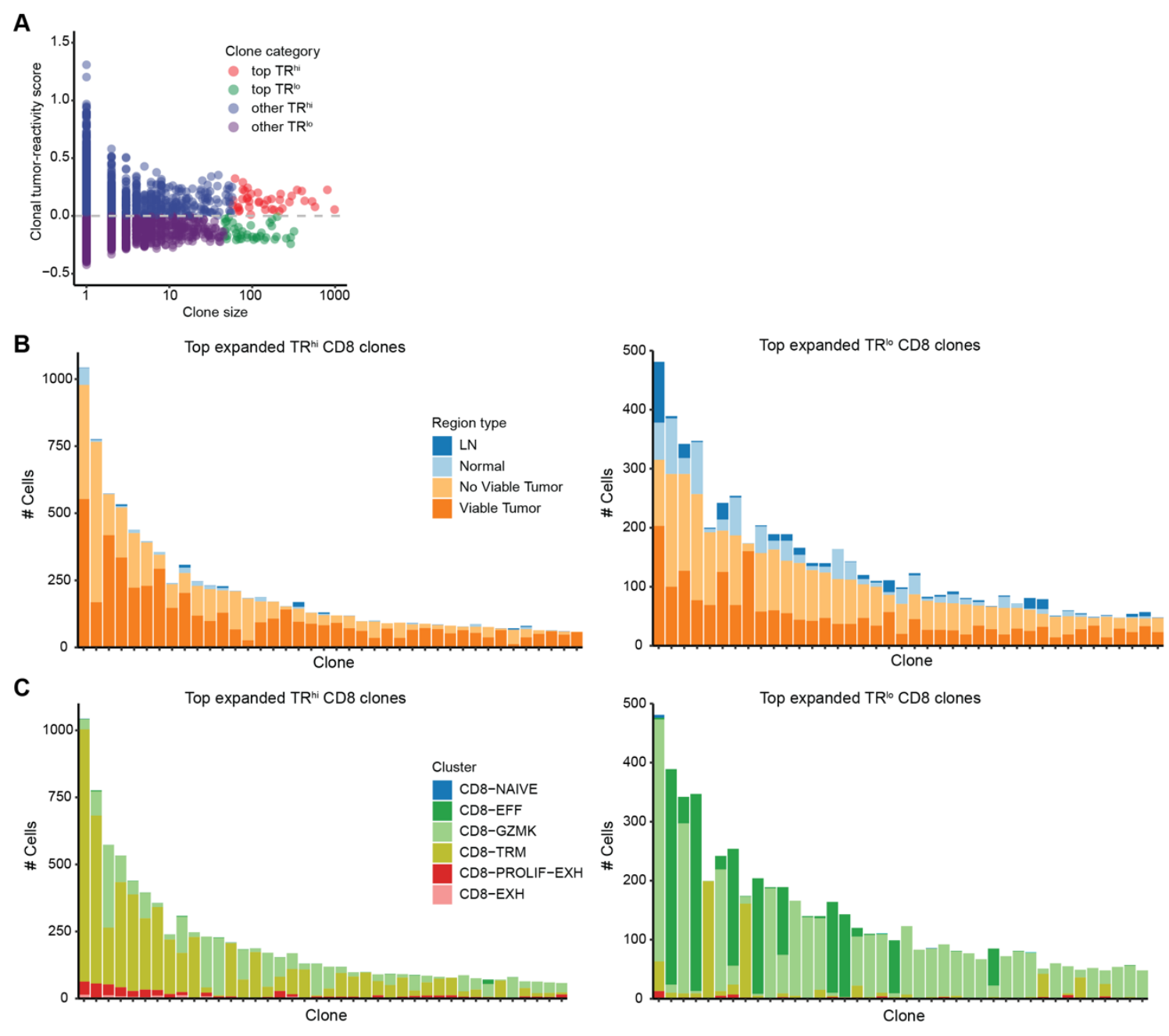

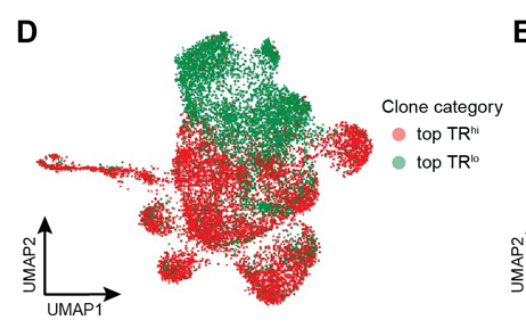

E

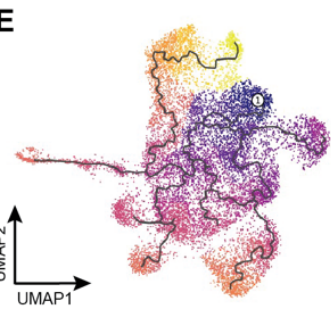

G

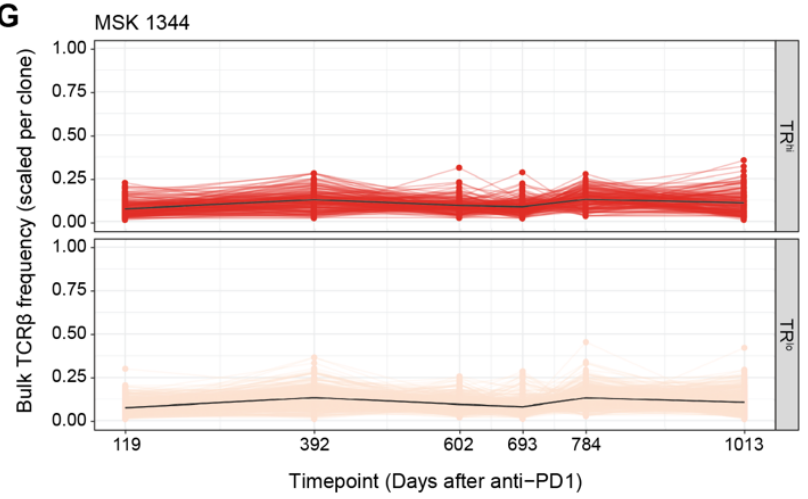

$\mathbf{F}$

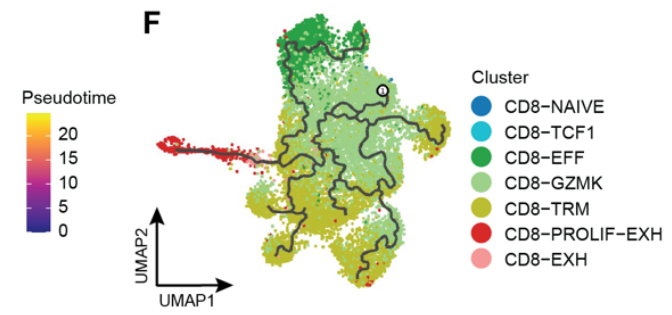


bioRxiv preprint doi: https://doi.org/10.1101/2021.09.27.461389; this version posted September 27, 2021. The copyright holder for this preprint (which was not certified by peer review) is the author/funder, who has granted bioRxiv a license to display the preprint in perpetuity. It is made available under aCC-BY-NC-ND 4.0 International license.

Pai, Chow, et al., (SATPATHY, HELLMANN), p. 38

822

823

824

825

826

827

828

829

830

831

832
Figure S10. Characterization of $\mathrm{TR}^{\mathrm{hi}}$ and $\mathrm{TR}^{\mathrm{lo}} \mathrm{CD8} \mathrm{T}$ cell clones.

A) Scatterplot of clone size and tumor-reactivity score per clone, colored by tumor-reactivity category. 'Top $T R^{\text {hi' }}$ and 'top $T R^{\text {lo' }}$ represent the 40 most expanded $T R^{\text {hi }}$ or $T R^{10}$ CD8 clones, respectively.

B) Absolute number of cells in the indicated region types among the top 40 most expanded $T^{\text {hi }}$ (left) or $\mathrm{TR}^{\mathrm{lo}}$ (right) CD8 clones.

C) Absolute number of cells in the indicated clusters among the top 40 most expanded TR ${ }^{\text {hi }}$ (left) or TR ${ }^{l o}$ (right) CD8 clones.

$\mathrm{D}-\mathrm{F}$ ) Trajectory analysis comparing $\mathrm{TR}^{\mathrm{hi}}$ and $\mathrm{TR}^{\text {lo }} \mathrm{CD} 8 \mathrm{~T}$ cell clones. UMAP of cells from the top 40 most expanded $T R^{\text {hi }}$ and $T R^{\text {lo }} C D 8$ clones colored by tumor-reactivity category (D), pseudotime $(E)$, or phenotype cluster $(\mathrm{F})$.

G) Circulating frequency over time of TR ${ }^{\text {hi }}$ (top) and TR ${ }^{\text {lo }}$ (bottom) TCR clones from MSK 1344. 
bioRxiv preprint doi: https://doi.org/10.1101/2021.09.27.461389; this version posted September 27, 2021. The copyright holder for this preprint (which was not certified by peer review) is the author/funder, who has granted bioRxiv a license to display the preprint in perpetuity. It is made available under aCC-BY-NC-ND 4.0 International license.

Pai, Chow, et al., (SATPATHY, HELLMANN), p. 39

Figure S11 (related to Figure 7)

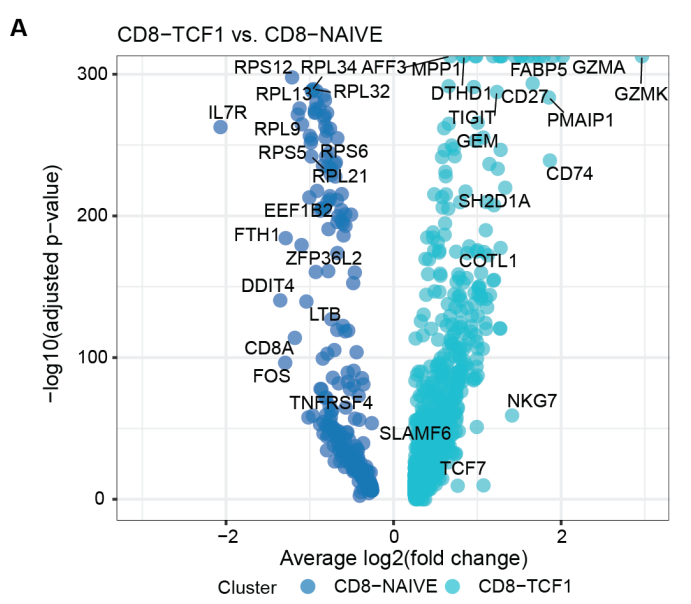

D CD8 clones in CD8-EXH and CD8-PROLIF-EXH MSK 1263 Thoracic MSK 1263 Adrenal MSK 1302

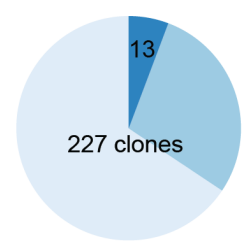

LN TCF7 ${ }^{\text {high }}$ status

F

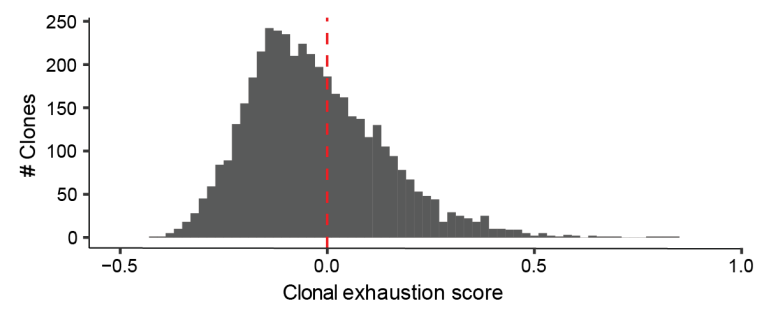

H

CD8 clones with high exhaustion scores

E

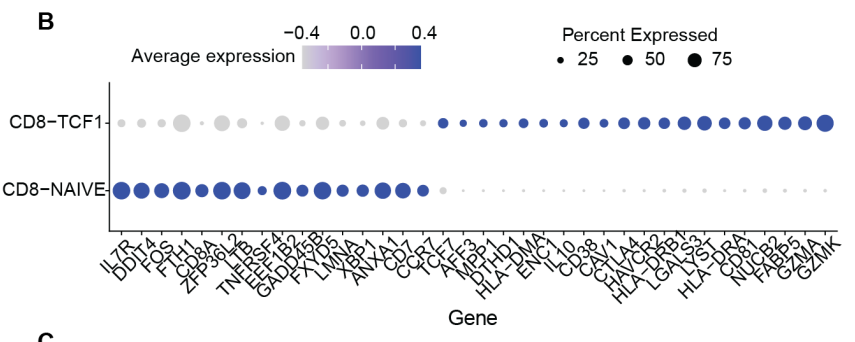

C
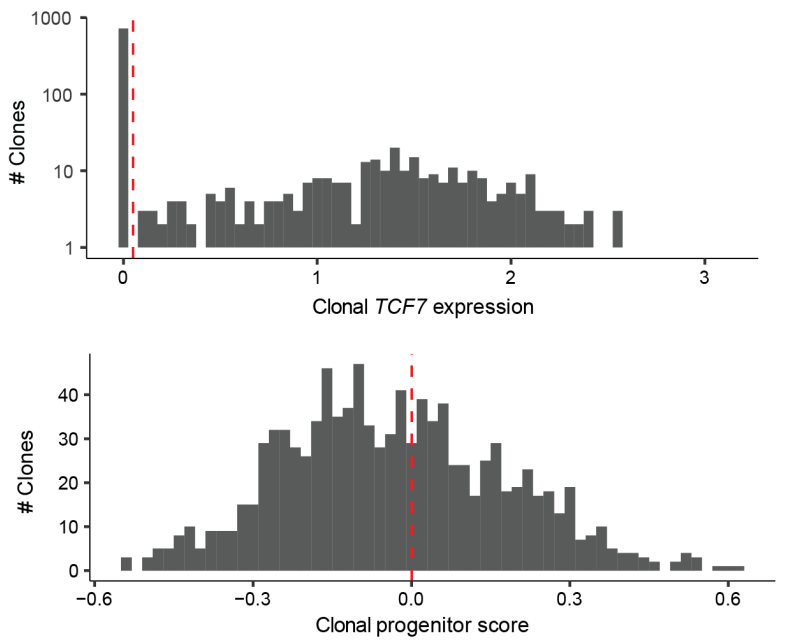

G

CD8 clones with high exhaustion scores

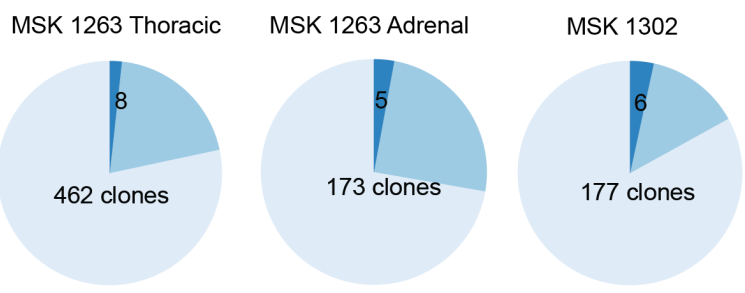

LN TCF7 $7^{\text {high }}$ status

TCR match in LN, TCF7 $>0$

TCR match in $L N, T C F 7=0$ no TCR match in LN

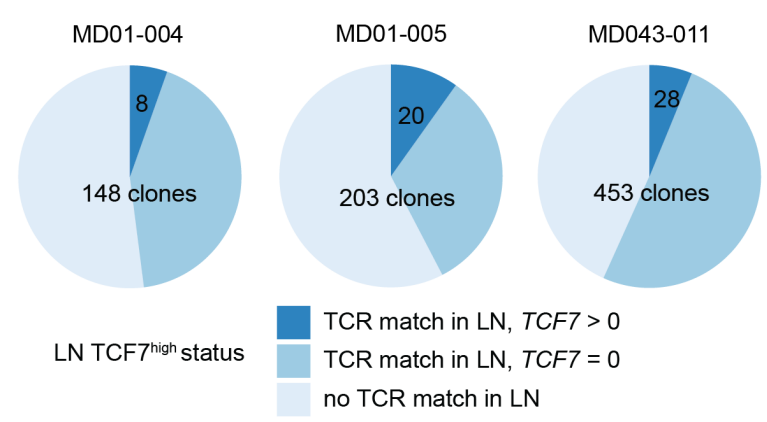

Figure S11. Identification of LN progenitor states.

A) Volcano plot of differentially expressed genes between clusters CD8-TCF1 and CD8-NAÏVE.

B) Dot plot of select differentially expressed genes between clusters CD8-TCF1 and CD8-NAÏVE colored 
bioRxiv preprint doi: https://doi.org/10.1101/2021.09.27.461389; this version posted September 27, 2021. The copyright holder for this preprint (which was not certified by peer review) is the author/funder, who has granted bioRxiv a license to display the preprint in perpetuity. It is made available under aCC-BY-NC-ND 4.0 International license.

Pai, Chow, et al., (SATPATHY, HELLMANN), p. 40

839

840

841

842

843

844

845

846

847

848
D) Pie chart of CD8 T cell clones in the CD8-EXH and CD8-PROLIF-EXH clusters in the tumor that could be matched to a clonotype in the LN (medium blue and dark blue, "TCR match in LN"). Dark blue slice indicates that the matched clone could be found expressing TCF7 in the LN.

E) Distribution of average progenitor score among CD8 clones in $L N$ regions.

F) Distribution of average exhaustion score among CD8 clones in tumor tissue regions. Clones with an average exhaustion score $>0$ were defined as CD8 clones with high exhaustion scores.

$\mathrm{G}, \mathrm{H})$ Pie chart of CD8 T cell clones with high exhaustion scores in the tumor that could be matched to a clonotype in the LN (medium blue and dark blue, "TCR match in LN") based on our scRNA/TCR-seq dataset $(\mathrm{G})$ or the dataset generated by Caushi et $\mathrm{al}^{27}(\mathrm{H})$. Dark blue slice indicates that the matched clone could be found expressing TCF7 in the LN. 


$$
\text { Pai, Chow, et al., (SATPATHY, HELLMANN), p. } 41
$$

\section{ACKNOWLEDGEMENTS}

We acknowledge the use of the Integrated Genomics Operation Core, which is funded by the $\mathrm{NCl}$ Cancer Center Support Grant (CCSG, P30 CA08748), Cycle for Survival, and the Marie-Josée and Henry R. Kravis Center for Molecular Oncology. This research was funded in part through the $\mathrm{NIH} \mathrm{NCl} \mathrm{Cancer} \mathrm{Center}$ Support Grant P30 CA008748, NCI R01 CA056821, U01 CA199215, U24 CA213274, P01 CA129243, R01 CA197936, R35 CA232130, K08 CA248723, and U01 CA260852; the Ludwig Collaborative and Swim Across America Laboratory; the Emerald Foundation; the Parker Institute for Cancer Immunotherapy, MSKCC and Stanford; the Department of Medicine, MSKCC; Stand Up To Cancer (SU2C)-American Cancer Society Lung Cancer Dream Team Translational research grant (SU2C-AACR-DT17-15). A.C. was supported by an MSKCC Investigational Cancer Therapeutics Training Program fellowship (T32 CA009207) and Clinical Investigator Award from National Cancer Institute (K08 CA-248723). J.A.P. was supported by NIH Training Grant 5T32AI007290. A.T.S. was supported by a Career Award for Medical Scientists from the Burroughs Wellcome Fund, a Technology Impact Award from the Cancer Research Institute, a Pew-Stewart Scholars for Cancer Research Award, and the Donald and Delia Baxter Foundation.

AUTHOR CONTRIBUTIONS: JAP conceived the project, analyzed the data, drafted and edited the manuscript. AC conceived the project, performed and analyzed experiments, drafted and edited the manuscript. MM, HR, NS, FZU, AQV, JMC, PM, VA and JC performed experiments and/or helped in procurement of biospecimens. JLS provided pathologic analyses of the resected tissues. AJP provided radiographic analyses of the tissues. HJW analyzed experiments. HW, MD, BHL, DQ, EdS, TS, JDW, TM, CMR supervised portions of the study. ATS and MDH conceived the project and supervised the study.

DECLARATION OF INTERESTS: JDW is a consultant for Adaptive Biotech, Amgen, Apricity, Ascentage Pharma, Arsenal IO, Astellas, AstraZeneca, Bayer, Beigene, Boehringer Ingelheim, Bristol Myers Squibb, Celgene, Chugai, Daiichi Sankyo, Dragonfly, Eli Lilly, Elucida, F Star, Georgiamune, Idera, Imvaq, Kyowa Hakko Kirin, Linneaus, Maverick Therapeutics, Merck, Neon Therapeutics, Polynoma, Psioxus, Recepta, Takara Bio, Trieza, Truvax, Trishula, Sellas, Serametrix, Surface Oncology, Syndax, Syntalogic, and Werewolf Therapeutics. JDW has received grant/research support from Bristol Myers Squibb and Sephora. JDW has equity in Tizona Pharmaceuticals, Adaptive Biotechnologies, Imvaq, Beigene, Linneaus, Apricity, Arsenal IO, and Georgiamune. JDW is a co-inventor on patent applications related to heteroclitic cancer vaccines and recombinant poxviruses for cancer immunotherapy. JDW and TM are co-inventors on patent applications related to CD40 and in situ vaccination (PCT/US2016/045970). TM is a consultant for Immunos Therapeutics and Pfizer. TM is a cofounder of and equity holder in IMVAQ Therapeutics. TM receives research funding from Bristol-Myers Squibb, Surface Oncology, Kyn Therapeutics, Infinity Pharmaceuticals, Peregrine Pharmaceuticals, Adaptive Biotechnologies, Leap Therapeutics, and Aprea Therapeutics. TM is an inventor on patent applications related to work on oncolytic viral therapy, alpha virus-based vaccine, neoantigen modeling, CD40, GITR, OX40, PD-1, and CTLA-4. C.M.R. has consulted regarding oncology drug development with AbbVie, Amgen, Ascentage, AstraZeneca, BMS, Celgene, Daiichi Sankyo, Genentech/Roche, Ipsen, Loxo and PharmaMar and is on the scientific advisory boards of Elucida, Bridge and Harpoon. Unrelated to this work, D.Z. reports clinical research support to his institution from Astra Zeneca, Plexxikon, and Genentech; and personal/consultancy fees from Merck, Synlogic Therapeutics, GSK, Genentech, Xencor, Memgen, Immunos, CrownBio, and Agenus. MDH received research grant from BMS; personal fees from Achilles, Arcus, AstraZeneca, Blueprint, BMS, Genentech/Roche, Genzyme, Immunai, Instil Bio, Janssen, Merck, Mirati, Natera, Nektar, Pact Pharma, Regeneron, Shattuck Labs, Syndax, as well as equity options from Arcus, Factorial, Immunai, and Shattuck Labs. A.T.S. is a founder of Immunai and Cartography Biosciences and receives research funding from Arsenal Biosciences, Allogene Biotherapeutics, and 10x Genomics. A patent filed by MSKCC related to the use of tumor mutational burden to predict response to immunotherapy (PCT/US2015/062208) is pending and licensed by PGDx. 
Pai, Chow, et al., (SATPATHY, HELLMANN), p. 42

\section{REFERENCES}

1. Yost, K.E., Chang, H.Y. \& Satpathy, A.T. Recruiting T cells in cancer immunotherapy. Science 372, 130-131 (2021).

2. Hiam-Galvez, K.J., Allen, B.M. \& Spitzer, M.H. Systemic immunity in cancer. Nat Rev Cancer (2021).

3. Osorio, J.C., et al. Lesion-Level Response Dynamics to Programmed Cell Death Protein (PD-1) Blockade. J Clin Oncol 37, 3546-3555 (2019).

4. Jia, Q., et al. Local mutational diversity drives intratumoral immune heterogeneity in non-small cell lung cancer. Nat Commun 9, 5361 (2018).

5. Sinjab, A., et al. Resolving the Spatial and Cellular Architecture of Lung Adenocarcinoma by Multiregion Single-Cell Sequencing. Cancer Discov (2021).

6. Pai, J.A. \& Satpathy, A.T. High-throughput and single-cell T cell receptor sequencing technologies. Nat Methods (2021).

7. Kallies, A., Zehn, D. \& Utzschneider, D.T. Precursor exhausted T cells: key to successful immunotherapy? Nat Rev Immunol 20, 128-136 (2020).

8. Connolly, K.A., et al. A reservoir of stem-like CD8<sup $>+</$ sup $>$ T cells in the tumor-draining lymph node preserves the ongoing anti-tumor immune response. Science Immunology $\mathbf{0}$, abg7836.

9. Krishna, S., et al. Stem-like CD8 T cells mediate response of adoptive cell immunotherapy against human cancer. Science 370, 1328-1334 (2020).

10. Rafiq, S., Hackett, C.S. \& Brentjens, R.J. Engineering strategies to overcome the current roadblocks in CAR T cell therapy. Nat Rev Clin Oncol 17, 147-167 (2020).

11. Stuart, T., et al. Comprehensive Integration of Single-Cell Data. Cell 177, 1888-1902 e1821 (2019).

12. Guo, X., et al. Global characterization of T cells in non-small-cell lung cancer by single-cell sequencing. Nat Med 24, 978-985 (2018).

13. Yost, K.E., et al. Clonal replacement of tumor-specific T cells following PD-1 blockade. Nat Med 25, 1251-1259 (2019).

14. Wu, T.D., et al. Peripheral T cell expansion predicts tumour infiltration and clinical response. Nature 579, 274-278 (2020).

15. Ghorani, E., et al. The T cell differentiation landscape is shaped by tumour mutations in lung cancer. Nat Cancer 1, 546-561 (2020).

16. Gueguen, P., et al. Contribution of resident and circulating precursors to tumor-infiltrating CD8(+) T cell populations in lung cancer. Sci Immunol 6(2021).

17. Joshi, K., et al. Spatial heterogeneity of the T cell receptor repertoire reflects the mutational landscape in lung cancer. Nat Med 25, 1549-1559 (2019).

18. Li, H., et al. Dysfunctional CD8 T Cells Form a Proliferative, Dynamically Regulated Compartment within Human Melanoma. Cell (2018).

19. Philip, M. \& Schietinger, A. CD8(+) T cell differentiation and dysfunction in cancer. Nat Rev Immunol (2021).

20. Fairfax, B.P., et al. Peripheral CD8(+) T cell characteristics associated with durable responses to immune checkpoint blockade in patients with metastatic melanoma. Nat Med 26, 193-199 (2020).

21. Larson, R.C. \& Maus, M.V. Recent advances and discoveries in the mechanisms and functions of CAR T cells. Nat Rev Cancer 21, 145-161 (2021).

22. van der Leun, A.M., Thommen, D.S. \& Schumacher, T.N. CD8(+) T cell states in human cancer: insights from single-cell analysis. Nat Rev Cancer 20, 218-232 (2020).

23. Gros, A., et al. PD-1 identifies the patient-specific CD8(+) tumor-reactive repertoire infiltrating human tumors. J Clin Invest 124, 2246-2259 (2014).

24. Thommen, D.S., et al. A transcriptionally and functionally distinct PD-1(+) CD8(+) T cell pool with predictive potential in non-small-cell lung cancer treated with PD-1 blockade. Nat Med 24, 9941004 (2018).

25. Duhen, T., et al. Co-expression of CD39 and CD103 identifies tumor-reactive CD8 T cells in human solid tumors. Nat Commun 9, 2724 (2018).

26. Simoni, Y., et al. Bystander CD8(+) T cells are abundant and phenotypically distinct in human tumour infiltrates. Nature 557, 575-579 (2018). 
Pai, Chow, et al., (SATPATHY, HELLMANN), p. 43

960 27. Caushi, J.X., et al. Transcriptional programs of neoantigen-specific TIL in anti-PD-1-treated lung

$961 \quad$ cancers. Nature (2021).

962 28. Oliveira, G., et al. Phenotype, specificity and avidity of antitumour CD8(+) T cells in melanoma.

$963 \quad$ Nature 596, 119-125 (2021).

964

965

966

967

968

969

970

971

972

973

974

975

976

977

978

29. Siddiqui, I., et al. Intratumoral Tcf1(+)PD-1(+)CD8(+) T Cells with Stem-like Properties Promote Tumor Control in Response to Vaccination and Checkpoint Blockade Immunotherapy. Immunity 50, 195-211 e110 (2019).

30. Miller, B.C., et al. Subsets of exhausted CD8(+) T cells differentially mediate tumor control and respond to checkpoint blockade. Nat Immunol 20, 326-336 (2019).

31. Dammeijer, F., et al. The PD-1/PD-L1-Checkpoint Restrains T cell Immunity in Tumor-Draining Lymph Nodes. Cancer Cell 38, 685-700 e688 (2020).

32. Schoenfeld, A.J. \& Hellmann, M.D. Acquired Resistance to Immune Checkpoint Inhibitors. Cancer Cell 37, 443-455 (2020).

33. Travis, W.D., et al. IASLC Multidisciplinary Recommendations for Pathologic Assessment of Lung

34. Kim, N., et al. Single-cell RNA sequencing demonstrates the molecular and cellular reprogramming of metastatic lung adenocarcinoma. Nat Commun 11, 2285 (2020).

35. Cao, J., et al. The single-cell transcriptional landscape of mammalian organogenesis. Nature 566, 496-502 (2019). 